San Jose State University

SJSU ScholarWorks

Master's Theses

Master's Theses and Graduate Research

1993

\title{
Geographic variation and cultural evolution in songs of humpback whales (Megaptera novaeangliae) in the eastern North Pacific
}

Salvatore Cerchio

San Jose State University

Follow this and additional works at: https://scholarworks.sjsu.edu/etd_theses

\section{Recommended Citation}

Cerchio, Salvatore, "Geographic variation and cultural evolution in songs of humpback whales (Megaptera novaeangliae) in the eastern North Pacific" (1993). Master's Theses. 614.

DOI: https://doi.org/10.31979/etd.edh4-6cad

https://scholarworks.sjsu.edu/etd_theses/614

This Thesis is brought to you for free and open access by the Master's Theses and Graduate Research at SJSU ScholarWorks. It has been accepted for inclusion in Master's Theses by an authorized administrator of SJSU ScholarWorks. For more information, please contact scholarworks@sjsu.edu. 


\section{INFORMATION TO USERS}

This manuscript has been reproduced from the microfilm master. UMI films the text directly from the original or copy submitted. Thus, some thesis and dissertation copies are in typewriter face, while others may be from any type of computer printer.

The quality of this reproduction is dependent upon the quality of the copy submitted. Broken or indistinct print, colored or poor quality illustrations and photographs, print bleedthrough, substandard margins, and improper alignment can adversely affect reproduction.

In the unlikely event that the author did not send UMI a complete manuscript and there are missing pages, these will be noted. Also, if unauthorized copyright material had to be removed, a note will indicate the deletion.

Oversize materials (e.g., maps, drawings, charts) are reproduced by sectioning the original, beginning at the upper left-hand corner and continuing from left to right in equal sections with small overlaps. Each original is also photographed in one exposure and is included in reduced form at the back of the book.

Photographs included in the original manuscript have been reproduced xerographically in this copy. Higher quality $6 " \mathrm{x} 9$ " black and white photographic prints are available for any photographs or illustrations appearing in this copy for an additional charge. Contact UMI directly to order.

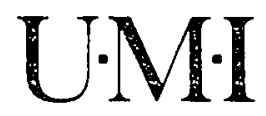

University Microfılms Internatıonal A Bell \& Howell Information Company 300 North Zeeb Road. Ann Arbor. MI 48106-1346 USA

$313: 761-4700 \quad 800: 521-0600$ 

Order Number 1954129

Geographic variation and cultural evolution in songs of humpback whales (Megaptera novaeangliae) in the eastern north Pacific

\author{
Cerchio, Salvatore, M.S.
}

San Jose State University, 1993 


\title{
GEOGRAPHIC VARIATION AND CULTURAL EVOLUTION IN SONGS OF HUMPBACK WHALES \\ (MEGAPTERA NOVAEANGLIAE) \\ IN THE EASTERN NORTH PACIFIC
}

\author{
A Thesis \\ Presented to \\ The Faculty of Moss Landing Marine Laboratories \\ San Jose State University \\ In Partial Fulfillment \\ of the Requirements for the Degree \\ Master of Science
}

by

Salvatore Cerchio

August, 1993 
APPROVED FOR THE DEPARTMENT OF MOSS LANDING MARINE LABORATORIES

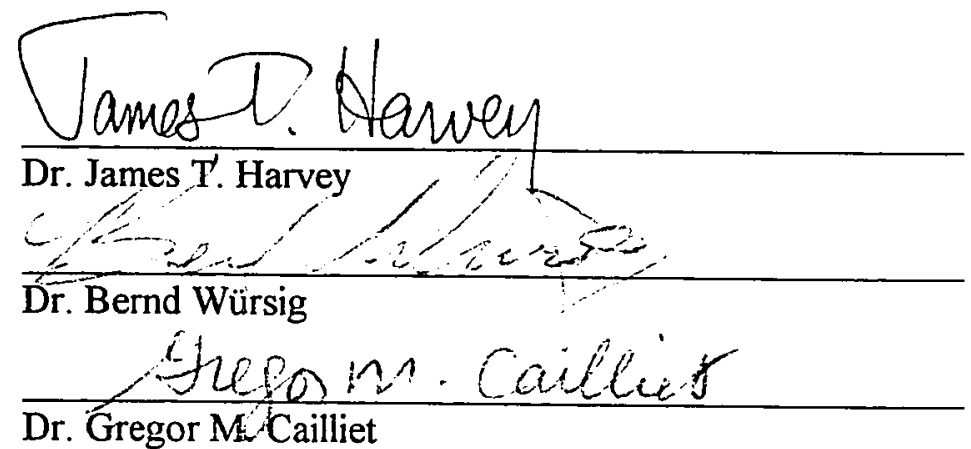

Dr. Gregor MCailliet

APPROVED FOR THE UNIVERSITY

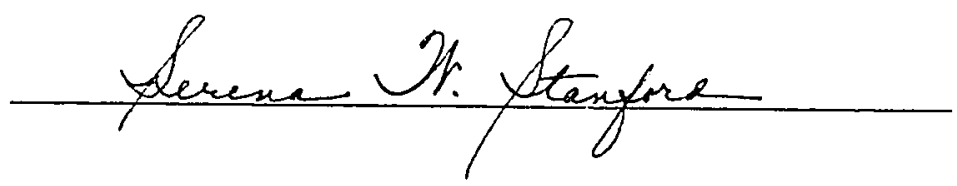




\section{Abstract \\ Geographic Variation and Cultural Evolution in Songs of Humpback Whales (Megaptera novaeangliae) in the Eastern North Pacific \\ by Salvatore Cerchio}

Songs of humpback whales off Hawaii and Mexico were examined to determine whether they changed similarly in both areas during a breeding season. Songs of 24 individuals were recorded off Kauai, Hawaii and Isla Socorro, Mexico during winter and spring of 1991. Forty-seven acoustic variables were measured for each singer. Similar variables were grouped together into six categories. Mean values for each singer were compared among regions and time periods using two-factor ANOVAs. All but three variables changed between winter and spring in at least one area. Groups of similar variables displayed similar trends. Quantitative characteristics of song elements often changed by the same amount in each area, with little variation within and among individuals.

Structures of song patterns often changed differently in each area. These results indicated whales may be predisposed to gradually change certain features of song independent of cultural influences. 


\section{Acknowledgments}

This thesis was made possible with the help of James T. Harvey, Bernd Würsig, and Gregor Cailliet. Dr. Harvey provided guidance, support, and patience throughout the project, and made sure I produced the best work possible. I thank him for hanging in there and helping me to actualize my potential. Dr. Würsig helped to get the project off the ground with his guidance and logistical support, and has been the source of much inspiration. Dr. Cailliet introduced me to the world of marine science and graduate school, and gave me my first lessons on how to write.

This study would not have been possible without the generosity and friendship of Jeff Jacobsen. I greatly appreciate his long hours on a desolate rock, his conversation, critiques, and moral support. I also thank Thomas Fredrich Norris, whose collaboration and effort made 1991 a successful field season on Kauai. Thanks, Brah, for struggling through these couple years, for your input, and your friendship.

Dan Shapiro, Thea Jenssen, Jacky Murphy, Chuck Moon, Ruthie Lewis, Johanna Slob, Marci Greenberg, Gene "Goatster" Kent and Renata Sponer assisted with the field work on Kauai. I thank Marine Operations of Moss Landing Miarine Laboratories for use of their equipment. I thank Shiela Baldridge, Sandy ONeil, Gail Johnston, Sandy Yarborough and the rest of the M.L.M.L. staff for their various modes of support. Mario A. Salinas Zacarías and Paloma Ladrón de Guevara Porras assisted on Socorro. The Socorro field work was done in conjunction with Dr. Anelio Aguayo of the National University of Mexico City (U.N.A.M.), and with the cooperation of the Secretary of the Navy, Mexico City. I thank Dr. Peter Marler and the Animal Communication Laboratory of U. C., Davis, for the use of their sonograph equipment. The manuscript was improved by thoughtful comments of Jim Darling, Tom Norris, Jeff Jacobsen, and Ann Louise Wagner. 
The Kauai portion of the project was funded by Whale Aid - Hawaii, Earthtrust, Ms. Laurel Kline, the Monterey Bay chapter of the American Cetacean Society, the Animal Behavior Society, Sigma Xi, and the American Museum of Natural History. The Socorro portion was funded in part by the Whale and Dolphin Conservation Society.

I graciously thank and honor Dr. John Martin (1935-1993) for his support of and dedication to the student body of Moss Landing Marine Laboratories. May his memory live on and serve as a model for future leaders of M.L.M.L.

Most of all, I thank my parents, Anne and Salvatore Cerchio, for their love and support throughout this project and my many years of schooling. None of this would have been possible without them. 


\section{Table of Contents}

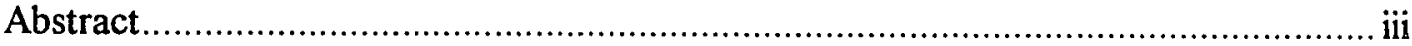

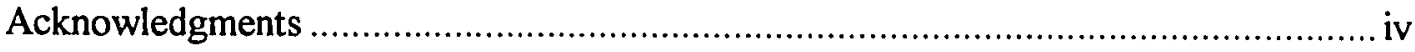

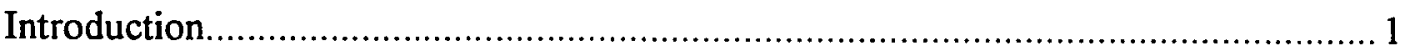

Cultural Transmission and Evolution .................................................... 1

Humpback Whale Song .................................................................... 3

Objectives and Hypotheses............................................................... 8

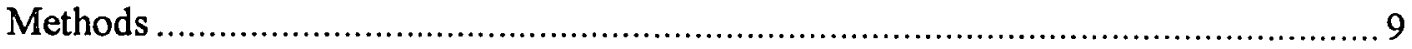

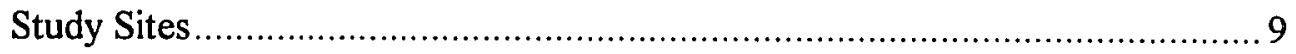

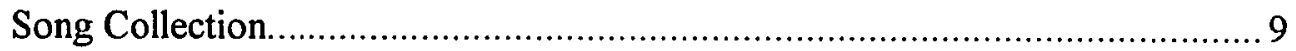

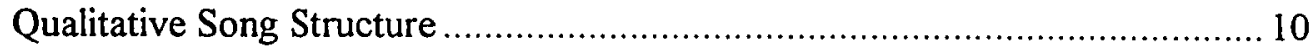

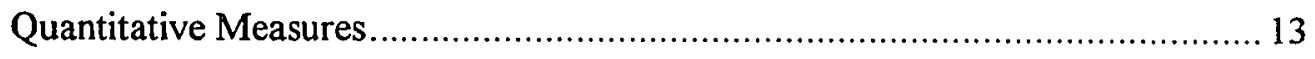

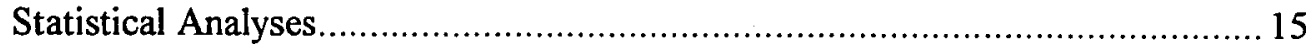

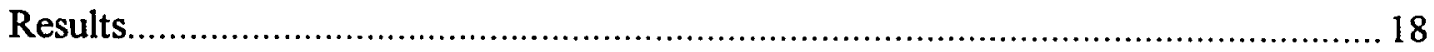

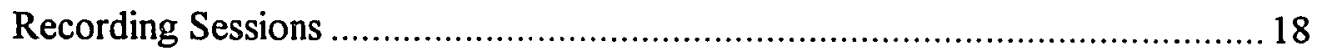

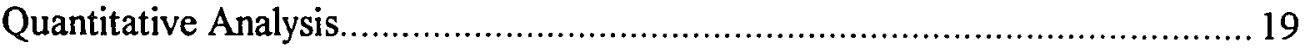

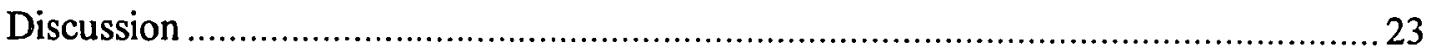

Cultural Transmission of Song Changes................................................... 25

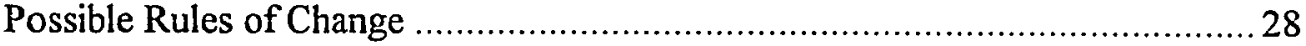

Geographic Variation and Cultural Evolution in Birdsong.......................... 30

Comparison with Humpback Whale Song ................................................. 35

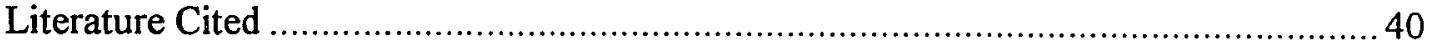

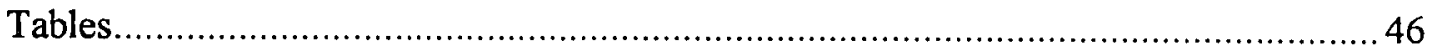

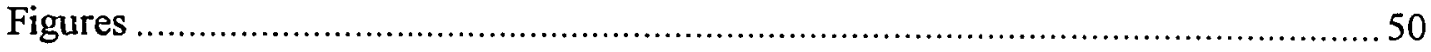




\section{Introduction}

Cultural Transmission and Evolution

"Traditions" have been described in taxonomically diverse animals, and consist of learned behaviors that are shared by members of a population and passed down through generations (Mundinger 1980; Cavelli-Sforza and Fieldman 1981). Groups of traditions displayed by a population of animals may be considered a "culture." Mundinger (1980) defined animal culture as a set of overtly expressed behaviors (models) and associated neural codes for the behaviors (memes, as in Dawkins 1976). Cultures are replicated generation after generation by learning (termed "cultural transmission"). Transmission of cultures, or traditions, can occur from parent to offspring (vertical transmission) or among individuals of the same generation (horizontal transmission; Cavelli-Sforza and Fieldman 1981). Cultural transmission is not always precise (Mundinger 1980; Slater 1986) and as a result, traditions change as they are passed across generations or among individuals of a population (Cavelli-Sforza and Fieldman 1981). The process by which traditions change through cultural transmission is termed "cultural evolution." New traditions appear, existing traditions disappear, and gradual changes may occur to persisting traditions (Payne 1985).

Mundinger (1980) described a general theory of animal culture and cultural evolution, drawing many analogies to genetic evolution. It is important to note that there is no genetic basis to cultural evolution (i.e., genes are not being exchanged or mutating), however, the analogy is quite useful. A meme, the analog of the gene, is the neural code created in the brain when an individual learns a behavior. In cultural evolution, variation is introduced into a group of traditions (and associated memes) through two forms of "cultural mutations": copy error and innovation. Copy error occurs when an individual miscopies information from a tutor, creating a new meme, or when a tutor does not 
accurately express a meme in its brain as the correct behavior. Innovation results from an insight on the part of an individual or an improvisation upon an existing model. Transmission of cultural mutations and their associated memes through the population results in cultural evolution as new, or slightly changed, traditions from copy errors and innovations are learned by all members of a population.

Mundinger (1980) stated that cultural mutations alone cannot drive rapid cultural evolution, but are simply the sources of variation. He proposed three causative factors that may work independently or together to produce rapid cultural evolution: 1) psychological selection, 2) meme flow, and 3) memetic drift. Psychological selection, the analog of natural selection, is the differential transmission of alternate memes, as specific behaviors are selected for or against (i.e., individuals preferentially learn specific behaviors). Factors affecting transmission include differential tutoring, differential learning predisposition, and social context. Meme flow is the analog of gene flow and is dependent upon migration. Three separate processes are involved: introduction of new memes via migration (this is the actual meme flow); transmission through the recipient population, involving psychological selection; and integration of the new traditions by the recipient population. Memetic drift, the analog of genetic drift, is the random transmission of alternate memes through small isolated populations. The resultant patterns of change in memetic drift would be random and non-directional, as opposed to the organized, directional change characteristic of psychological selection and meme flow.

Cultural transmission and evolution has been studied extensively in bird songs. Geographic variation in bird song and the existence of distinguishable local dialects are the result of cultural evolution (Krebs and Kroodsma 1980; Mundinger 1980, 1982; Slater 1986). In some species, dialects are stable for many years and cultural evolution occurs slowly during the course of generations (Jenkins 1977; Slater et al. 1980; Payne et al. 
1981; Slater 1986). In a few species, rapid cultural evolution has been documented; dialects change progressively during a season and changes can accumulate over years (Payne 1979; Feekes 1982; Payne 1985; Trainer 1989). Rapid cultural evolution also has been documented in songs of humpback whales (Guinee et al. 1983; Payne K. et al. 1983; Payne and Guinee 1983; Payne and Payne 1985).

\section{Humpback Whale Song}

Humpback whales (Megaptera novaeangliae) migrate between summer feeding areas in sub-polar or cold-temperate waters and tropical or sıb-tropical winter areas. In the eastern North Pacific, humpback whales spend summer and autumn off Alaska and central California, feeding on planktonic crustaceans and small schooling fish (Baker et al. 1986; Calambokidis et al. 1990; Perry et al. 1990). Migration starts in late autumn, and whales spend winter and spring off the Hawaiian Islands, Mexico, and the Bonin and Ryukyuan Islands south of Japan (Darling and Jurasz 1983; Darling and McSweeney 1985; Baker et al. 1986; Perry et al. 1990; Darling 1991). At these locations calving occurs and mating presumably occurs (Darling 1983; Baker and Herman 1984).

Male humpbacks sing lengthy, complex songs while in their winter breeding areas (Payne and McVay 1971; Winn and Winn 1978). Nearly all whales of known sex that have been observed singing were males (Darling et al. 1983; Glockner 1983), and it was hypothesized that songs are important to male breeding success (Tyack 1981; Darling 1983; Tyack and Whitehead 1983; Baker and Herman 1984). Although it is difficult to define the specific role of humpback song, researchers have suggested songs function to communicate an individual's species, location, sex, readiness to mate, or willingness to engage in aggression (Payne and McVay 1971; Winn and Winn 1978; Tyack 1981). Mobley and Herman (1981) proposed a modified lek model to explain humpback breeding 
behavior. They suggested songs define temporary acoustic territories, or leks, immediately surrounding each singing male. Estrous females could move freely among males to choose a mate; however, the authors did not suggest a basis of mate selection by females. Darling (1983) noted similarities between the breeding behavior of humpback whales and that of some ungulates. He suggested that humpback song is an acoustic "display" that may have a similar function to the visual display of some ungulates' horns and antlers. Songs and singing behavior, therefore, may help to determine dominance order amongst male humpback whales. How males might use songs to establish dominance was not proposed.

The structure of humpback whale song was first described by Payne and McVay (1971). The vocal displays are characterized by a hierarchical series of songs, themes, phrases, subphrases, units, and subunits (Fig. 1). A unit, analogous to a note, is a signal that appears aurally continuous. Units may be subdivided into subunits, too short and closely spaced to be resolved as individual signals, such as clicks in a pulse train. Units have fundamental frequencies ranging from $30 \mathrm{~Hz}$ to greater than $10,000 \mathrm{~Hz}$ (pers. observ.). Units are structurally diverse with a wide range of bandwidths, often complex harmonic structure, and a variety of frequency and amplitude modulations. Different units are organized into distinct, stereotyped patterns, termed phrases. Phrases, with 3 to 20 or more units, are approximately 5 to 30 seconds duration. Longer phrases can often be subdivided into subphrases. Several distinct phrase types are usually found in a whale's repertoire. The next level of organization is the theme, and three types of themes have been described: static, shifting, and unpatterned themes (Payne and Payne 1985). In a static theme, a distinct phrase type is repeated a variable number of times, with little variation among repetitions of the phrase. Different static themes have distinctly different phrase types. Shifting themes start with a given phrase type, which gradually changes with 
each repetition until it appears very different by the end of the theme. Unpatterned themes do not have a recognizable phrase structure, and consist of a long series of units. A song consists of several different themes sung in a consistent, cyclical order (Payne and McVay 1971; Frumhoff 1983; Payne et al. 1983). Transitional phrases are often found at the boundaries of two themes, sometimes combining elements of phrase types from both themes. Songs are usually repeated without pauses, and a group of consecutive songs is a song session.

All males within a region (e.g., the Hawaiian Islands) sing very similar songs at any given time (Payne 1978; Winn and Winn 1978). Songs progressively change during the breeding season, with all males in an area incorporating the same changes into their songs (Payne et al. 1983; Payne and Guinee 1983; Payne and Payne 1985). Change is gradual, but changes accumulate over several seasons so that songs recorded four or five years apart are very different (Payne et al. 1983; Payne and Payne 1985). This type of rapid cultural evolution has been documented for only two species of songbird, the yellowrumped cacique, Cacicus cela (Feekes 1977; Feekes 1982; Trainer 1989), and the village indigobird, Vidua chalybeata (Payne 1979; Payne 1985).

Humpback songs change at all levels of structure (Payne et al. 1983). Units may be altered in frequency, duration or structure, and new units may be added or existing units disappear. Phrases may be altered in duration or composition of units. Phrase types can differentiate into two or more phrase types, thus adding new themes. Themes and associated phrase types may become extinct. Mean song duration may increase or decrease. Most changes in the song occur throughout winter when singing is a prevalent behavior, whereas songs change little during intervening summers (Payne et al. 1983) when singing is uncommon (McSweeney et al. 1989). Guinee et al. (1983) reported that individual males change their songs throughout the breeding season and years, so that at 
any given time, a male's songs more closely resemble? the songs of whales around him than his own songs from previous years or months. They interpreted this as evidence of cultural transmission among individuals.

Geographically isolated groups of humpback whales in separate ocean basins (i.e., separate populations) use the same general song structure, but sing songs with different content, whereas whales in the same ocean basin sing very similar songs (Winn et al. 1981; Payne and Guinee 1983; Helweg et al. 1990). Payne and Guinee (1983) compared songs recorded off Maui, Hawaii and the Islas Revillagigedo, Mexico, $4800 \mathrm{~km}$ apart, in February 1977 and March 1979. In a quantitative analysis of 14 variables, they found few significant differences between the two 1979 samples. From 1977 to 1979 , the variables also changed in essentially the same ways in both areas. In 1977, songs from either area had five themes in common, and songs off Hawaii had an additional four themes not recorded off Mexico. The sample from Mexico was small, consisting of one song from one individual, which may explain the absence of some themes. In 1979, sample sizes were more equal, and all seven themes were common to both areas. Furthermore, of the four themes that were unique to whales off Hawaii in 1977, two disappeared off Hawaii and the other two appeared off Mexico by 1979 . The results of this study clearly indicated cultural transmission among whales in these two areas.

A preliminary comparison of songs recorded off Japan and Hawaii in 1988 indicated striking similarities as well (Darling and Ford 1988); of six themes found in songs off Hawaii, five occurred in songs off Japan. Helweg et al. (1990) compared humpback whale songs recorded off coastal Mexico, the Hawaiian Islands, and the Bonin and Ryukyuan Islands of Japan, during a one month period in 1989. Sample sizes were small, consisting of recordings from no more than three individuals in each area; recordings were also short, from 2 to 30 minutes. The Mexico, Hawaii, and Bonin songs 
had three themes in common, indicating some degree of cultural transmission among these areas. Each area had some unique themes and the degree of overlap between pairs of areas varied among the pairs. They attempted to qualitatively rank similarities among the regions' songs, and concluded that songs off Hawaii and Mexico were most similar, followed by songs off Hawaii and Bonin, and then songs off Mexico and Bonin. Songs of whales off the Ryukyuan Islands shared no themes with whales off Hawaii or Mexico; however, the three samples from the Ryukyuan Islands were all less than five minutes and probably did not contain a complete song. Because variation exists among individuals and within an individual's song session (Hafner et al. 1979; Frumhoff 1983; Payne et al. 1983), conclusions regarding the relatedness of songs from different regions based on such small samples are questionable. No statistical analyses were attempted, apparently due to paucity of data.

Three hypotheses have been proposed concerning the mechanism of cultural transmission among distant wintering areas (Payne and Guinee 1983). Firstly, singers may exchange information while in high-latitude feeding areas or during migration. Although uncommon, singing has been reported in high-latitude regions during summer (Mattila et al. 1987; McSweeney et al. 1989), and more frequently during autumn (Baker et al. 1985; Mattila et al. 1987; Straley 1990). Straley (pers. comm.) reporteci singing increased during late autumn when whales were apparently preparing to migrate. Humpback whales from different winter regions (e.g., the Hawaiian Islands and Mexico) have been sighted at a single feeding area (Darling and Jurasz 1983; Baker et al. 1986), so whales would have the opportunity to learn songs from different breeding areas. Singing also has been reported in the open ocean, presumably along the migration routes (Clapham and Mattila 1990); however, it is unknown whether whales going to or from different wintering areas share migration routes. 
Secondly, singers may visit different breeding areas in subsequent winters, bringing with them all the song changes they learned the previous year. There have been four reported records of an individual humpback whale sighted in Mexico and Hawaii in different years (Darling and Jurasz 1983; Darling and McSweeney 1985; Baker et al. 1986) and one record of an individual sighted in Japan and Hawaii in different years (Darling and Cerchio 1993). Chittleborough $(1960,1962)$ also reported three occurrences of individual whales sighted in different winter areas in the South Pacific.

Lastly, singers may visit different winter areas within a breeding season. To date one whale was sighted in Mexico and Hawaii in the same winter (North Pacific Humpback Whale Working Group et al., unpublished data). Baker et al. (1986) suggested, however, there was little exchange of whales between Hawaii and Mexico within a breeding season, as well as little tendency for whales to alternate between areas in different years.

\section{Objectives and Hypotheses}

The objective of this study was to compare songs recorded off Hawaii with those off Mexico to determine whether songs from both areas changed in the same manner during a single breeding season. It was hypothesized that if whales in Hawaii and Mexico were isolated from each other during the breeding season, then divergent change of songs would occur due to rapid cultural evolution in each area and absence of cultural transmission between whales using both areas. Conversely, if whales moved between areas during the breeding season, then the same changes would occur in each area due to cultural transmission between individuals. In the latter scenario, differences between songs from each area may exist due to a delay in transmission of changes as individuals traveled between Hawaii and Mexico. However, variables would change in the same manner in each area (i.e., both increasing or decreasing at relatively the same rate). 


\section{Methods}

Study Sites

Humpback whale song was recorded off the island of Kauai $\left(21^{\circ} 55^{\prime} \mathrm{N}, 159^{\circ} 40^{\prime} \mathrm{W}\right)$ in the Hawaiian Islands and Isla Socorro $\left(18^{\circ} 45^{\prime} \mathrm{N}, 111^{\circ} 00^{\prime} \mathrm{W}\right)$ off the Pacific coast of Mexico in the Islas Revillagigedo chain, approximately 4800 km from Kauai (Fig. 2a). The study area off Kauai was the south and west coasts out to approximately $12 \mathrm{~km}$ offshore, although most recordings were made off the west coast within 3 to $5 \mathrm{~km}$ of shore (Fig. 2b). Off Socorro, the study area ranged around the entire island to $10 \mathrm{~km}$ offshore, although recordings occurred primarily off the southwest coast within $5 \mathrm{~km}$ of shore (Fig. 2c).

\section{Song Collection}

From 21 January to 19 April 1991, songs of humpback whales were recorded off Kauai. Recordings were conducted from an inflatable boat using a modified 41C Sonobuoy hydrophone, a home-built preamplifier system, and a Sony TCD-5M or Marantz PMD430 cassette tape deck. These systems were calibrated and the frequency response range was flat $\pm 5 \mathrm{~dB}$ from approximately $100-15,000 \mathrm{~Hz}$ for the Sony deck, and $100-17,000 \mathrm{~Hz}$ for the Marantz deck. Concurrently, songs were recorded off Socorro by Jeff Jacobsen and Mario Salinas using a similar Sonobuoy hydrophone, preamplifier system, and Sony TCD-5M cassette tape deck. A Sony Professional Walkman was used in five early winter recordings off Socorro, probably resulting in a slightly narrower frequency response range. This second system was not available for calibration. Duration of recordings was from a few minutes to greater than 4 hours. A recording was used only if greater than 45 minutes duration and with at least three complete songs from a song session of one singer. 
Humpback whales tended to sing while solitary and singing whales were usually separated by several kilometers. Whales also tended to breath during the same recognizable theme of the song. It was, therefore, relatively easy to identify which whale in an area was being recorded. Individual singers were identified by photographs of the pigmentation patterns on the underside of their flukes (Katona et al. 1979, Katona and Beard 1987). If songs of a whale were recorded on more than one occasion, I used only one sample in the analysis. Whales recorded but not photographed may have been recorded previously. To account for this, probability of repeat (non-independent) samples was determined by calculating the proportion of identified (photographed) whales recorded more than once.

\section{Qualitative Song Structure}

Nine samples (five from Kauai, four from Socorro) were haphazardly chosen for preliminary analysis, spaced evenly across the time periods. Sonograms of these tapes were made at the Animal Communication Laboratory of the University of California, Davis, using a PAR model 4512 digital spectrum analyzer. A sonogram, or sound spectrogram, is a graphical display of sound, with frequency on the $y$-axis, time on the $x-$ axis, and intensity coded as darkness on a gray scale. The analysis bandwidth of the sonograms ranged from $0-2,000 \mathrm{~Hz}$ to $0-10,000 \mathrm{~Hz}$, depending on the highest fundamental frequencies of signals analyzed. Frequency resolution ranged from $4 \mathrm{~Hz}$ to $20 \mathrm{~Hz}$, depending on the analysis bandwidth. This system produced a continuous realtime sonogram on a strip of $35 \mathrm{~mm}$ photographic paper. These strips were then cut and mounted on poster board for examination.

All phrase types were categorized, and the general sequence of themes was determined. Six different themes were identified qualitatively, and all occurred in both 
areas (themes R/RT, 1, 2A, 2B, 3A, and 3B; Fig. 3a and 3b). Sonograms of songs recorded off Kauai in 1989 and 1990 were examined to determine how single themes may have differentiated into two or more separate themes by 1991 (Cerchio, unpublished data). Each theme was labeled based on its sequence in the songs and origins. Thus, themes $2 \mathrm{~A}$ and $2 \mathrm{~B}$ were derived from the same theme of 1989 , as well as themes $3 \mathrm{~A}$ and $3 \mathrm{~B}$. Theme $\mathrm{R}$ was labeled to reflect its ratchet-like aural quality. Whales usually surfaced to breathe during this theme, and it was arbitrarily chosen as the first theme in the song.

Themes 2A, 2B, 3A and 3B were "static themes" (Payne and Payne 1985), phrase structure remained consistent with each consecutive repetition in a song. Theme $\mathrm{R}$ and theme 1 were "shifting themes" (Payne and Payne 1985); phrase structure changed slightly with each consecutive repetition so that the phrase type appeared to change progressively from the beginning to the end of the theme (Fig. $3 a$ and $3 b$ ). Theme $R$ began with pulse trains of broad band clicks. With consecutive repetitions of the phrase, the pulse trains became longer and the pulse rate increased until individual clicks became indistinguishable and the unit took on a harmonic structure at a frequency resolution of $19.5 \mathrm{~Hz}$. The unit also split into multiple units. These phrases in the latter part of the theme were labeled phrase type RT for ratchet transition (Fig. $3 \mathrm{a}$ and $3 \mathrm{~b}$ ). Theme 1 was subdivided into phrase types $1 \mathrm{a}$ and $\mathrm{lb}$ (lower case letters were used to distinguish this division from that used for separate themes). With each repetition of phrase type 1 , the component units progressively dropped in peak frequency and frequency range. If the frequency range of the second unit was $>500 \mathrm{~Hz}$, the phrase was labeled 1a; once the second unit flattened out with a frequency range of $\leq 500 \mathrm{~Hz}$, the phrase was labeled $1 \mathrm{~b}$ (Fig. 3a and 3b). At the beginning of the sample period this division was less pronounced and there were often sequences where a whale would alternate between phrase types $1 \mathrm{a}$ and $1 \mathrm{~b}$. By the end of the sample period the division became quite distinct and rarely did a whale repeat a Ia 
phrase once it began singing $1 \mathrm{~b}$ phrases, suggesting that this theme was in the process of differentiating in 1991. Examination of sonograms of songs recorded off Kauai in 1992 (Cerchio and Norris, unpublished data) confirmed that this theme was differentiating into two separate themes.

A song was defined as in Frumhoff (1983): a sequence of "at least three themes which are repeated in the same order two or more times during a recorded song session." The following was a typical theme sequence constituting a complete song with all themes present:

R-1-2A-2B-3A-3B-R...

Themes $2 \mathrm{~B}$ and $3 \mathrm{~A}$ were often excluded resulting in the following song sequences:

$\mathrm{R}-1-2 \mathrm{~A}-2 \mathrm{~B}-3 \mathrm{~B}-\mathrm{R} \ldots$ or

R-1-2A-3B-R...

These sequences were all considered typical songs. There was one common theme reversal, or aberrant transition as defined by Frumhoff (1983), in which a whale followed theme $2 \mathrm{~B}$ with theme 1, skipping the sequence $3 \mathrm{~A}-3 \mathrm{~B}-\mathrm{R}$. This resulted in two atypical songs as follows:

R-1-2A-2B-

1-2A-2B-(3A)-3B-R... (note: $3 \mathrm{~A}$ was often absent)

Occurrences of these transitions were included in quantitative analysis (see below).

Other aberrant theme transitions occurred, but were uncommon, appearing in the session of only one or two singers. These transitions were not considered in quantitative analysis due to their low frequency of occurrence in the sample. 


\section{Quantitative Measures}

Variables describing all levels of song structure (unit, phrase, theme, and song) were chosen for quantitative analysis. Some variables were chosen because they appeared to change during the study period in at least one area, thereby allowing an investigation of cultural transmission between areas. For other variables, such as phrase durations, it was impossible to qualitatively determine if there was any change through time.

Forty-seven variables were measured for each individual (Table 1). These were grouped into six categories, phrases and song durations, peak frequencies of phrases, phrase repetitions, unit structure, phrase structure, and theme and song structure. Within each category several variables were chosen to determine whether similar variables changed through time in similar ways (e.g., durations of seven different phrase types). This also allowed comparison of different groups of variables (e.g., phrase durations vs. phrase structure).

Phrase duration was measured from the start of the first unit in the phrase to the start of the first unit in the next phrase (Table 1, variables 1-7). All whole phrases were averaged for each individual. Song duration was measured from the start of the first theme in the song to the start of the first theme in the next song (Table 1, variable 8). Only complete songs were used in the analysis. A separate analysis was conducted for typical songs (Table 1 , variable 9) without the $2 \mathrm{~B}-1$ a transition.

Peak frequency of a phrase was the highest frequency of a unit in the phrase (Table 1, variables 10-11). This measurement was made on phrase types la and $3 \mathrm{~B}$, and only phrases from complete themes were included. In the shifting phrase type la, the peak frequency of the phrase steadily decreased with each repetition of the phrase as the theme progressed. To account for this non-random variability, only the phrase with the highest 
peak frequency was measured in each repetition of the theme; therefore, the variable measured was actually peak frequency for each theme.

Phrase repetition per song was the mean count of phrases per song for each phrase type (Table 1, variables 12-18). Only complete songs were used and typical and atypical songs were lumped. Theme 1 was treated as three variables, phrase types $1 \mathrm{a}$ and $1 \mathrm{~b}$ lumped and each separate (Table 1, variables 13, 14 and 15).

Measurements were made of two units from a shifting theme (theme 1; Table 1, variables 19-24) and two units from a static theme (theme 2A; Table 1, variables 25-32). Unit 2 of phrase type la was a highly variable unit that changed in frequency as the theme progressed; therefore, frequency range was excluded from analyses. Initial frequency was also excluded due to possible measurement bias resulting from the large frequency bandwidth required to view this unit (at times in excess of $10,000 \mathrm{~Hz}$ ).

Phrase structure was evaluated by the number and types of units that composed a phrase (Table 1, variables 33-4,1). Number of units was measured for phrase types RT, 1a and $1 \mathrm{~b}$, as well as for subphrase 2 of $2 \mathrm{~A}$ (abbreviated 2AS2) and subphrase 1 of 3B (abbreviated 3BS1). The proportion of $1 \mathrm{~b}$ phrases that contained only two units was measured by summing across the total sample of each individual (only complete themes were used). Relative proportions of different types of units in a phrase were measured for 2AS2 and 3BS1. In 2AS2, units were described as either "flat" or rapidly "ascending" (frequency modulated; Fig. 4a). Only units in which the sonogram had a nearly vertical slope and had a characteristic "whoop" sound were classified "ascending." Units in 3BS1 were categorized by whether they contained low frequency energy ( < approximately 500 $\mathrm{Hz}$ ) before sweeping up (Fig. 4b). The entire subphrase of 3BS1 also was classified by the presence of "discrete" versus "run-on" units (Fig. 4b), so that phrases containing one or 
more units where frequency swept up, down and then up again were classified as "runon."

The final group of variables considered was the relative occurrence of themes, theme transitions, and phrase types (Table 1, variables $42-47$ ). Occurrence of themes $R$, 2B, 3A, and 3B was measured as the proportion of complete songs (typical and atypical) that contained each theme. The proportion of songs that contained the atypical 2B-1 transition also was measured for each individual. Finally, the proportion of phrase types $1 \mathrm{a}$ and $\mathrm{lb}$ that composed theme 1 was measured by summing all occurrences of each phrase type for each individual (only complete themes were used).

\section{Statistical Analyses}

The samples were divided among four three-week periods starting from 28 January 1991. Quantitative analysis was restricted to the first and last time periods, 21 January 16 February and 31 March - 20 April, representing the beginning and end of the sample period. Because I wanted to examine changes in songs during the breeding season, it was reasonable to analyze recordings from early and late season. All usable recordings in both areas (greater than 45 minutes and containing at least three complete songs) were analyzed for the first period. An equivalent number of recordings was chosen from the last period, taking into consideration length of recording, recording quality, and whether the whale was identified (Table 2).

Continuous sound spectrograms of each recording were viewed on a $486 \mathrm{CPU} / 25$ $\mathrm{MHz}$ personal computer equipped with real-time digital signal processing software produced by Engineering Design, Inc. Analysis parameters were similar to that used for the PAR system; analysis bandwidth ranged from $0-1000 \mathrm{~Hz}$ to $0-12,000 \mathrm{~Hz}$, depending on the highest fundamental frequency of the signals, and frequency resolution varied 
accordingly from $4.9 \mathrm{~Hz}$ to $58.7 \mathrm{~Hz}$. The 16 color display could be paused at any time, allowing precise measurement of time and frequency domain variables using a mouse controlled cursor. Durations of phrases and units were measured as the difference between start and finish on the x-axis. All frequency measurements were made on the fundamental frequency or the lowest harmonic of a unit. Measurements were stored in data files along with occurrence and counts of specific variables.

For each singer, means, standard errors, and coefficients of variation were calculated for each variable listed in Table 1. Means for each singer were used as samples in all statistical analyses. By using a mean for each of 24 singers as opposed to the raw data, analyses were not biased towards singers with longer samples. Means (more accurately, means of means) and standard errors were then calculated for each period within each area.

A Model I two-factor analysis of variance was used to test for significant differences among means of each variable between islands, between periods, and for interaction between the two factors. Before ANOVAs were conducted, probit plots of each cell were examined for deviations from normality. Underwood (1981) stated ANOVA procedures are generally robust to moderate deviations. If the deviation was severe (i.e., the probit plot displayed a parabolic function), then the data were transformed using an arcsine (Zar 1984) in the case of proportions (the only data that required transformation). The resulting transformed data were then checked for normality. Bartlett's test was used to test for heterogeneity of variances among cells. Underwood (1981) and Day and Quinn (1989) stated that Bartlett's test is particularly sensitive to nonnormality and that slight deviations from normal will result in an inflated estimate of $\alpha$ error. Therefore, if Bartlett's test indicated differences among the variances at $P<0.01$ 
(rather than $P<0.05)$, the data were transformed using square root $(\operatorname{Zar} 1984)$, and checked for heterogeneity of variances.

Underwood (1981) reported that heterogeneity of variances among cells in an ANOVA could increase the probability of an $\alpha$-error above that stated in the ANOVA table. He suggested that if heterogeneity of variances is suspected, the probability of a type I error be reduced using $\alpha<0.05$. Therefore, for variables in which Bartlett's test yielded $0.05>\mathrm{P}>0.01$, significance level for the ANOVA was set at $\mathrm{P}<0.01$.

Interpretation of results fell into three major categories: no change during time, similar change during time, and divergent change during time. If an ANOVA yielded no significant interaction and no significant difference between periods, I concluded that the variable either did not change through time or contained too much variation within cells (among individuals) to make a determination. If an ANOVA yielded no significant interaction and a significant difference between periods, I concluded that the variable changed through time in the same manner in each area (i.e., both increased or both decreased). The variable also was further classified as to whether the mean was significantly larger off one island. Finally, if the ANOVA yielded a significant interaction between the two factors, I concluded that the variable changed differently during time in the two areas. The cell means were then examined to determine whether the variable changed in opposite ways (i.e., increasing in one area and decreasing in the other), or if it changed in one area while remaining relatively stable in the other area.

In order to examine the amount of variation within an individual's songs (i.e., intraindividual variation: the variation among repetitions of an individual's units, phrases, themes and songs), coefficients of variation were calculated for each variable for each individual (Appendix A). These coefficients were then averaged across all individuals and plotted to examine the relative intra-individual variation among variables. In order to 
examine the amount of variation among individuals (i.e., inter-individual variation), coefficients of variation among the means of individuals were calculated for each variable. Since differences might exist between individuals from different islands and time periods, it was not possible to calculate a coefficient across all individuals. Therefore, a coefficient was calculated for each cell (island and time period), and these four coefficients were then averaged and plotted to examine relative inter-individual variation among variables.

\section{Results}

Recording Sessions

Songs of 60 whales were recorded off Kauai between 21 January and 19 April 1991, for approximately 65 hours. Recording sessions were 7 minutes to 4.5 hours each in duration. For 36 whales, recordings were greater than 45 minutes and averaged 94 minutes. Off Socorro, 97 whales were recorded between 28 January and 20 April 1991 for approximately 80 hours. Recordings were 2 minutes to 2.25 hours duration, with 59 sessions greater than 45 minutes and averaging 67 minutes.

Of 20 singers identified off Kauai, $10 \%$ were recorded twice, whereas off Socorro $17 \%$ of 29 identified singers were recorded twice. Six whales recorded off Kauai and six off Socorro were unidentified singers (Table 2). Each recording of an unidentified whale off Kauai had an approximately $10 \%$ chance of being a sample from a previously recorded whale, whereas there was an approximately $17 \%$ chance of a non-independent sample off Socorro. The actual probability of re-recording an individual is probably less than calculated due to individual differences in behavior. Singers recorded more than once may have a greater probability of being re-sighted and re-recorded because they may have a tendency to remain in the study range longer than others, or may sing for longer periods of time, allowing more opportunities for recording. 
Twenty-four recording sessions were chosen for analysis, 11 from Kauai and 13 from Socorro (Table 2). All usable recording sessions in the first period were included in the analysis, five from Kauai and seven from Socorro. To increase sample size, a recording of singer KI-91-04 was included even though it was $<45$ minutes duration. Six sessions were used in the second period from each area so sample sizes among cells in ANOVAs would be relatively equal. I analyzed 31 hours of recordings and 159 complete songs. Measurements were made on 7963 phrases and 4997 units.

\section{Quantitative Analysis}

Means of variables changed in four ways between periods and areas; 1) variable means (e.g., phrase duration of phrase type 1a) increased or decreased the same amount in each area, with no significant difference between areas (Fig. 5a); 2) variable means (e.g., peak frequency of theme 1a) increased or decreased in both areas, however, means differed between areas (Fig. 5b); 3) variable means (e.g., number of units per phrase of phrase type 1a) increased or decreased in only one area (Fig. 5c); or 4) variable means (e.g., proportion of phrases of $3 \mathrm{~B}$ with discrete versus run-on units) increased in one area and decreased in the other (Fig. 5d). "Similar change" occurred if the first or second pattern was observed (Fig. 5a and b), whereas "divergent change" occurred if the third or fourth pattern was observed (Fig. 5c and d). Three variables (variables 6, 24 and 33) did not change in either area, and will not be considered further (Tables 3 and 4).

Mean duration of most ( 6 of 7 ) phrase types and mean song duration changed similarly (Table 4). Mean duration of phrase types $1 \mathrm{a}, 1 \mathrm{~b}, 2 \mathrm{~A}$, and 3B increased significantly in each area with no difference between islands (Tables 3 and 4; Fig. 6). Mean duration of phrase type $\mathrm{R}$ also increased in both areas (Fig. 6); however, the difference between periods was not significant (Table 3). Mean duration of phrase type 
RT increased significantly in both areas, with a significant difference between islands (Table 4; Fig. 6). There were no significant interactions between island and period.

Mean song duration increased significantly between periods and was significantly greater off Kauai than Socorro (Tables 3 and 4; Fig. 7). Mean duration of typical songs increased (Fig. 7), however not significantly ( $p=0.061$; Table 3); the difference between islands remained significant.

Mean peak frequencies for two themes changed similarly in each area (Table 4). Mean peak frequency for theme $1 \mathrm{a}$ increased off both islands, but was significantly greater off Kauai than Socorro (Tables 3 and 4; Fig. 8). Mean peak frequency for phrase type 3B increased significantly off both islands with no significant difference between islands (Tables 3 and 4; Fig. 8).

Mean repetitions for three phrase types changed similarly, whereas for four phrase types they changed divergently (Table 4). Mean repetitions of phrase type $\mathrm{R}$ significantly decreased in both areas, and was significantly greater off Kauai than Socorro (Tables 3 and 4 ; Fig. 9). Mean repetitions of phrase type 1 ( $1 \mathrm{a}$ and $1 \mathrm{~b}$ lumped) and phrase type $1 \mathrm{a}$ increased significantly in both areas with no difference between areas (Tables 3 and 4; Fig. 9). Mean repetitions of the other four phrase types indicated divergent change in each area (Fig. 9); however, none of these relationships resulted in significant interaction between island and period, possibly due to high variation among individuals (Tables 3 and 4).

All unit measurements for phrase types $1 \mathrm{a}, 1 \mathrm{~b}$, and $2 \mathrm{~A}$ indicated similar change in each area (Table 4). Mean duration of unit 2 in phrase type la increased significantly in both areas, with a small but significant difference between islands (Tables 3 and 4; Fig. 10). Mean average slope (frequency range $\div$ duration) of unit 2 in la decreased significantly in both areas, with no difference between islands. For unit 2 of phrase type 
1b, mean initial frequency significantly decreased, whereas mean frequency range and mean duration significantly increased in both areas; each variable was significantly different between areas (Tables 3 and 4; Fig. 10). Most ( 7 of 8 ) measurements of units 1 and 2 in phrase type $2 \mathrm{~A}$ changed in similar ways off both islands, with no difference between islands (Tables 4 and 5; Fig. 11). Mean initial frequency and mean duration decreased, mean frequency range increased, and mean average slope increased accordingly (Fig. 11). Mean initial frequency of unit 1 was significantly different between islands (Table 3); however, the difference between means was slight.

Of nine phrase structure variables, seven indicated divergent change between areas (Table 4). Mean number of units for phrase types $1 \mathrm{a}, 1 \mathrm{~b}$, and 3BS1, and mean proportion of phrase $1 \mathrm{~b}$ with only two units exhibited significant interactions between island and period, indicating divergent change; although one variable (mean number units for phrase type $1 b)$ may be suspect due to heterogeneity of variances (Tables 3 and 4). Mean number of units for phrase types 1a, 1b, and 3BS1 each increased off Kauai and remained stable off Socorro (Fig. 12). Mean number of units for phrase type 2AS2 also increased off Kauai while remaining relatively stable off Socorro (Fig. 12); however, the interaction term was not significant, possibly due to variation among individuals in Socorro (Tables 3 and 4; Fig. 12).

Mean proportion of "flat" units in phrase type 2AS2 increased off Socorro and remained stable off Kauai (Fig. 13); however, the interaction term was not significant (Table 3), possibly due to high variation among individuals in some groups (Fig. 13). The mean proportion of units with low frequency energy in phrase type 3BS1 was the only phrase structure variable that changed similarly in both areas (Fig. 13). This variable increased significantly in both areas and was greater off Kauai than Socorro (Tables 3 and 4). The mean proportion of phrase type $3 B$ with "run-on" units increased off Kauai but 
decreased off Socorro (Fig. 13), so there was a highly significant interaction term (Table 3).

Of six variables concerning theme and song structure, three indicated similar change and three divergent change (Table 4). Mean proportions of songs containing themes $R$ and 3B increased significantly off both islands, and the $2 \mathrm{~B}-1$ theme transition showed a decreasing trend (although not significant, $p=0.069$ ) off both islands (Tables 3 and 4; Fig. 14). Mean proportion of songs with theme $3 \mathrm{~A}$ decreased from 0.58 ( \pm s.d. 0.30 ) to 0.005 ( \pm s.d. 0.029 ) off Kauai, whereas the theme was rare in Socorro throughout the study period (Fig. 14). This resulted in a significant interaction term, and apparent divergent change between the two areas (Tables 3 and 4). Mean proportion of songs with theme $2 \mathrm{~B}$ decreased off Socorro, and was in nearly $100 \%$ of songs off Kauai (Fig. 14). Mean proportion of phrase types $1 \mathrm{a}$ and $1 \mathrm{~b}$ in theme 1 , increased off Socorro but decreased slightly in Kauai (Table 4 and Fig. 14), resulting in a highly significant interaction term (Table 3).

Mean coefficients of variation among all individuals were used to examine intraindividual variation (Fig. 15). Phrase durations were the least variable within individuals (Fig. 15a). Song durations were more variable than phrase durations, but were moderate relative to other variables. Unit measurements for phrase type 1 were highly variable for particularly frequency range and average slope, probably because frequency range of the units was constantly changing throughout the theme. Variation among units of phrase type $2 \mathrm{~A}$ was considerably less than phrase type 1 . For each phrase type, duration and initial frequency of units were the least variable of unit measurements. Phrase repetitions exhibited some of the highest variation (Fig. 15d). Large standard deviations for phrase repetitions indicated that some individuals were more variable than others (Table A.3). 
Coefficients of variation among the means of individuals were used to examine inter-individual variation (Fig. 16). The results were similar to intra-individual variability, phrase durations were least variable and phrase repetition were most variable. In all cases, there was less variability among the means of individuals than within individuals (Figs. 15 and 16). This suggested that although there was variability within songs of individuals, the variability was generally the same among individuals.

\section{Discussion}

If humpback whales off Kauai and Socorro were isolated during the breeding season, and cultural evolution occurred through the season, we would expect some divergent change of song variables between areas. Conversely, if there was cultural transmission between whales in the areas, we would expect all or most variables to change similarly in the two areas. The results of this study do not indicate such simple explanations; some variables changed similarly, whereas others changed divergently.

Similar variables tended to display the same patterns of change. The variables used in my analysis were grouped into six categories describing different levels of song structure. Although all variables did not follow either similar or divergent change, variables within groups tended to follow the same pattern (Table 4). Variables of phrase duration $(n=6)$, song duration $(n=2)$, peak frequencies $(n=2)$, and unit structure $(n=13)$ changed similarly in each area. Variables of phrase structure $(n=7)$ changed divergently. Variables of theme and song structure changed similarly $(n=3)$ or divergently $(n=3)$. Variables of song structure that changed similarly (\#42, \#45, and \# 46), however, were directly related; a $2 \mathrm{~B}-1$ theme transition resulted in a song without theme $3 \mathrm{~B}$ or $\mathrm{R}$, so, as the frequency of occurrence of the $2 \mathrm{~B}-1$ theme transition decreased, the proportion of songs with themes $3 \mathrm{~B}$ and $\mathrm{R}$ increased (Fig. 14). Therefore, of four 
unrelated variables of theme and song structure, three changed divergently. Phrase repetitions was the only variable group that did not follow one predominant pattern of change; three variables changed similarly, whereas four changed divergently.

It may be argued that differences and similarities between areas and time periods may be due to chance or the gathering of different assemblages of individuals at different times and places. If the similarities between Hawaii and Mexico were due to chance, then we would expect an equal probability of divergent and similar change. In such a system, the songs of individuals off Mexico and Hawaii would quickly diverge over several years; however, Payne and Guinee (1983) showed that songs were similar in 1977 and 1979, and they still remain similar in 1991. If differences between periods were due to the presence of different assemblages of individuals at different times, then we would expect random rather then directional change through time. Payne et al. (1983) and Payne and Payne (1985) showed consistent directional change of songs over two years off Hawaii and 17 years off Bermuda, respectively. Furthermore, Guinee et al. (1983) showed that twice recorded individuals changed their songs through time in the same ways as the population as a whole. It is, therefore, unlikely that the trends observed in this study were due to chance or the behaviors of different assemblages of individuals.

Two alternative hypotheses may be proposed to explain the results of this study. First, whales may have traveled between the islands during the breeding season, culturally transmitting changes that occurred in each area. Second, whales may change some levels of song structure according to a set of rules, either innate or learned, whereas other levels may change via cultural evolution. I will discuss each hypothesis separately, indicating supporting data and inherent weaknesses. 


\section{Cultural Transmission of Song Changes}

Payne and Guinee (1983) first suggested that male humpback whales moved between Hawaii and Mexico during a breeding season. This was one of three mechanisms proposed to explain cultural transmission among individuals in these two areas. In this scenario, new traditions (changes in various elements of the song) would be generated in each area and transmitted to the other area via meme flow and cultural diffusion during the breeding season. My data potentially support this hypothesis, because at least three groups of variables changed similarly in each area during a 12 week period.

Traditions undergoing cultural evolution in geographically isolated areas diverge (Mundinger 1980). Although 14 variables were classified under divergent change (Table 4), only change of one variable of phrase structure (variable 41) was negatively correlated between areas, increasing in one area and decreasing in the other. Changes in two variables of phrase repetition also were negatively correlated between areas (variables 16 and 18), however not significantly. The remaining 11 variables changed off one area and did not change off the other. Therefore, the low number of variables that increased in one area while decreasing in the other also may indicate cultural transmission between areas.

There are three main problems apparent with this hypothesis. First, there is little existing evidence of movements of individuals from Hawaii to Mexico within a breeding season (Baker et al. 1986). There is only one documented record of an individual photographed in Hawaii and Mexico in the same season (North Pacific Humpback Whale Working Group et al., unpublished data). However, this record comes from a small sample of photographs from Mexico, and further analysis currently in progress may reveal a greater amount of exchange (J. Urban, pers. comm.). Mate et al. (1992) recently documented two cases of a North Atlantic right whale (one of which was a mother with 
calf) traveling over $3000 \mathrm{~km}$ in six weeks. Therefore, it is likely that humpback whales can travel extensive distances in a short time as well.

Second, not all variables changed similarly in each area. Most variables associated with phrase structure changed divergently (Table 4). Five variables (\# 34, \# 35, \# 36, \# 37, and \# 38) changed off Kauai, whereas they remained stable in Socorro, and one variable (\# 39) changed only in Socorro. One variable (\# 41) increased in Kauai while decreasing in Socorro. If small changes in phrase duration are thoroughly integrated into the recipient population, then changes in phrase structure should be integrated also. Three variables of theme and song structure (\# 43, \# 44, and \# 47) also changed divergently in each area (Table 4).

Third, considering the size of the North Pacific population of humpback whales, and the distances separating the primary winter congregations of whales, cultural transmission would probably result in greater variation among individuals and areas than is exhibited by many variables measured in this study. Current population estimates of humpback whales in Hawaii are 1,000 - 2,100 (Darling and Morowitz 1986, using several techniques including a rate of discovery curve) and 1,407 \pm 294 (Baker and Herman 1987, using a mark-recapture Schnabel estimator). These researchers used data from the late 1970 's to early 1980's. A more recent estimate of 3,022 \pm 1647 (Cerchio et al. 1991, using a Schnabel estimator) used data from 1989 to 1991. There are no current estimates from Mexico. If half of the population is male, then there could be thousands of males transmitting and receiving song information. These individuals are spread over distances of 100 to $500 \mathrm{~km}$ within breeding areas (e.g., the Hawaiian Islands) and up to $5000 \mathrm{~km}$ between breeding areas. It seems unlikely that all individuals in different breeding areas could synchronously change their songs and maintain low inter-individual variability via 
cultural transmission. Yet, variation among individuals and between areas was low for many variables, particularly variables of phrase duration.

Furthermore, if meme flow and cultural diffusion were responsible for transmission of song changes between Hawaii and Mexico, we would expect a change to occur later in one area than in the other area. The shortest known transit of an individual whale from southeastern Alaska to Hawaii was 39 days (Gabriele and Straley, pers. comm.). This represents a distance of approximately $4500 \mathrm{~km}$; therefore, this whale had a minimum average speed of 2.6 knots if traveling 24 hours/day for all 39 days. Assuming the whale was not constantly traveling during this period, 2.6 knots would be an underestimate. An animal with an average traveling speed of 4 knots would take approximately 4 weeks to travel $4800 \mathrm{~km}$, the distance between Kauai and Socorro. During its transit, song changes would continue to appear and progress at the whale's origin. After arriving at its destination, there would be an additional delay before information from the individual's origin was transmitted and fully integrated into the recipient population. Therefore, we would expect similar change in each area with significant differences between islands, due to whales off one area "lagging behind" whales off the other. Many variables that changed similarly in each area were not significantly different between areas (Table 4). It is difficult to attribute these similarities between Kauai and Socorro, therefore, to cultural transmission.

Some variables changed similarly with significant differences between areas, and therefore, may be the result of cultural transmission. This is the case with mean song duration and mean peak frequency of theme 1a. The data presented here, however, do not conclusively indicate a lag between changes in each area, because only two time periods were analyzed. The differences, therefore, may be attributable to differences between the populations of whales in each area. Mean measurements of units in phrase types 1a and 
Ib also changed similarly with significant differences between areas. Examination of the data, however, reveals an inconsistent trend. Mean duration of unit 2 in phrase type la increased in both areas and the mean for Socorro was shorter in each period. If this relationship was due to a lag in cultural transmission, we would conclude that this change was transmitted from Kauai to Socorro. However, mean slope for the same unit decreased in each area and the mean for whales off Kauai was larger. If this was the result of a lag, then transmission would have been from Socorro to Kauai, the opposite direction. The same relationship existed among measurements of unit 2 in phrase type $1 \mathrm{~b}$. Because these variables are measurements of the same units, the difference between areas is probably not due to time lags in cultural transmission.

\section{Possible Rules of Change}

As an alternative hypothesis, some features of humpback whale song (such as phrase duration and unit structure) may undergo change according to a predetermined pattern or "set of rules." This predisposition toward change could be innate or learned as a juvenile. Other features (such as phrase structure and song structure) could be culturally transmitted among individuals, and changes would be the result of cultural evolution. The similarities between songs in Hawaii and Mexico would, therefore, be due to a combination of mechanisms.

This hypothesis is supported by the low level of variation in mean phrase durations among areas, among individuals, and within individuals. Individuals may increase duration of phrases at a fixed rate, independent of information they receive from other whales. Payne et al. (1983) found mean phrase duration of most phrase types increased through time during two consecutive seasons in Hawaii, and Frumhoff (1983) reported phrase duration among individuals was the least variable of five measures of song structure. 
These findings are consistent with the proposed hypothesis. This should be testable by comparing the mean phrase durations of known whales recorded more than once, and calculating rates of change for several individuals over different time spans.

This hypothesis also could explain the similar change between areas and low variation in unit structure measurements, particularly of the static theme $2 \mathrm{~A}$. It is difficult, however, to propose a general rule that would govern change in all units. Unlike phrase durations, different units changed in different ways (e.g., units in la and $1 \mathrm{~b}$ increased in duration, whereas units in $2 \mathrm{~A}$ decreased in duration). These changes might better be attributed to cultural causes. Perhaps change in a specific unit (e.g., an increase in frequency range) is initiated culturally, via innovation. Individual whales then continue to progressively change the unit (continue to increase the frequency range) at a predetermined rate. This also should be testable with multiple samples from known individuals.

Changes in phrase, theme, and song structure may be introduced by cultural mutation, and propagated through the population via meme flow and cultural diffusion. The results of this study, however, do not clearly indicate a route of cultural transmission. Meme flow and cultural diffusion between Hawaii and Mexico could occur during a season, between seasons, or during migration as suggested by Payne and Guinee (1983). Only one variable (involving phrase structure in 3BS1) was negatively correlated between areas. All other variables that changed divergently changed in one area (primarily Kauai) while remaining stable in the other (Table 4). Some of these relationships (Figs. 12, 13 and 14) may be due to lags in the progression of changes in either area. Therefore, there is little evidence indicating isolation during the breeding season, and cultural transmission throughout the season cannot be dismissed. 
To my knowledge there are no examples of animal populations that are "programmed" to continuously change a tradition. In all examples cited, change of a tradition through time is the result of cultural mutation and imitation, the characteristic processes of cultural evolution (Jenkins 1977; Payne 1979; Ince et al. 1980; Mundinger 1980; Slater et al. 1980; Feekes 1982; Payne 1985; Lynch et al. 1989; Trainer 1989). If certain elements of humpback whale song follow a predetermined pattern of change, it would be a unique phenomenon. This idea is speculative, because several problems are apparent with this hypothesis:

1.) This sample of individuals is relatively small and represents the events of only one breeding season. These results need to be replicated in other years with larger samples to determine general "rules of change."

2.) Predisposition towards change may be innate, or "rules of change" may be learned early in life by cultural transmission. It is probably not possible to distinguish between these alternatives, because it is impossible to isolate an immature whale.

3.) Any proposed mechanism governing reproductive vocal behavior must be adaptive, with defensible reasons explaining its development.

\section{Geographic Variation and Cultural Evolution in Birdsong}

Humpback whale songs bear many similarities to birdsong in both structure and possible function. Birdsong in passerines consists of distinct, stereotyped patterns of notes, which in some species can be quite complex. Tyack (1981) proposed humpback whale songs function as a male breeding display similar to birdsong. Slater (1986) commented on the similarities between humpback whale song and the songs of village indigobirds. It is, therefore, appropriate to review birdsong literature in the interpretation of my results and evaluation of my hypotheses. Terminology used in birdsong literature 
differs from that used for humpback whale song, as well as among birdsong studies. I will, therefore, avoid a discussion of song structure, and present a brief review of geographic variation and cultural evolution in birdsong.

Mundinger (1982) reviewed birdsong literature to describe geographic variation among 124 species representing 24 passerine and 4 non-passerine families. Vocal learning was taxonomically widespread, occurring in 53 species of 20 families. Learning was usually expressed as vocal imitation, whereas improvisation was relatively infrequent. Using a linguistic approach, he grouped spatial variation in a species' song types into two major categories: institutions and dialects. The institution is defined as a regional population of similar song syllables, or patterns; in linguistic terms this is considered a lexicon, or vocabulary. Within an institution, there is often a spatial distribution of song type variations, differing phonetically. These local populations of phonetic variants are considered dialects within the institution. Not all researchers agree on the definition of "dialect," and the term is used differently in various studies (Krebs and Kroodsma 1980).

Geographic variation in bird song can be divided into macrogeographic and microgeographic variation. Macrogeographic variation describes the distribution of institutions, and emphasizes species-specific features and limitations (Mundinger 1982). Cultural evolution is often not apparent on this gross level, although it can be instrumental in the establishment of regional institutions. Researchers of microgeographic variation attempt to establish phonological distributions, and describe dialects and dialect boundaries as well as their causal processes. Mundinger (1982) found distributions of distinct, local dialects were common among songbirds, and appeared to be the rule rather than the exception. Dialects are the product of cultural evolution; however, the function of local dialects with distinct boundaries is debated among researchers. Dialects may maintain genetic isolation, promoting inbreeding and maintaining adaptations to local 
habitats (Krebs and Kroodsma 1980; Slater 1986). Conversely, they may function to promote outbreeding, assuring genetic diversity in a population (Jenkins 1977; Slater 1986). Mundinger (1982) and Slater (1986) argue that dialects may be incidental byproducts of vocal learning and local dispersion patterns of individuals, with no real biological function or adaptive value. Krebs and Kroodsma (1980) and Mundinger (1982) emphasize the presence of vocal learning ability over the existence of dialects when considering the adaptive function of song in reproduction.

Bird song, particularly in true songbirds (oscines), fits the criteria for animal culture as defined by Mundinger (1980). It is learned and transmitted through generations by imitation, and males in a population share common song patterns (Mundinger 1980; Slater 1986). Culturai transmission and evolution have been documented in the songs of several wild populations of birds (Jenkins 1977; Payne 1979; Ince et al. 1980; Slater et al. 1980; Feekes 1982; Payne 1985; Lynch et al. 1989; Trainer 1989).

Jenkins (1977) observed cultural transmission of song types during a five-year period in a small population of New Zealand saddlebacks (Philesturnus carunculatus). Dialectal groups were highly stable, and there were several documented instances of copy error (cultural mutations) by young individuals that resulted in new traditions. Chaffinches (Fringilla coelebs) are exceptionally accurate learners, and cultural evolution of chaffinch song occurs at a very slow rate (Ince et al. 1980; Slater 1986). Some song types in a Great Britain population remained stable for 18 years (Ince et al. 1980). Slater et al. (1980) concluded that occasional copy error, with the possibility of migration and meme flow, was the probable cause of evolution, and estimated a mutation rate of $15 \%$ to explain the amount of change observed. Differential selection of song types (psychological selection) was ruled out as a causal agent. Lynch et al. (1989) studied a population of chaffinches in New Zealand, and also concluded that selection pressure was 
not a factor in song evolution. They concluded that song differentiation was the result of mutation (copy error), memetic drift, and meme flow.

Rapid cultural evolution has been documented in two passerine birds, the yellowrumped cacique, Cacicus cela, in Suriname and Panama (Feekes 1977; Feekes 1982; Trainer 1989), and the village indigobird, Vidua chalybeata, in Zambia (Payne 1979; Payne 1985). Feekes $(1977,1982)$ first reported rapid change in songs of caciques in Suriname

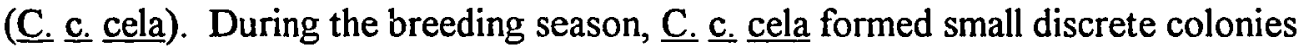
separated by a few kilometers. Each colony had a specific set of one to four songs, which was shared by all males in a colony. At the start of each breeding season, songs changed completely in each colony. During the breeding season, immigration of new males into a colony sometimes produced an abrupt change in song types, but more often it did not. Gradual, progressive evolution also occurred during the season. Trainer (1989) studied cultural evolution in songs of caciques in Panama ( $\underline{\text { C. }}$ c. vitellinus). She reported a similar situation of several colonies scattered across a region, each with a colony-specific dialect of five to eight songs. Within a colony there was little inter-individual variation, and songs persisted throughout a breeding season. Within a season some songs gradually changed, and banded males incorporated all changes. At the start of a new season, some songs persisted, whereas others apparently were new. Most new songs appeared to arise from songs of the previous season. Few songs appeared to originate from other dialects. Trainer (1989) concluded that introduction of songs from other colonies (meme flow) was less significant than the process of progressive change within a colony. Change was too fast and directional to be attributed to copy error and memetic drift. Therefore, she suggested that the non-random change might be due to innovation and preferential adoption of certain traits, or preferential imitation of certain individuals (psychological selection in Mundinger 1980). 
Payne (1979) identified rapid cultural evolution in songs of a population of village indigobirds (Vidua chalybeata) in Zambia. Several local dialects were reported, each with approximately 23 songs (Payne 1985). Within a "song neighborhood" (dialect) all males shared all or nearly all song types. Each local song type changed gradually from year to year, and changes accumulated so that after four to five years songs were very different. Some songs changed progressively during a single breeding season. Adult males with the greatest mating success appeared to be copied more often than less successful conspecifics. Payne (1985) concluded that immigration from other dialects (meme flow) was not a significant source of new traditions, and that most changes were the result of gradual accumulation through the years. Survival and transmission of traditions was apparently related to the number of individuals in a song neighborhood and male breeding success, therefore attributable to social context and psychological selection.

To address adaptive function of rapid cultural evolution of songs, Trainer (1989) contrasted the reproductive behaviors of caciques and village indigobirds (species with songs that undergo rapid evolution), with chaffinches and indigo buntings (species with stable songs that change slowly through time). Caciques and village indigobirds are polygynous, males are not territorial and frequently engage in competitive contact, males disperse widely, and songs can be learned as adults. Chaffinches and indigo buntings are usually monogamous, males are territorial and there is less social contact, males usually return to the same territory throughout their lifetime, and learning ability is restricted to a period in early life. Behavior of New Zealand saddlebacks is similar to that of chaffinches and indigo buntings, and saddlebacks also have a stable song that changes slowly (Jenkins 1977).

Trainer (1989), therefore, suggested that rapid cultural evolution of bird song occurs in species with a high degree of male-male competition. Payne (1985) suggested 
that male village indigobirds with the most matings were imitated most and initiated changes in songs. Trainer (1989) did not directly observe this in caciques, but proposed a process based on preferential adoption of songs of successful males. Dominant males innovate on an existing song model to make their song distinguishable from other males. This song variant, from a high ranking male, acts as a strong stimulus to either threaten males or attract females. Other males will try to imitate this song to confer its selective advantage upon themselves. Once all males share the song, it is no longer effective, and the dominant male makes a new improvisation. Therefore, there is continual incentive to improvise, and the repeating cycle results in non-random, directional change.

This model works well within the behavioral context of caciques and indigobirds. In both species, social organization is characterized by local colonies with distinct dialects (Feekes 1982; Payne 1985; Trainer 1989). Each colony is composed of a relatively small number of closely associated individuals. In each species, males that switched colonies usually learned the dialect of the new colony, rather than introducing songs from its previous colony (Payne 1985; Trainer 1989). Different songs in a male's repertoire may have a different message, usually associated with aggressive or courtship behavior (Payne 1979; Trainer 1987).

\section{Comparison with Humpback Whale Song}

Song behavior in humpback whales resembles that of caciques and village indigobirds in many respects: all males in a region share the same song patterns, songs gradually change throughout the season, males incorporate changes into their own songs and changes accumulate through time (Guinee et al. 1983; Payne et al. 1983; Payne and Payne 1985). Humpback whales also share many of the reproductive behaviors noted for caciques and village indigobirds. The mating system is presumed to be polygynous 
(Darling 1983), males are not territorial (Tyack 1981; Darling 1983), there is a high level of male-male competition during the breeding season (Tyack and Whitehead 1983; Baker and Herman 1984), there is a high degree of dispersal of males throughout the ureeding areas (Darling and Jurasz 1983; Darling and McSweeney 1985; Baker et al. 1986; Cerchio et al. 1991; Darling and Cerchio 1993), and males have the ability to learn songs as adults (Guinee et al. 1983). Although these characteristics fit the behavioral trends proposed by Trainer (1989) very well, it is intuitively difficult to apply her model to humpback whales.

Songs of humpback whales differ from cacique and village indigobird song in that there are no distinct local dialects. In humpback song there is little variation over an extensive geographic area. Although differences were apparent between songs from Hawaii and Mexico, this variation was subtle in comparison to the similarities. Different dialects in cacique and indigobird populations consist of distinct sets of songs with different patterns of notes (Payne 1985; Trainer 1989). In both species, neighboring dialects may share some patterns, whereas dialectal groups several kilometers apart share few if any patterns. The patterns in humpback whale songs (phrase types) were virtually the same in Hawaii and Mexico. Predominant differences were subtle details within phrase types (e.g., frequency ranges of specific units), and frequency of occurrence of some phrase types. Helweg et al. (1990) reported that the number of shared phrase types among songs from Japan, Hawaii, and Mexico decreased with increasing distance. This may be evidence for dialects in humpback whale songs. However, Helweg et al. (1990) found songs from Hawaii and Mexico in 1989 shared only five phrase types, and did not share three phrase types. I have shown that songs from whales off Hawaii and Mexico shared all phrase types in 1991, and Payne and Guinee (1983) found songs shared all phrase types in 1979. Furthermore, qualitative analysis of songs from six whales off Kauai and five off Socorro, recorded between late January and early April of 1989, indicated that 
songs off Hawaii and Mexico shared all of seven phrase types in 1989 (Cerchio and Jacobsen, unpublished data). Therefore, it is likely that the results of Helweg et al. (1990) concerning songs from Hawaii and Mexico were artifacts due to small sample size. Darling and Ford (1988) indicated greater similarities between songs from Japan and Hawaii in 1988 than Helweg et al. (1990) found in 1989, so the conclusions of Helweg et al. (1990) concerning songs from Japan also may be erroneous.

Humpback whale songs also differ from cacique and indigobird songs in the number of individuals that share the same songs. In the North Pacific, probably thousands of whales share the same songs. Therefore, it is difficult to see how the song of a dominant male in Hawaii would have any relevance to males in Mexico. If copying dominant males is the sole driving force for cultural evolution, then one would expect highly divergent change in these distant areas. Whales tend to sing while alone, separating themselves by several kilometers (Tyack 1981; Frankel et al. 1991), and song may serve a spacing function (Frankel et al. 1991). Most competitive interactions among males apparently occur in large groups of active whales, when males do not often sing (Tyack and Whitehead 1983; Baker and Herman 1984). Therefore, it would be difficult for an individual to connect a specific song with a specific dominant male.

It has been hypothesized that the selective advantage of humpback whale song may lie with those males that can demonstrate conformity to the current version of the song as well as display innovation (K. Payne, pers. comm.). Therefore, males would avoid singing both "old" songs, and songs too different from conspecifics in the region. Mundinger (1982) stated that, although specific dialects in bird song may have no biologically adaptive significance, the ability to sing the appropriate dialect may have a socially useful significance and confer a selective advantage. He uses an example of central European chaffinches that respond to playbacks of Spanish chaffinch song as if they were songs of a 
different species. That male caciques and village indigobirds learn new dialects when they change colonies further supports this theory (Payne 1985; Trainer 1989). Although dialects apparently do not occur among humpback whales within an ocean basin, differences in humpback songs through time may be viewed as dialects in the time domain (as opposed to the spatial domain). Therefore, singing the current "dialect" may have an immediate social significance for male humpback whales.

If it is adaptive to sing the current dialect, and individuals commonly move between distant breeding areas, it is reasonable that a mechanism would evolve to facilitate the ability of a male to sing the appropriate song. In such a scenario, a set of rules might exist that govern the temporal evolution of basic structural elements of song (e.g., phrase duration). Superimposed on this change, cultural evolution of the fine structure of patterns (e.g., phrase structure) may occur driven by selective forces similar to those proposed by Trainer (1989). Cultural evolution would be independent within local areas (e.g., Hawaii and Mexico), and changes in patterns would be transmitted between areas via meme flow and cultural diffusion. Thus, individuals in Hawaii and Mexico could maintain similar songs with a limited amount of cultural transmission.

Several questions can be asked to test this hypothesis. Is this pattern of change between songs from Mexico and Hawaii characteristic of other years? Do songs from Japan also follow the same patterns within a breeding season, changing in phrase duration similarly with Hawaii and Mexico, but divergently in phrase structure? Do known individuals change phrase duration or any other variables at a fixed rate? Do geographically isolated populations with different songs also follow the same patterns of change? As Mundinger (1980) stated, a study of macrogeographic variation (i.e., songs from different ocean basins with different lexicons) will reveal species-specific traits, such as innate structural rules or a predisposition to a specific pattern of change; a study of 
microgeographic variation (i.e., songs within an ocean basin that use the same general lexicon, such as Hawaii, Mexico, and Japan) will reveal patterns of cultural transmission and evolution. Future studies should include detailed comparisons, such as presented here, of songs from different breeding areas within an ocean basin, and from different ocean basins, spanning several consecutive years of sampling. An effort should also be made to view results in the context of cultural evolution of behavioral traditions that have been more extensively studied (e.g., birdsong). 


\section{Literature Cited}

Baker, C. S., and L. M. Herman. 1984. Aggressive behavior between humpback whales (Megaptera novaeangliae) wintering in Hawaiian waters. Can. J. Zool. 62: 19221937.

Baker, C. S., and L. M. Herman. 1987. Alternative population estimates of humpback whales (Megaptera novaeangliae) in Hawaiian waters. Can. J. Zool. 65: 28182821.

Baker, C. S., L. M. Herman, A. Perry, W. S. Lawton, J. M. Straley, and J. H. Straley. 1985. Population characteristics and migration of summer and late-season humpback whales (Megaptera novaeangliae) in southeastern Alaska. Mar. Mamm. Sci. 1 (4): 304-323.

Baker, C. S., L. M. Herman, A. Perry, W. S. Lawton, J. M. Straley, A. A. Wolman, G. D. Kaufman, H. E. Winn, J. D. Hall, J. M. Reinke, and J. Ostman. 1986. Migratory movement and population structure of humpback whales (Megaptera novaeangliae) in the central and eastern North Pacific. Mar. Ecol. Prog. Ser. 31: 105-119.

Calambokidis, J., J. C. Cubbage, G. H. Steiger, K. C. Balcomb and P. Bloedel. 1990. Population estimates of humpback whales in the Gulf of the Farallones, California. Rep. Int. Whal. Commn. (special issue 12): 325-333.

Cavelli-Sforza, L. L. and M. W. Fieldman 1981. Cultural transmission and evolution: a quantitative approach. Princeton University Press. Princeton, New Jersey. 389 pp.

Cerchio, S., C. Gabriele and A. Frankel. 1991. Inter-island movements of humpback whales (Megaptera novaeangliae) in the Hawaiian Islands: three seasons off Hawaili and Kaua'i. Paper presented at the Ninth Biennial Conference on the Biology of Marine Mammals. December 5-9, 1991. Chicago, Illinois.

Chittleborough, R. G. 1960. Australian catches of humpback whales 1959. CSIRO Australian Division of Fisheries and Oceanography. Rep. No. 29.

Chittleborough, R. G. 1962. Australian catches of humpback whales 1960. CSIRO Australian Division of Fisheries and Oceanography. Rep. No. 34.

Clapham, P. J. and D. K. Mattila. 1990. Humpback whale songs as indicators of migration routes. Mar. Mamm. Sci. 6(2):155-160. 
Darling, J. D. 1983. Migrations, abundance and behavior of "Hawaiian" humpback whales (Megaptera novaeangliae). Ph.D. diss. Univ. Calif. Santa Cruz.

Darling, J. D. 1991. Humpback whales in Japanese waters: Ogasawara and Okinawa fluke identification catalogue 1987-1990. World Wide Fund for Nature - Japan. Tokyo. $56 \mathrm{pp}$.

Darling, J. D. and S. Cerchio. 1993. Movement of a humpback whale (Megaptera novaeangliae) between Japan and Hawaii. Mar. Mam. Sci. 9 (1): 84-89.

Darling, J. D. and J. K. B. Ford. 1988. A study of the current status of humpback whales in Japan. Progress report. August 1988. Available: World Wide Fund for Nature Japan, Tokyo, or West Coast Whale Research Foundation, Vancouver, 10 pp.

Darling, J. D., Gibson, and G. Silber. 1983. Observations on the abundance and behavior of humpback whales (Megaptera novaeangliae) off West Maui, Hawaii, 1977-79. In R. Payne (editor), Communication and behavior of whales. AAAS Selected Symposia Series, p. 201-222. Westview Press, Boulder, Colo.

Darling, J. D., and Jurasz, C. M. 1983. Migratory destinations of North Pacific humpback whales (Megaptera novaeangliae). In R. Payne (editor), Communication and behavior of whales. AAAS Selected Symposia Series, p. 359-368. Westview Press, Boulder, Colo.

Darling, J. D., and D. J. McSweeney. 1985. Observations of the migrations of North Pacific humpback whales (Megaptera novaeangliae). Can. J. Zool. 63: 308-314.

Darling, J. D., and H. Morowitz. 1986. Census of "Hawaiian" humpback whales (Megaptera novaeangliae) by individual identification. Can. J. Zool. 64: 105-111.

Dawkins, R. 1976. The selfish gene. Oxford University Press. New York.

Day, R. W., and G. P. Quinn. 1989. Comparisons of treatments after an analysis of variance in ecology. Ecol. Monog. 39 (4): 433-463.

Feekes, F. 1977. Colony specific song in Cacicus cela: the password hypothesis. Ardea 65:197-202.

Feekes, F. 1982. Song mimesis within colonies of Cacicus cela cela: a colonial password? Z. Tierpsychol. 58: 192-152. 
Frankel, A. S., C. W. Clark, L. H. Herman, T. R. Freeman, C. M. Gabriele and M. A. Hoffhines. 1991. The spacing function of humpback whale song. Paper presented at the Ninth Biennial Conference on the Biology of Marine Mammals. December 5-9, 1991. Chicago, Illinois.

Frumhoff, P. 1983. Aberrant songs of humpback whales (Megaptera novaeangliae): clues to the structure of humpback songs. In R. Payne (editor), Communication and behavior of whales. AAAS Selected Symposia Series, p. 81-127. Westview Press, Boulder, Colo.

Glockner, D. A. 1983. Determining the sex of humpback whales (Megaptera novaeangliae) in their natural environment. In R. Payne (editor), Communication and behavior of whales. AAAS Selected Symposia Series, p. 447-464. Westview Press, Boulder, Colo.

Guinee, L. N., K. Chu and E. M. Dorsey. 1383. Changes over time in the songs of known individual humpback whales (Megaptera rovaeangliae). In $\mathrm{R}$. Payne (editor), Communication and behavior of whales. AAAS Selected Symposia Series, p. 5980. Westview Press, Boulder, Colo.

Hafner, G. W., C. L. Hamilton, W. W. Steiner, T. J. Thomas and H. E. Winn. 1979. Signature information in the song of the humpback whale. J. Acoust. Soc. Am. 66 (1): $1-6$

Helweg, D. A., L. M. Herman, S. Yamamoto and P. H. Forestell. 1990. Comparison of songs of humpback whales (Megaptera novaeangliae) recorded in Japan, Hawaii, and Mexico during the winter of 1989. Sci. Rep. Cetacean Res. 1: 1-20

Ince, S. A., P. J. B. Slater and C. Weismann. 1980. Changes with time in the songs of a population of chaffinches. Condor 82 : $285-290$

Jenkins, P. F. 1977. Cultural transmission of song patterns and dialect development in a free-living bird population. Anim. Behav. 25: 50-78.

Katona, S., B. Baxter, O. Brazier, S. Kraus, J. Perkins, and H. Whitehead. 1979. Identification of humpback whales by fluke photography. In H. E. Winn and B. L. Olla. (editors), Behavior of marine animals, Vol. 3, p. 33-44. Plenum Press, New York.

Katona, S .K., and J. A. Beard. 1987. The North Atlantic humpback whale fluke catalog. In Abstracts of the Seventh Biennial Conference on the Biology of Marine Mammals, Miami, Florida, p 36. 
Krebs, J. R. and D. E. Kroodsma. 1980. Repertoires and geographical variation in bird song. In Rosenblatt, J. S., R. A. Hinde, C. Beer and M. C. Busnel (editors), Advances in the Study of Behavior, Vol. 11. Academic Press. New York. pp. 143177.

Lynch, A., G. M. Plunkett, A. J. Baker and P. F. Jenkins. 1989. A model of cultural evolution of chaffinch song derived with the meme concept. Am. Nat. 133: 634653.

Mate, B. R., S. Nieukirk, R. Mesecar and T. Martin. 1992. Application of remote sensing methods for tracking large cetaceans: North Atlantic right whales (Eubalaena glacialis). Final report to the Minerals Management Service 91-0069. 167 pp.

Mattila, D. K., L. N. Guinee, and C. A. Mayo. 1987. Humpback whale songs on a North Atlantic feeding ground. J. Mamm. 68(4): 880-883.

McSweeney, D. J., K. C. Chu, W. F. Dolphin and L. N. Guinee. 1989. North Pacific humpback whale songs: a comparison of southeast Alaskan feeding ground songs with Hawaiian wintering ground songs. Mar. Mamm. Sci. 5(2):139-148.

Mobley, J. R., and L. M. Herman. 1981. Dynamic pod composition among humpback whales in Hawaiian waters. In Proceedings of the 4th Biennial Conference on the Biology of Marine Mammals. San Francisco, December 14-18, 1981. p 81. (Abstr.)

Mundinger, P.C. 1980. Animal cultures and a general theory of cultural evolution. Ethol. Sociobiol. 1: 183-223.

Mundinger, P.C. 1982. Microgeographic and macrogeographic variation in the acquired vocalizations of birds. In Kroodsma, D. E. and E. H. Miller (editors), Acoustic Communication in Birds, Vol. 2. Academic Press. New York. pp 147-208.

Payne, K. and R. Payne. 1985. Large scale changes over 17 years in songs of humpback whales in Bermuda. Z. Tierpsychol. 68: 89-114.

Payne, K, P. Tyack, and R. Payne. 1983. Progressive changes in the songs of humpback whales (Megaptera novaeangliae): A detailed analysis of two seasons in Hawaii. In R. Payne (editor), Communication and behavior of whales. AAAS Selected Symposia Series, p. 9-57. Westview Press, Boulder, Colo.

Payne, R. B. 1979. Song structure, behavior, and sequence of song types in a population of village indigobirds, Vidua chalybeata. Anim. Behav. 27: 997-1013. 
Payne, R. B. 1985. Behavioral continuity and change in local song populations of village indigobirds Vidua chalybeata. Z. Tierpsychol. 70: 1-44.

Payne, R. B., W. L. Thompson, K. L. Fiala and L. L. Sweany. 1981. Local song tradition in indigo buntings: cultural transmission of behavior across generations. Behav.

77:199-221.

Payne, R. S. 1978. Behavior and vocalizations of humpback whales (Megaptera sp.). In K. S. Norris and R. R. Reeves (editors), Report on a workshop on problems related to humpback whales (Megaptera novaeangliae) in Hawaii. U.S. Dept. Commer. NTIS PB-280 794, pp 56-78.

Payne, R. S., and L. N. Guinee. 1983. Humpback whale songs as an indicator of "stocks". In R. Payne (editor), Communication and behavior of whales. AAAS Selected Symposia Series, p. 333-358. Westview Press, Boulder, Colo.

Payne, R. S., and S. McVay. 1971. Songs of humpback whales. Science 173: 585-597 (Wash. D.C.).

Perry, A., C. S. Baker and L. M. Herman. 1990. Population characteristics of individually identified humpback whales in the central and eastern North Pacific: a summary and critique. Rep. Int. Whal. Commn. (special issue 12): 307-317.

Slater, P. J. B. 1986. The cultural transmission of bird song. Tr. Ecol. Evol. 1: 34-37.

Slater, P. J. B., S. A. Ince and P. W. Colgan. 1980. Chaffinch song types: their frequencies in the population and distribution between repertoires of different individuals. Behav. 75: 207-218.

Straley, J. M. 1990. Fall and winter occurrence of humpback whales (Megaptera novaeangliae) in southeastern Alaska. Rep. Int. Whal. Commn. (special issue 12): 319-323.

Trainer, J. M. 1987. Behavioral associations of song types during aggressive interactions among male yellow-rumped caciques. Condor 8 (4): 731-738.

Trainer, J. M. 1989. Cultural evolution in song dialects of yellow-rumped caciques in Panama. Ethol. 80: 190-204.

Tyack, P. 1981. Interactions between singing Hawaiian humpback whales and conspecifics nearby. Behav. Ecol. Sociobiol. 8: 105-116. 
Tyack, $\mathrm{P}$., and H. Whitehead. 1983. Male competition in large groups of wintering humpback whales. Beh. 83: 132-154.

Underwood, A. J. 1981. Techniques of analysis of variance in experimental marine biology and ecology. Oceanog. Mar. Biol. Ann. Rev. 19: 513-605.

Winn, H. E., T. J. Thompson, W. C. Cummings, J. Hain, J. Hudnall, H. Hays, and W. W. Steiner. 1981. Song of the humpback whale: population comparisons. Behav. Ecol. Sociobiol. 8: 41-46.

Winn, H. E., and L. K. Winn. 1978. The song of the humpback whale (Megaptera novaeangliae) in the West Indies. Mar. Biol. 47: 97-114.

Zar, J. H. 1984. Biostatistical analysis. Second Edition. Prentice-Hall, Englewood Cliffs, New Jersey, USA. 
Table 1. Variables used in quantitative analysis. Labels R, RT, $1 \mathrm{a}, 1 \mathrm{~b}, 2 \mathrm{~A}, 2 \mathrm{~B}$, and 3B refer to different phrase types identified in songs from 1991.

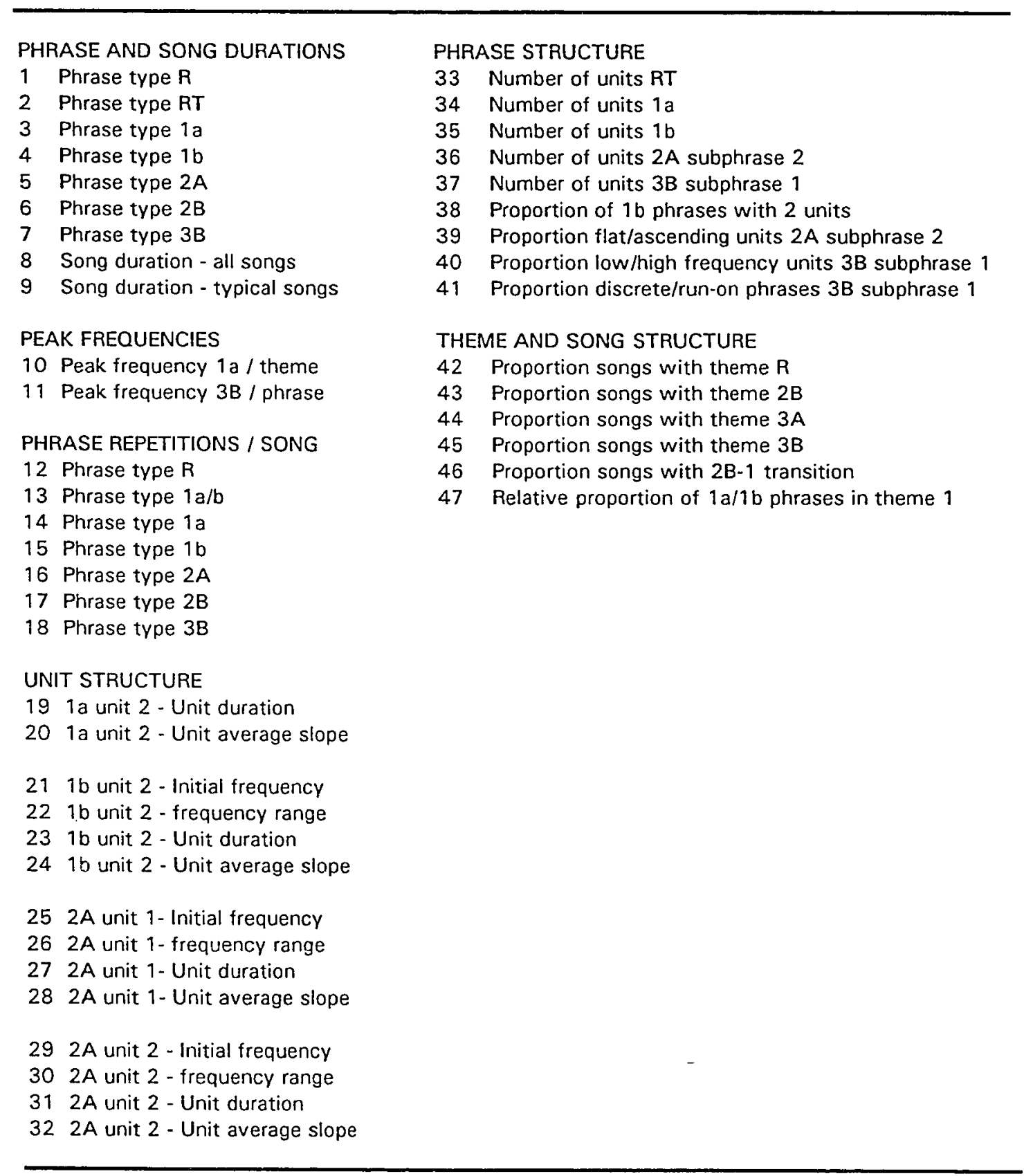


Table 2. Samples of humpback whale song used in analysis. Period 1 was 21 January to 16 February, 1991, and Period 4 was 31 March to 20 April 1991. "ID \#" indicates the catalog number assigned to the individual whale if identified with a photograph; if the whale was not photographed, this column contains "no ID". Column 6 indicates the duration of the sample in minutes. Column 7 indicates the number of complete songs in the sample, and column 8 the number of incomplete songs or song "fragments".

\begin{tabular}{|c|c|c|c|c|c|c|c|}
\hline Island & Period & Date & Singer \# & ID \# & Dur.(min.) & \# Songs & \# Frag. \\
\hline \multirow[t]{5}{*}{ Kauai } & 1 & $1 / 29 / 91$ & KI-91-04 & no ID & 33 & 2 & 4 \\
\hline & & $2 / 1 / 91$ & KI-91-05 & SC-200 & 121 & 11 & 5 \\
\hline & & $2 / 1 / 91$ & KI-91-06 & no ID & 112 & 7 & 9 \\
\hline & & $2 / 6 / 91$ & KI-91-07 & no ID & 75 & 5 & 3 \\
\hline & & $2 / 16 / 91$ & $\mathrm{KI}-91-10$ & no ID & 83 & 7 & 2 \\
\hline \multirow[t]{6}{*}{ Kauai } & 4 & $4 / 4 / 91$ & KI-91-40 & no ID & 61 & 3 & 2 \\
\hline & & $4 / 4 / 91$ & $\mathrm{KI}-91-42$ & SC- 117 & 82 & 6 & 2 \\
\hline & & $4 / 8 / 91$ & $\mathrm{KI}-91-46$ & SC-378 & 90 & 5 & 2 \\
\hline & & $4 / 10 / 91$ & KI-91-52 & SC-381 & 113 & 6 & 2 \\
\hline & & $4 / 11 / 91$ & $\mathrm{KI}-91-53$ & no ID & 80 & 6 & 2 \\
\hline & & $4 / 17 / 91$ & KI-91-57 & SC-266 & 77 & 7 & 2 \\
\hline \multirow[t]{7}{*}{ Socorro } & 1 & $1 / 28 / 91$ & So-91-01 & JJ-007 & 46 & 6 & 2 \\
\hline & & $2 / 2 / 91$ & So-91-04 & no ID & 46 & 6 & 2 \\
\hline & & $2 / 3 / 91$ & So-91-05 & no ID & 46 & 8 & 2 \\
\hline & & $2 / 8 / 91$ & So-91-08 & JJ-155 & 92 & 14 & 2 \\
\hline & & $2 / 8 / 91$ & So-91-09 & no ID & 91 & 8 & 5 \\
\hline & & $2 / 11 / 91$ & so-91-10 & no ID & 93 & 8 & 2 \\
\hline & & $2 / 16 / 91$ & So-91-12 & no ID & 66 & 7 & 3 \\
\hline \multirow[t]{6}{*}{ Socorro } & 4 & $3 / 31 / 91$ & So-91-70 & no ID & 59 & 4 & 2 \\
\hline & & $4 / 3 / 91$ & So-91-75 & JJ-135 & 70 & 5 & 4 \\
\hline & & $4 / 6 / 91$ & So-91-81 & JJ-142 & 80 & 6 & 2 \\
\hline & & $4 / 11 / 91$ & SO-91-88 & $J J-121$ & 54 & 5 & 3 \\
\hline & & $4 / 17 / 91$ & So-91-95 & $\mathrm{JJ}-170$ & 86 & 12 & 2 \\
\hline & & $4 / 20 / 91$ & So-91-97 & JJ-127 & 85 & 5 & 5 \\
\hline
\end{tabular}


Table 3. Results of Bartlett's test for heterogeneity of variances and two factor analysis of variance for each variable.

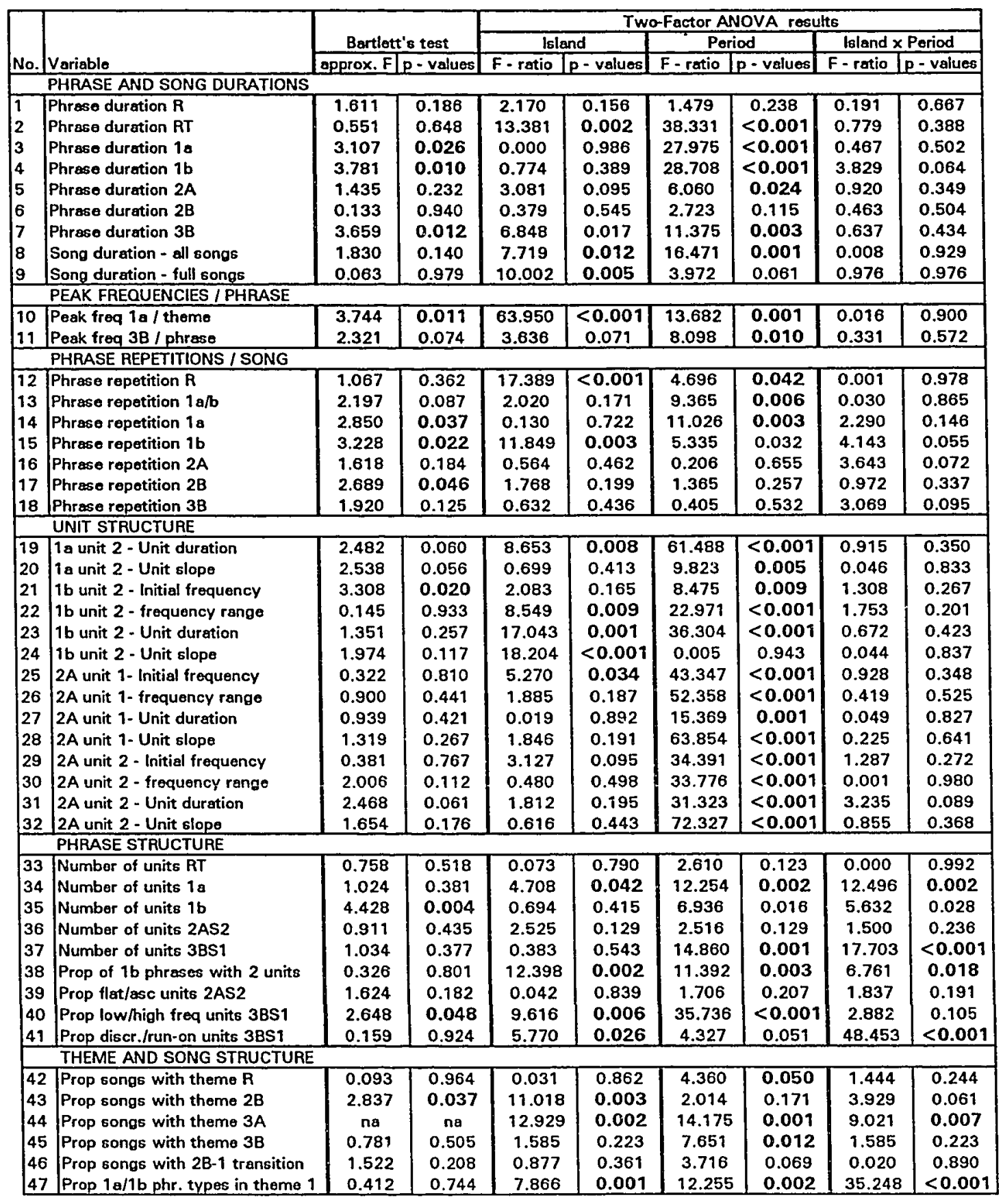


Table 4. Interpretation of results: change over time and differences between areas. An ' $x$ ' indicates that results were statistically significant, while '(x)' means the trend was evident but not significant.

\begin{tabular}{|c|c|c|c|c|c|c|c|c|c|}
\hline \multirow{2}{*}{ No. } & \multirow{2}{*}{\multicolumn{2}{|c|}{ Variable }} & \multicolumn{2}{|c|}{ change in same way } & \multicolumn{3}{|c|}{ change differently } & \multicolumn{2}{|c|}{ no change } \\
\hline & & & \multirow[t]{2}{*}{ same } & \multirow[t]{2}{*}{ different } & \multirow[t]{2}{*}{ opposite } & \multirow[t]{2}{*}{ KI only } & \multirow[t]{2}{*}{ So only } & \multirow[t]{2}{*}{ same } & \multirow[t]{2}{*}{ different } \\
\hline & PHRASE AND SONG DURATIONS & & & & & & & & \\
\hline 1 & Phrase duration $\mathrm{R}$ & & $(x)$ & & & & & & \\
\hline 2 & Phrase duration RT & & & $x$ & & & & & \\
\hline 3 & Phrase duration 1a & & $\mathbf{x}$ & & & & & & \\
\hline 4 & Phrase duration 1b & & $x$ & & & & & & \\
\hline 5 & Phrase duration 2A & & $x$ & & & & & & \\
\hline 6 & Phrase duration 2B & & & & & & & $x$ & \\
\hline 7 & Phrase duration 3B & & $\mathbf{x}$ & & & & & & \\
\hline 8 & Song duration - all songs & 7 & & $x$ & & & & & \\
\hline \multirow[t]{2}{*}{9} & Song duration - typical songs & \lrcorner & & $(x)$ & & & & & \\
\hline & \multicolumn{2}{|l|}{ PEAK FREQUENCIES / PHRASE } & & & & & & & \\
\hline \multirow{3}{*}{$\begin{array}{l}10 \\
11 \\
\end{array}$} & Peak freq 1a / theme & & & $x$ & & & & & \\
\hline & Peak freq 3B / phrase & & $\mathbf{x}$ & & & & & & \\
\hline & \multicolumn{2}{|l|}{ PHRASE REPETITIONS / SONG } & & & & & & & \\
\hline \multirow{8}{*}{$\begin{array}{l}12 \\
13 \\
14 \\
15 \\
16 \\
17 \\
18 \\
\end{array}$} & Phrase repetition $\mathrm{R}$ & & & $\mathrm{x}$ & & & & & \\
\hline & Phrase repetition $1 \mathrm{a} / \mathrm{b}$ & 7 & $x$ & & & & & & \\
\hline & Phrase repetition 1a & -1 & $x$ & & & & & & \\
\hline & Phrase repetition 1b & \lrcorner & & & & $(x)$ & & & \\
\hline & Phrase repetition 2A & & & & $(x)$ & & & & \\
\hline & Phrase repetition 2B & & & & & & $(x)$ & & \\
\hline & Phrase repetition 3B & & & & $(x)$ & & & & \\
\hline & UNIT STRUCTURE & & & & & & & & \\
\hline 19 & 1 a unit 2 - Unit duration & 7 & & $x$ & & & & & \\
\hline 20 & 1 a unit 2 - Unit slope & 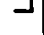 & & $x$ & & & & & \\
\hline 21 & 1b unit 2 - Initial frequency & 7 & $x$ & & & & & & \\
\hline 22 & 1b unit 2 - frequency range & -1 & & $\mathbf{x}$ & & & & & \\
\hline 23 & 1b unit 2 - Unit duration & 7 & & $x$ & & & & & \\
\hline 24 & 1b unit 2 - Unit slope & \rfloor & & & & & & & $\mathrm{x}$ \\
\hline 25 & 2A unit 1- Initial frequency & 7 & & $\mathbf{x}$ & & & & & \\
\hline 26 & $2 A$ unit 1 - frequency range & -1 & $x$ & & & & & & \\
\hline 27 & $2 \mathrm{~A}$ unit 1 - Unit duration & -1 & $\mathrm{x}$ & & & & & & \\
\hline 28 & 2A unit 1 - Unit slope & \lrcorner & $x$ & & & & & & \\
\hline 29 & 2A unit 2 - Initial frequency & 7 & $x$ & & & & & & \\
\hline 30 & 2A unit 2 - frequency range & -1 & $x$ & & & & & & \\
\hline 31 & 2A unit 2 - Unit duration & -1 & $x$ & & & & & & \\
\hline 32 & 2A unit 2 - Unit slope & 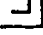 & $\underline{x}$ & & & & & & \\
\hline & PHRASE STRUCTURE & & & & & & & & \\
\hline 33 & Number of units RT & & & & & & & $x$ & \\
\hline 34 & Number of units 1a & & & & & $\mathbf{x}$ & & & \\
\hline 35 & Number of units $1 \mathrm{~b}$ & 7 & & & & $(x)$ & & & \\
\hline 36 & Number of units 2AS2 & & & & & $(x)$ & & & \\
\hline 37 & Number of units 3BS1 & & & & & $\mathbf{x}$ & & & \\
\hline 38 & Prop of $1 \mathrm{~b}$ phrases with 2 units & 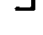 & & & & $\mathbf{x}$ & & & \\
\hline 39 & Prop flat/asc units $2 A S 2$ & & & & & & $(x)$ & & \\
\hline 40 & Prop low/high freq units 3BS1 & & & $x$ & & & & & \\
\hline 41 & Prop discr./run-on units 3BS1 & & & & $\mathbf{x}$ & & & & \\
\hline & THEME AND SONG STRUCTURE & & & & & & & & \\
\hline 42 & Prop songs with theme $\mathbf{R}$ & 7 & $x$ & & & & & & \\
\hline 43 & Prop songs with theme 2B & & & & & & $(x)$ & & \\
\hline 44 & Prop songs with theme 3A & & & & & $x$ & & & \\
\hline 45 & Prop songs with theme 38 & -1 & $\mathbf{x}$ & & & & & & \\
\hline 46 & Prop songs with $2 \mathrm{~B}-1$ transition & 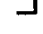 & $(x)$ & & & & & & \\
\hline 47 & Prop 1a/1b phr. types in theme 1 & & & & & & $\underline{x}$ & & \\
\hline
\end{tabular}




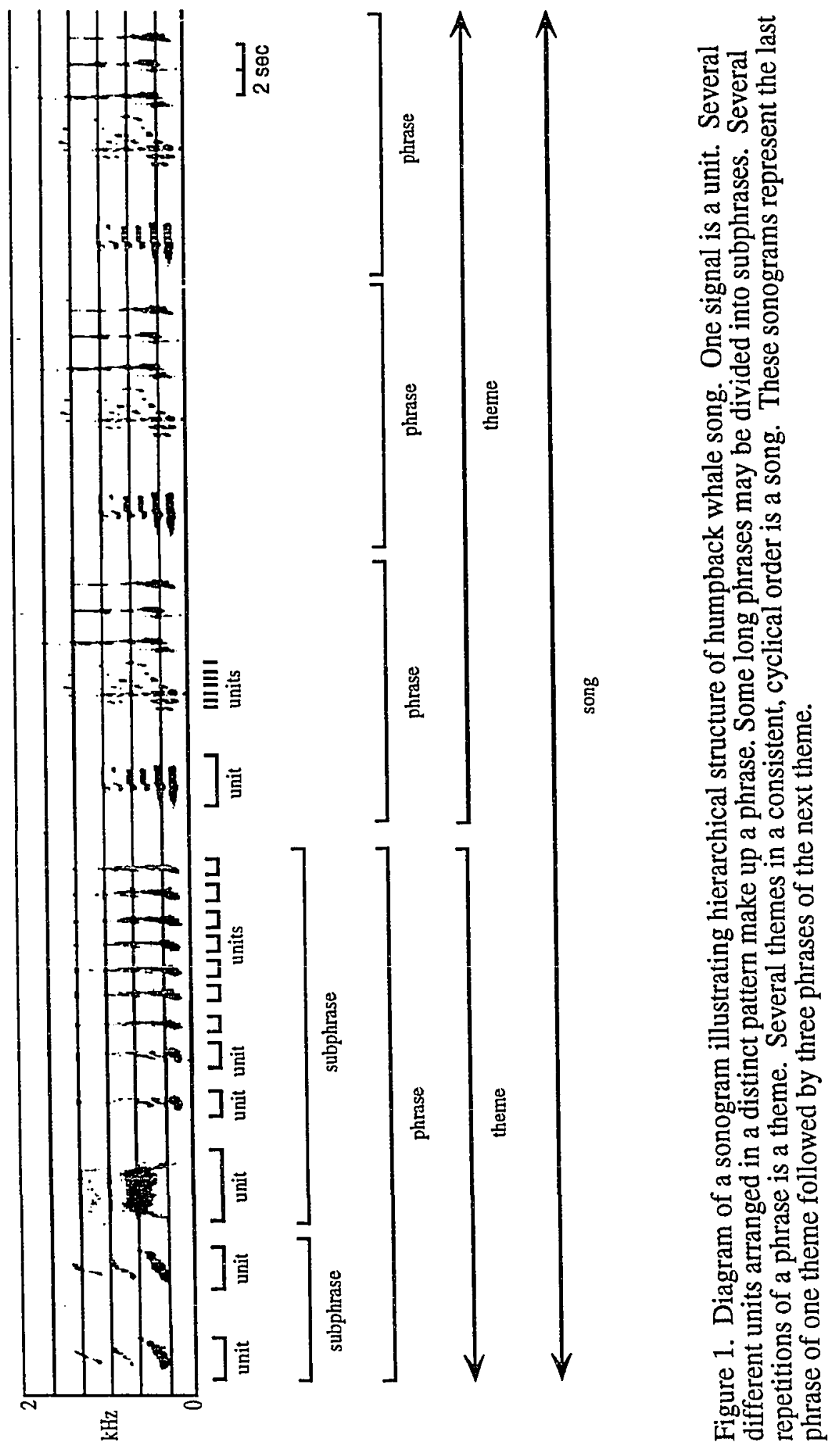




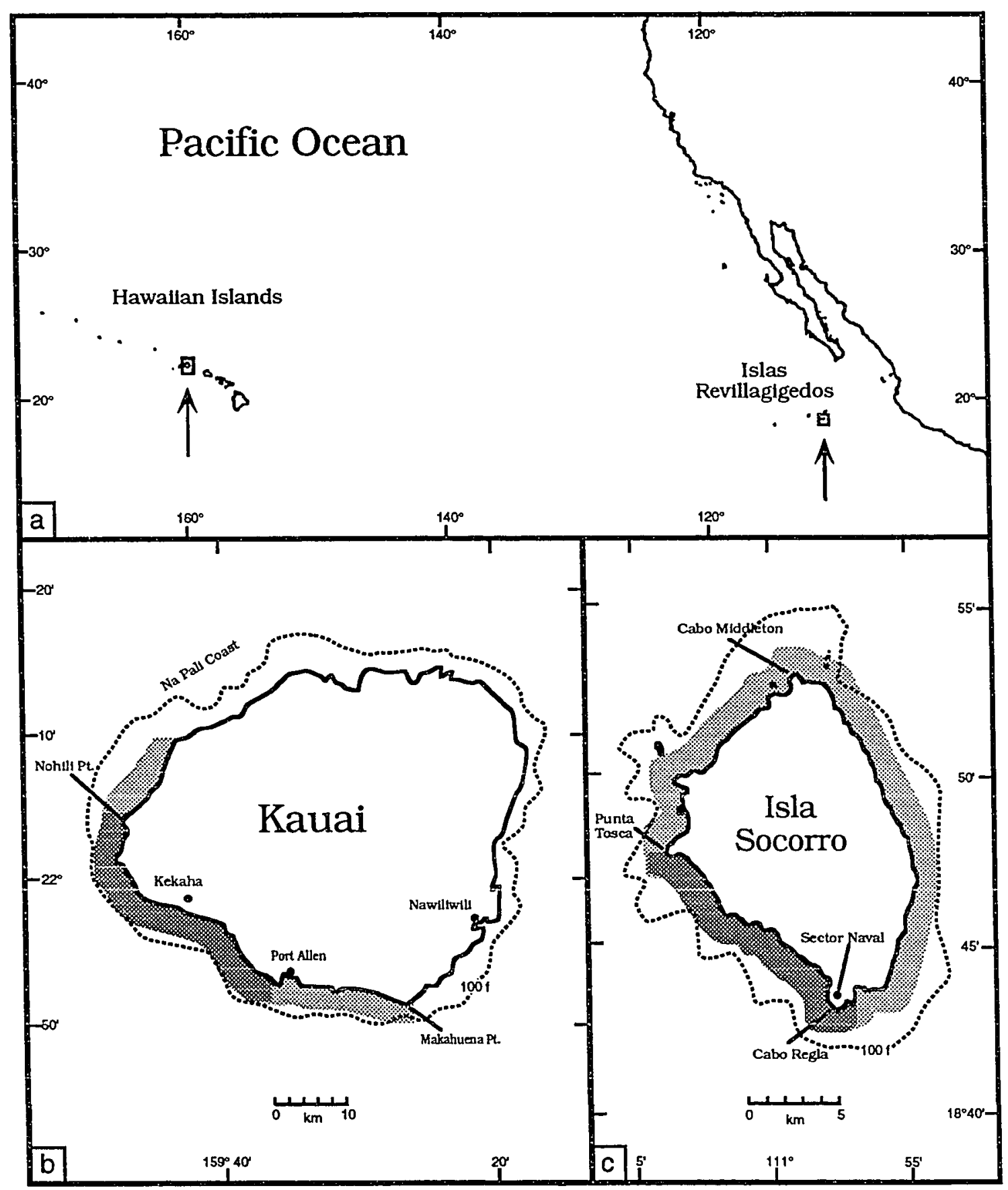

Figure 2. a. Location of each study site in the North Pacific, and details of b. Kauai, and c. Socorro. Light shaded areas indicate study ranges, dark shading indicates areas were most samples were recorded. Depth contours in fathoms. 
$\mathbf{R}$

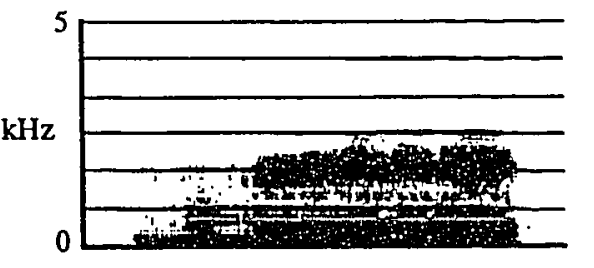

$1 \mathrm{a}$

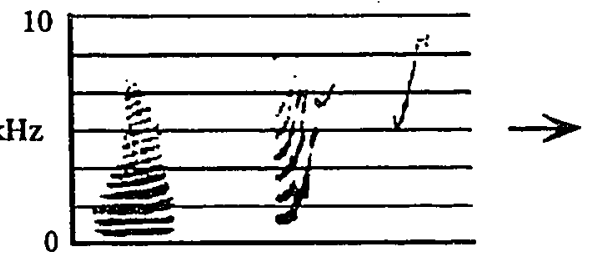

1b

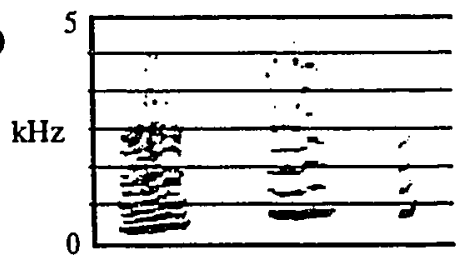

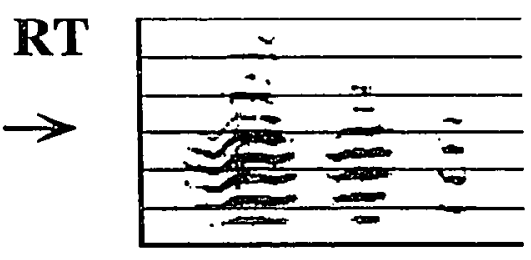

$\mathrm{kHz}$
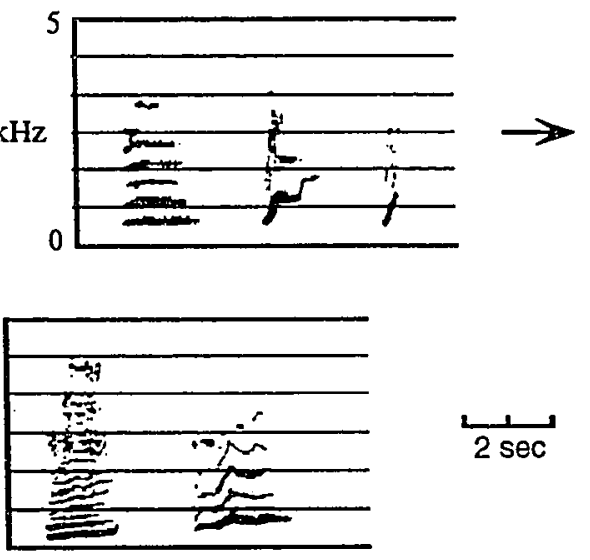

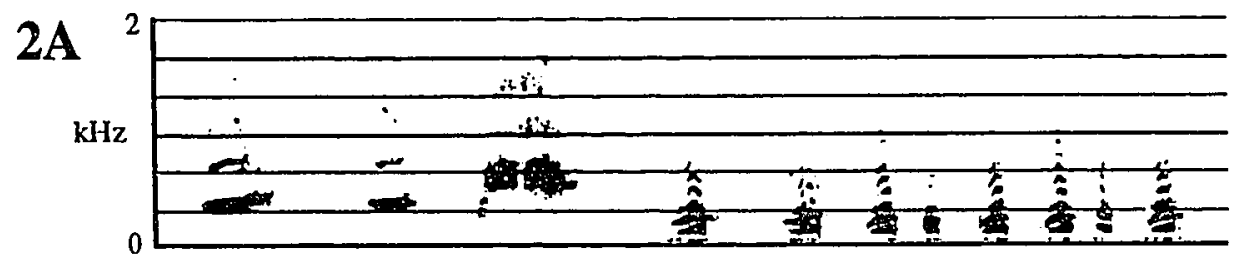

2B

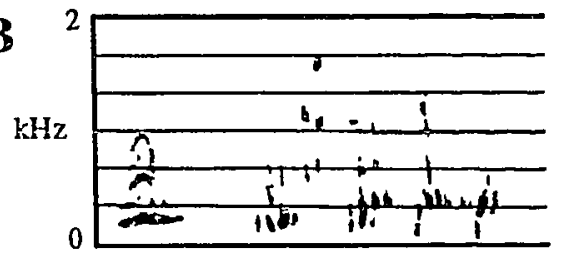

3A

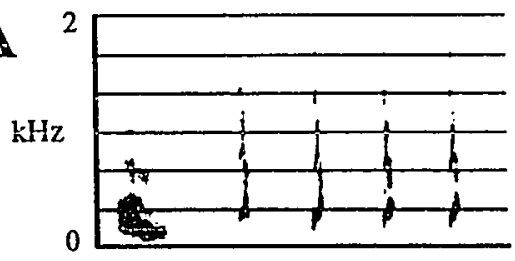

3B

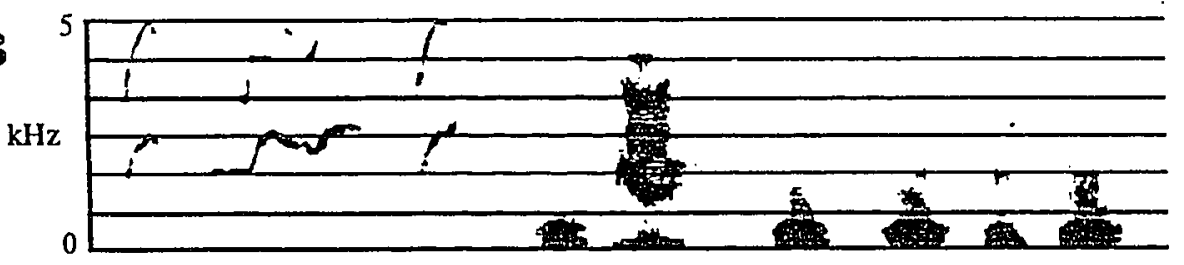

Figure 3. a. Sonograms showing examples of different phrase types (R, RT, 1a, 1b, 2A, 2B, 3A and 3B) recorded from whale KI-91-05 off Kauai on February 1, 1991 (period 1). Themes $R$ and 1 were shifting themes, in which the phrase structure progressively changed with each repetition of the phrase in a song. Arrows indicate progressive change from one form of the phrase to the next. Themes $2 \mathrm{~A}, 2 \mathrm{~B}, 3 \mathrm{~A}$ and $3 \mathrm{~B}$ were static themes, in which the phrase structure remained stable with each repetition. 
$\mathbf{R}$
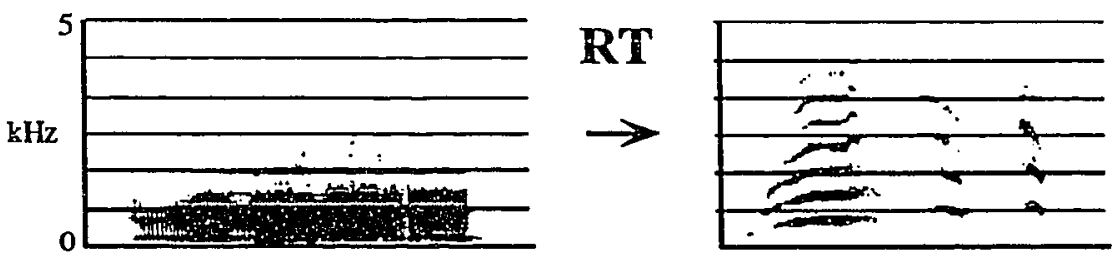

$1 \mathbf{a}$
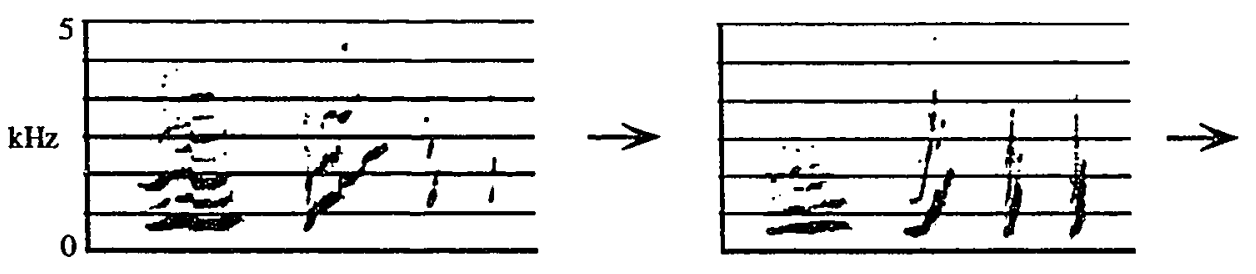

$1 \mathrm{~b}$

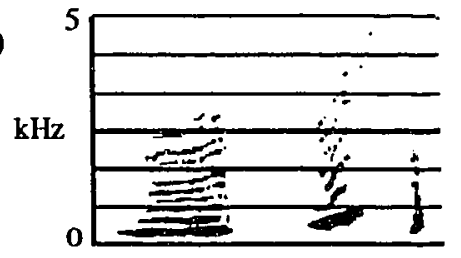

2A

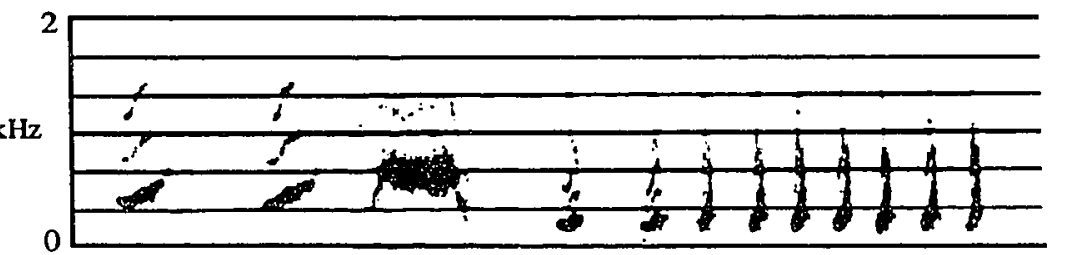

2B
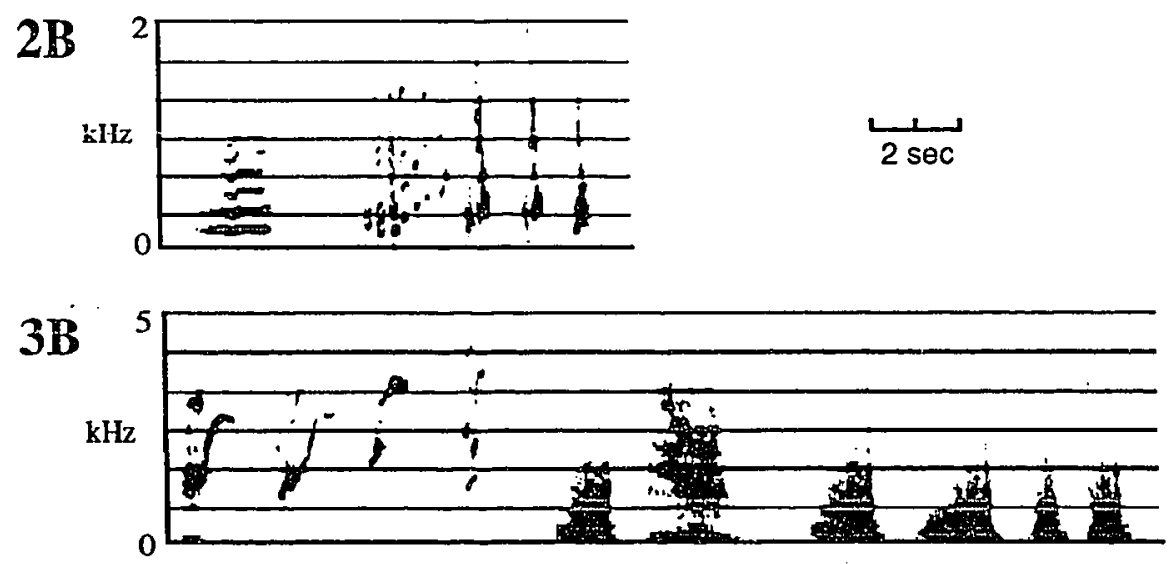

Figure 3. b. Sonograms showing examples of different phrase types (R, RT, 1a, 1b, 2A, 2B and 3B) recorded from whale SO-91-04 off Socorro on February 2, 1991 (period 1). All phrase types were qualitatively similar to those recorded off Kauai (a). Phrase type $3 \mathrm{~A}$ was not found in the songs of this whale, however, other whales off Socorro sang phrase type $3 \mathrm{~A}$ as found off Kauai. 
a.

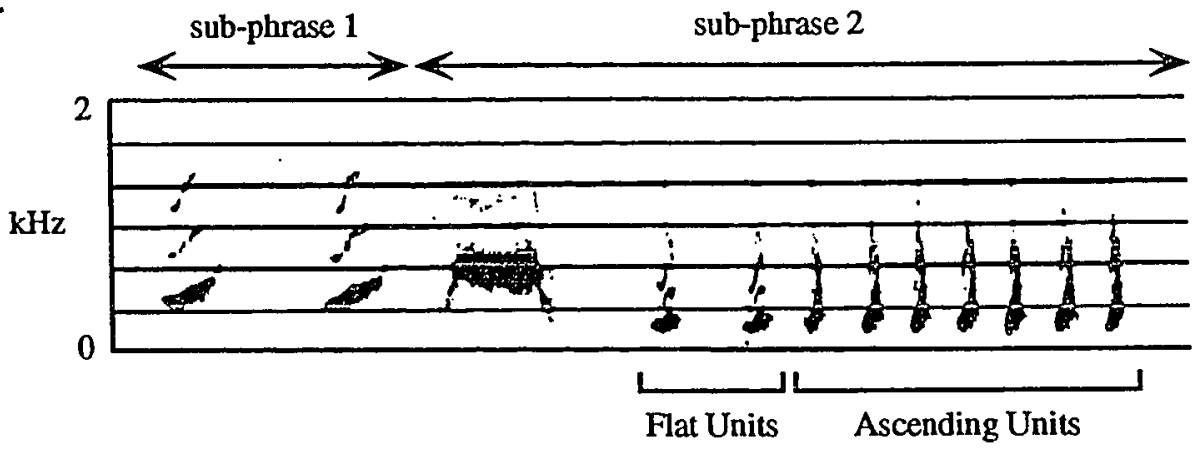

b.

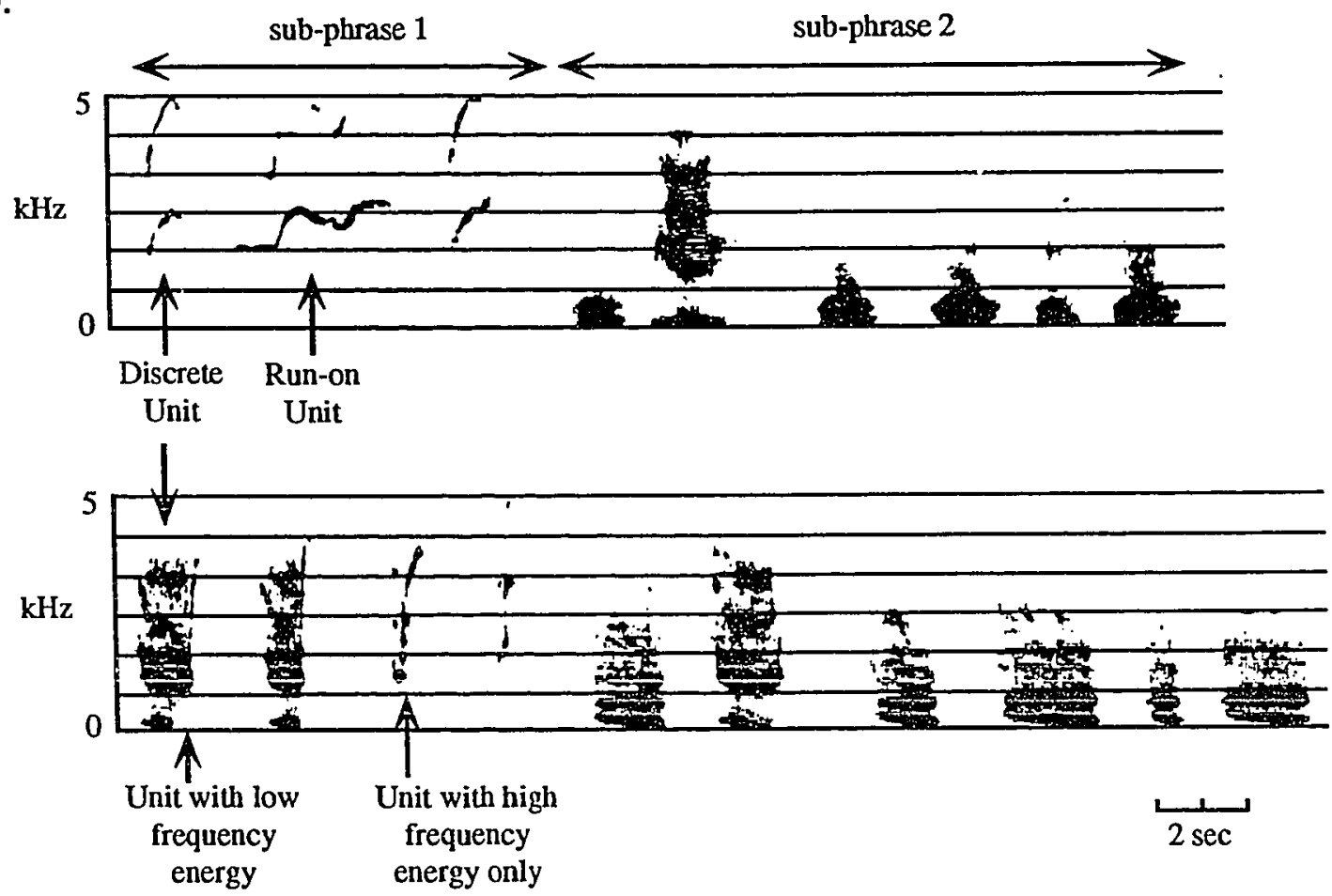

Figure 4. a. Sonogram of phrase type 2A recorded off Socorro on February 2, 1991. Division between subphrase 1 and 2 is indicated, along with examples of "flat" and "ascending" units in subphrase 2. b. Sonograms of phrase type 3B recorded off Kauai on February 2, 1991 (top), and April 17, 1991 (bottom). Definitions of structural variables for units in subphrase 1 are indicated. A unit was considered "run-on" if it frequency modulated up, down, and then up again; otherwise it was considered "discrete". Units were also classified as to whether they contained low frequency energy below approximately $500 \mathrm{~Hz}$. 

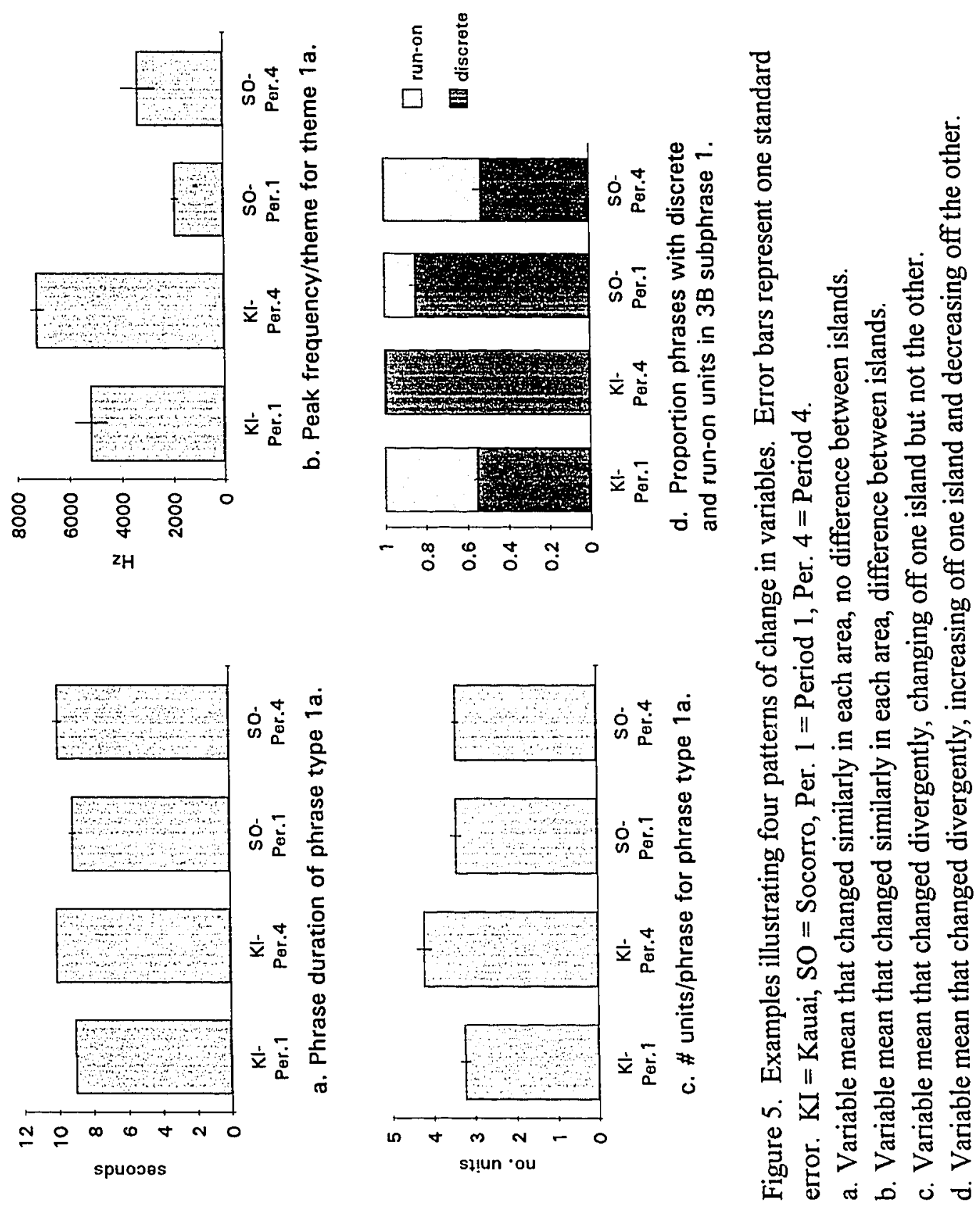


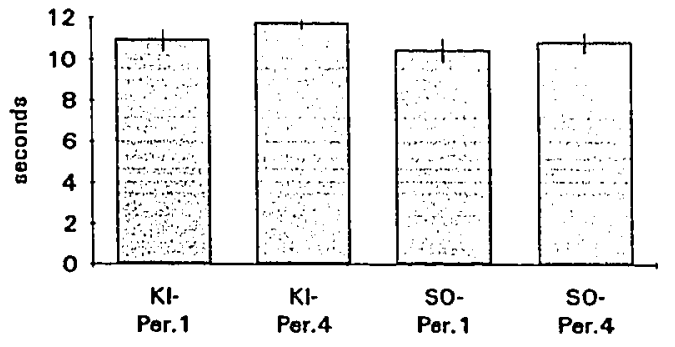

a. Phrase type R.

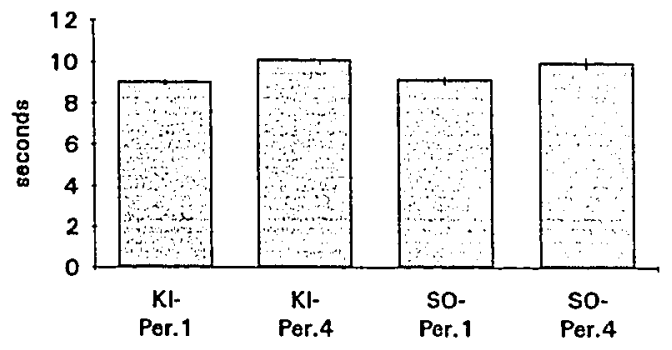

c. Phrase type $1 \mathrm{a}$.

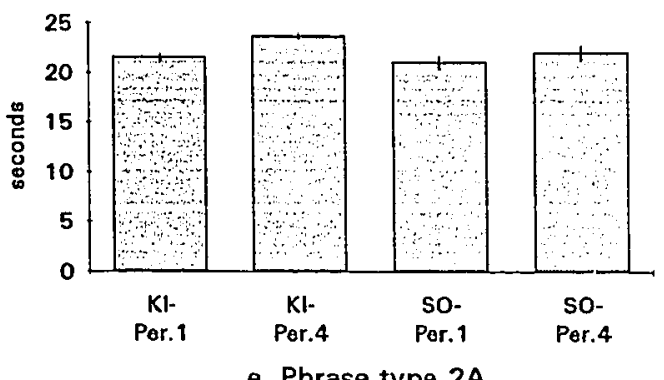

e. Phrase type $2 A$.

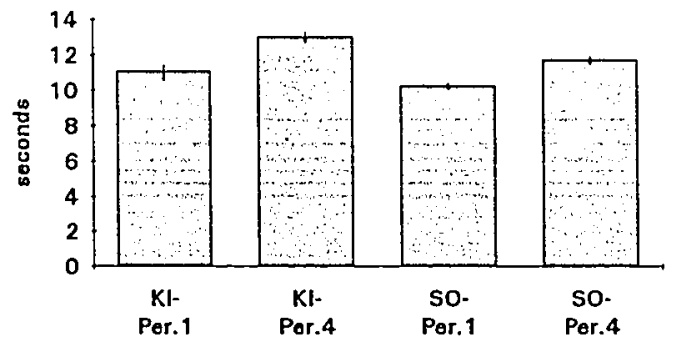

b. Phrase type RT.

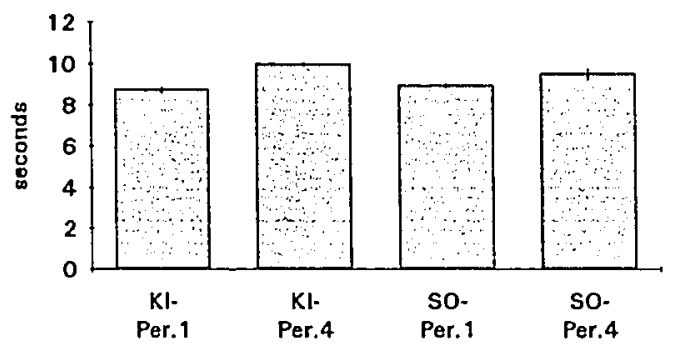

d. Phrase type $1 \mathrm{~b}$.

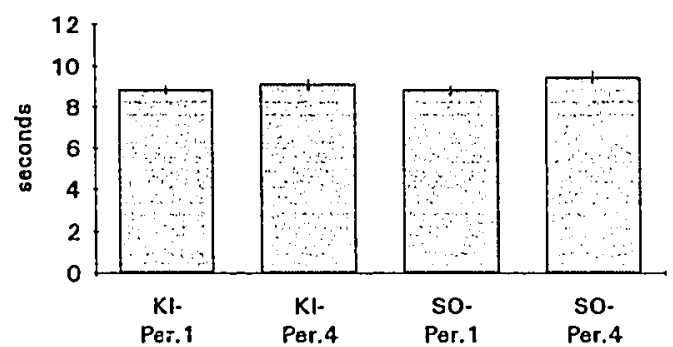

f. Phrase type 28 .

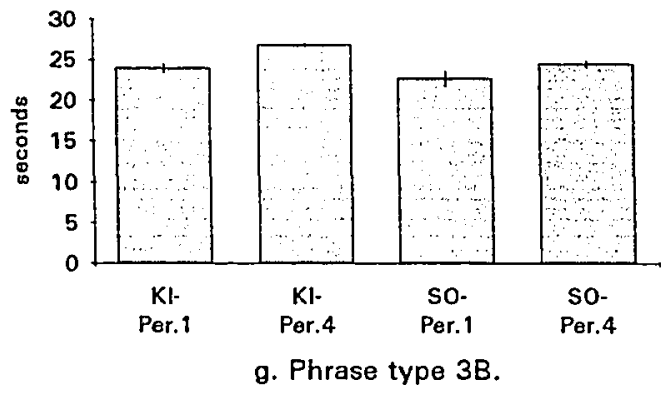

Figure 6. Mean phrase durations for each area and time period. Error bars represent one standard error. $\mathrm{KI}=$ Kauai, $\mathrm{SO}=$ Socorro, Per. $1=$ period 1 , Per. $4=$ period 4 . 

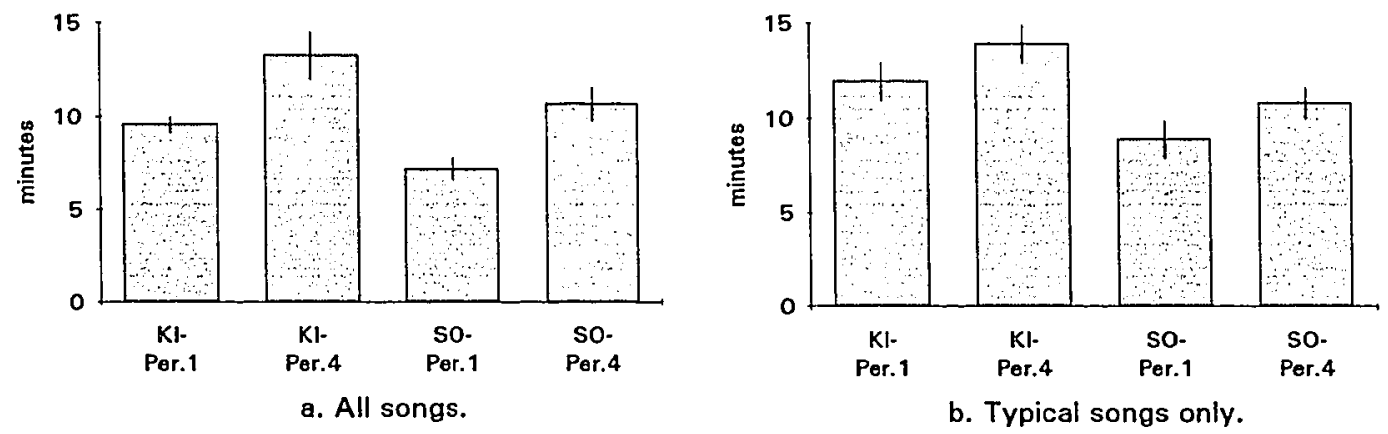

Figure 7. Mean song duration for each area and time period. a. Includes all songs. b. Includes only songs without the aberrant theme $2 \mathrm{~B}$ - theme 1 transition (typical songs). Error bars represent one standard error. $\mathrm{KI}=$ Kauai, $\mathrm{SO}=$ Socorro, Per. $\hat{\imath}=$ period $\mathrm{i}$, Per. $4=$ period 4 . 


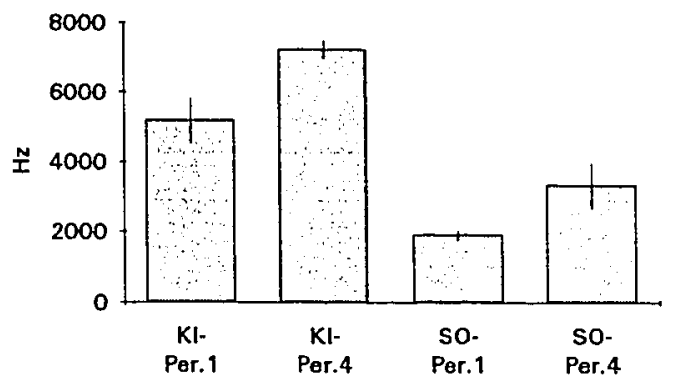

a. Theme $1 \mathrm{a}$.

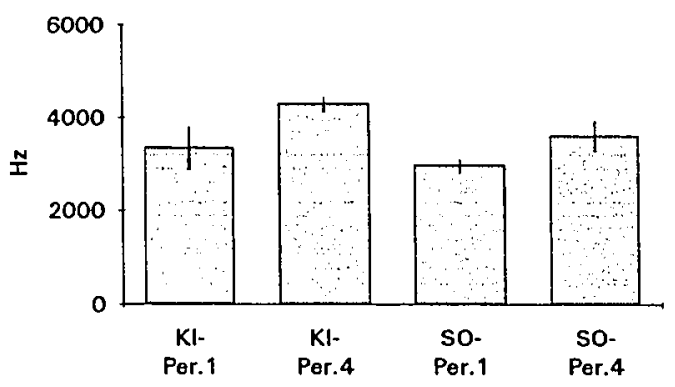

b. Phrase type 3B.

Figure 8. Mean peak frequency of a. phrase type $1 \mathrm{a}$, and $\mathrm{b}$. phrase type $3 \mathrm{~B}$ for each area and time period. Data represents peak frequency per theme for $1 \mathrm{a}$ and per phrase for $3 \mathrm{~B} . \mathrm{KI}=$ Kauai, $\mathrm{SO}=$ Socorro, Per. $1=$ period 1 , Per. $4=$ period 4 . 


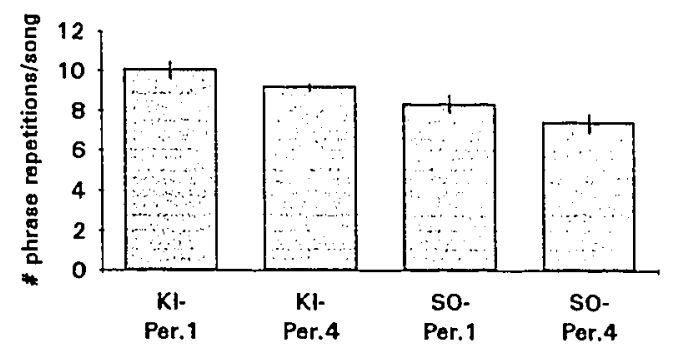

a. Phrase type R.
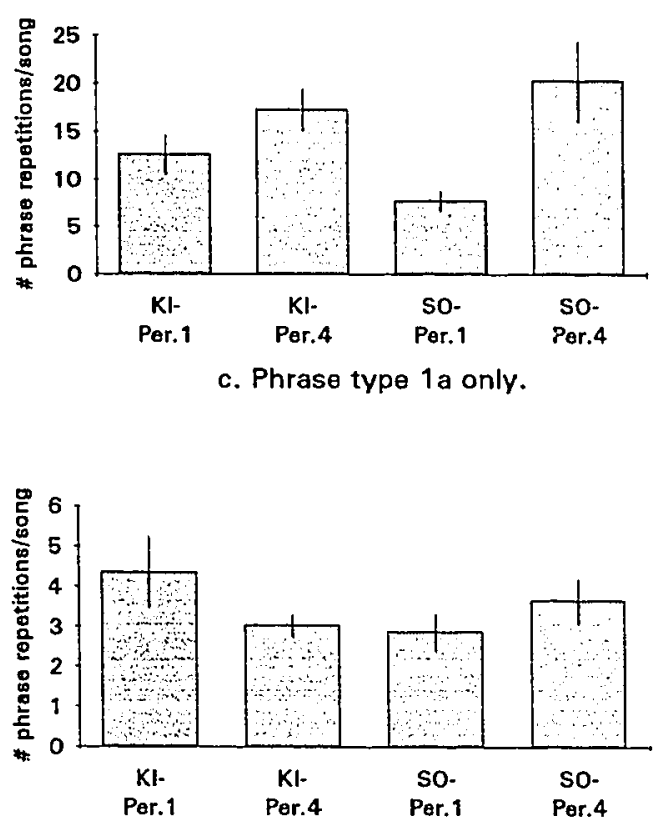

e. Phrase type $2 A$.

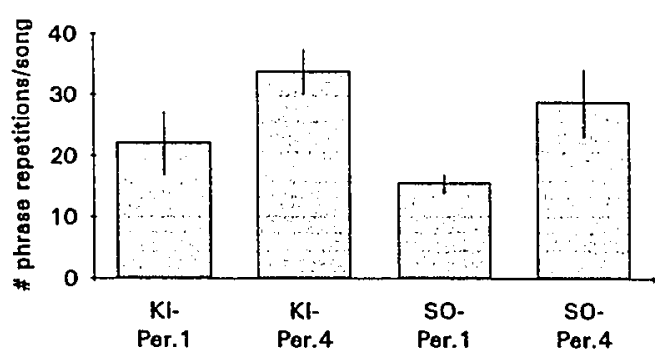

b. Phrase type 1 (1a and $1 \mathrm{~b}$ ).

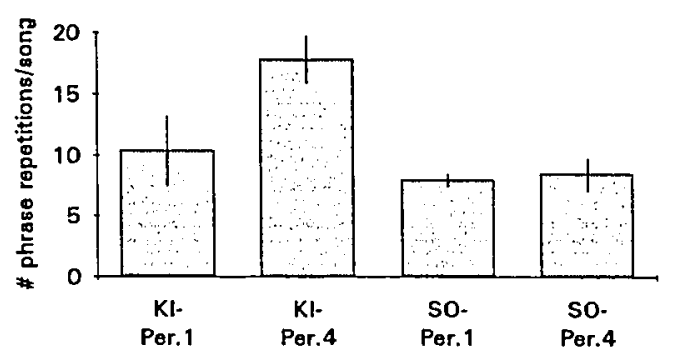

d. Phrase type 1b only.

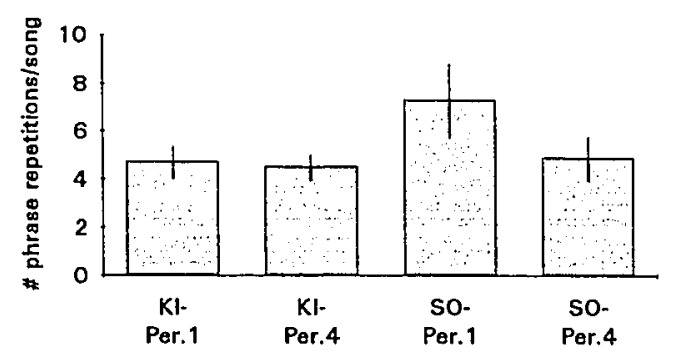

f. Phrase type 2B.

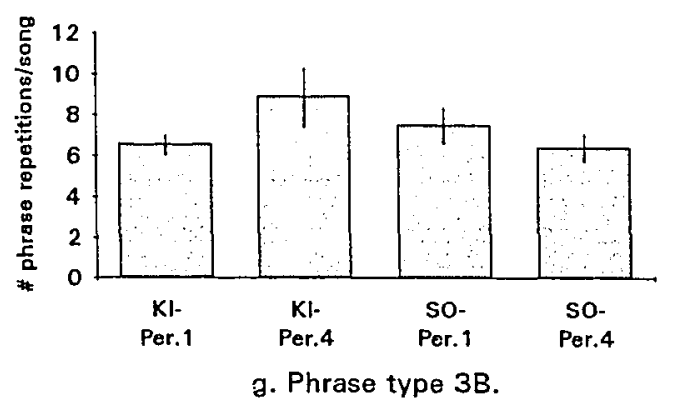

Figure 9. Mean phrase repetitions per song for each area and time period. Error bars represent one standard error. $\mathrm{KI}=$ Kauai, $\mathrm{SO}=$ Socorro, Per. $1=$ period 1 , Per. 4 = period 4 . 


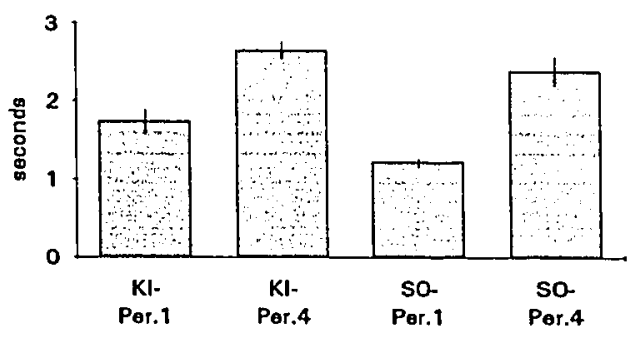

a. Mean duration, unit 2 in 18 .

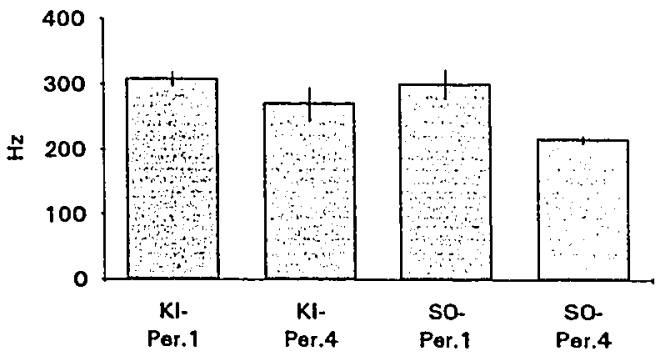

c. Mean initial frequency, unit 2 in $1 \mathrm{~b}$.

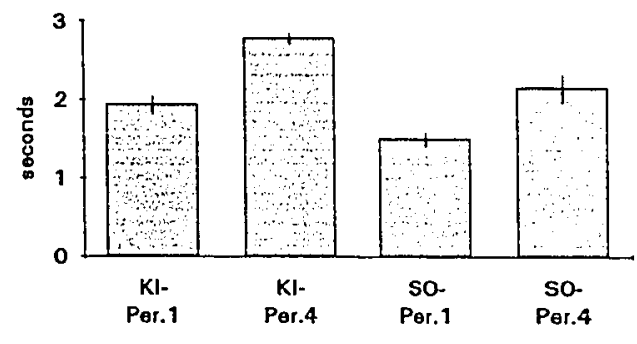

e. Mean duration, unit 2 in $1 \mathrm{~b}$.
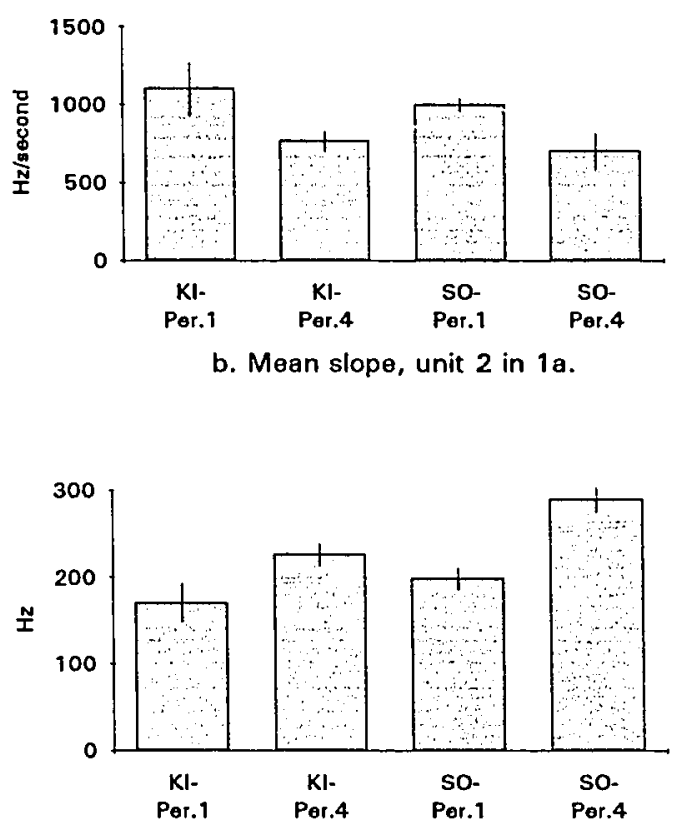

d. Mean frequency range, unit 2 in $1 b$.

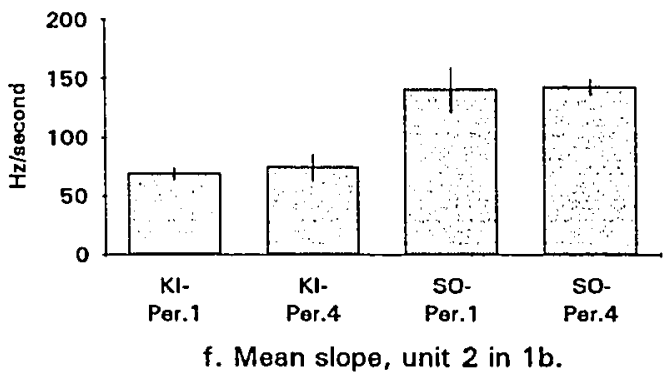

Figure 10. Mean unit measurements for units of phrase types $1 \mathrm{a}$ and $1 \mathrm{~b}$ for each area and period. Error bars represent one standard error. $\mathrm{KI}=$ Kauai, $\mathrm{SO}=$ Socorro, Per. $1=$ period 1 , Per. 4 = period 4 . 

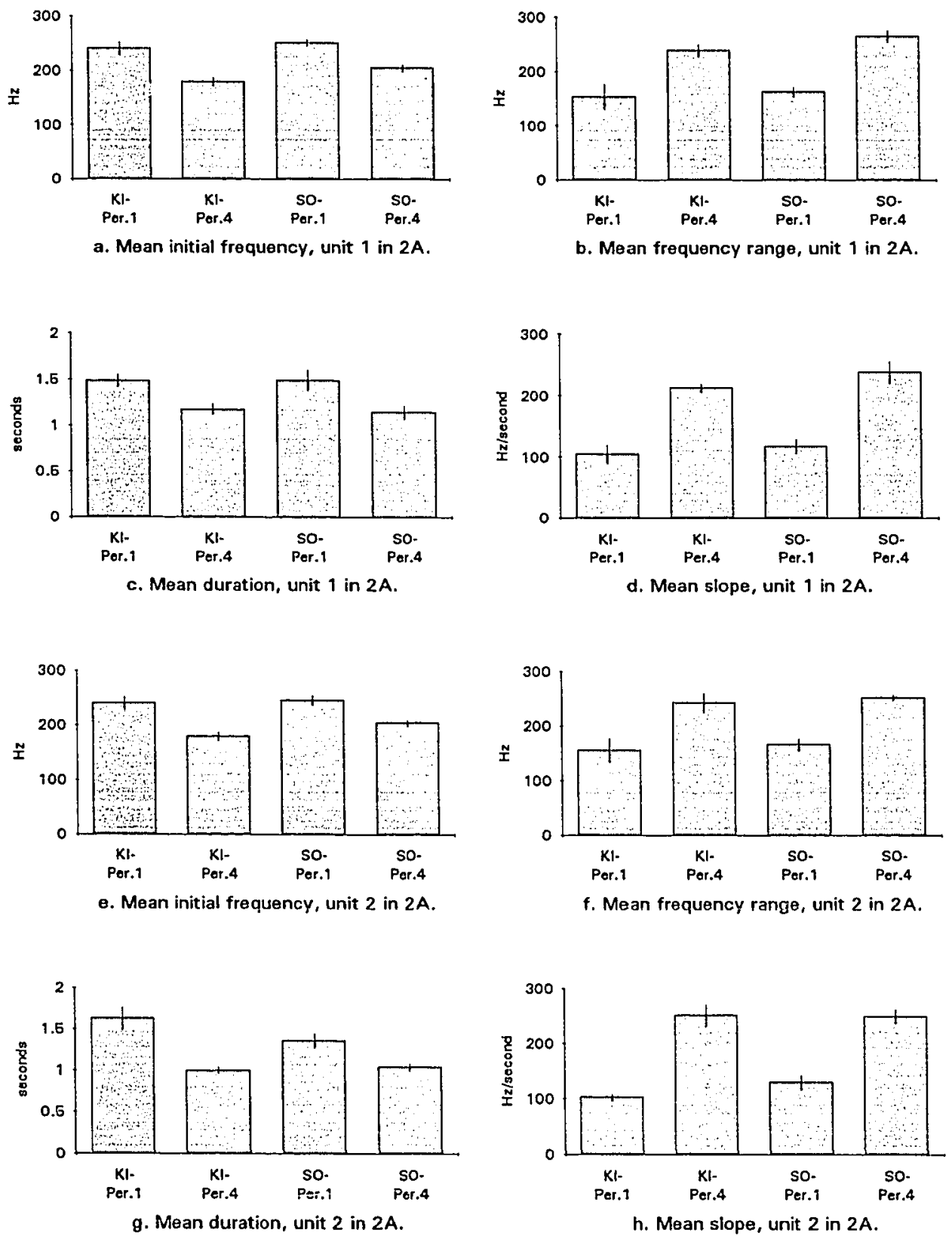

Figure 11. Mean unit measurements for units 1 and 2 of phrase type $2 \mathrm{~A}$ for each area and period. Error bars represent one standard error. $\mathrm{KI}=$ Kauai, $\mathrm{SO}=$ Socorro, Per. $1=$ period 1 , Per. $4=$ period 4 . 


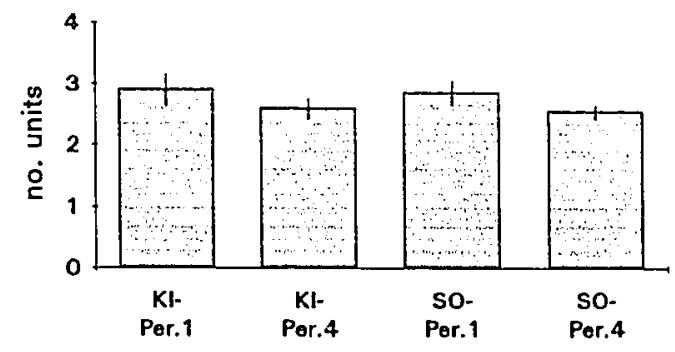

a. Phrase type RT.
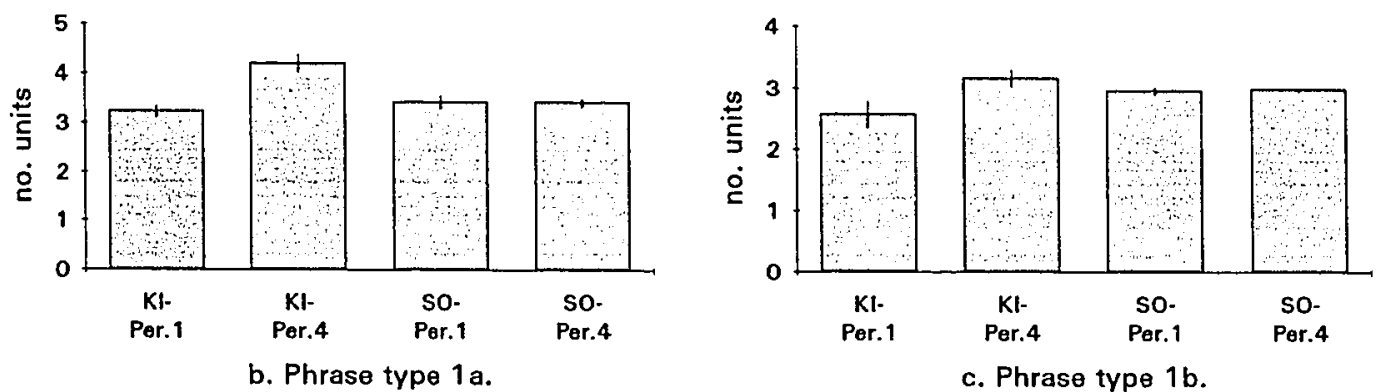

c. Phrase type 16 .
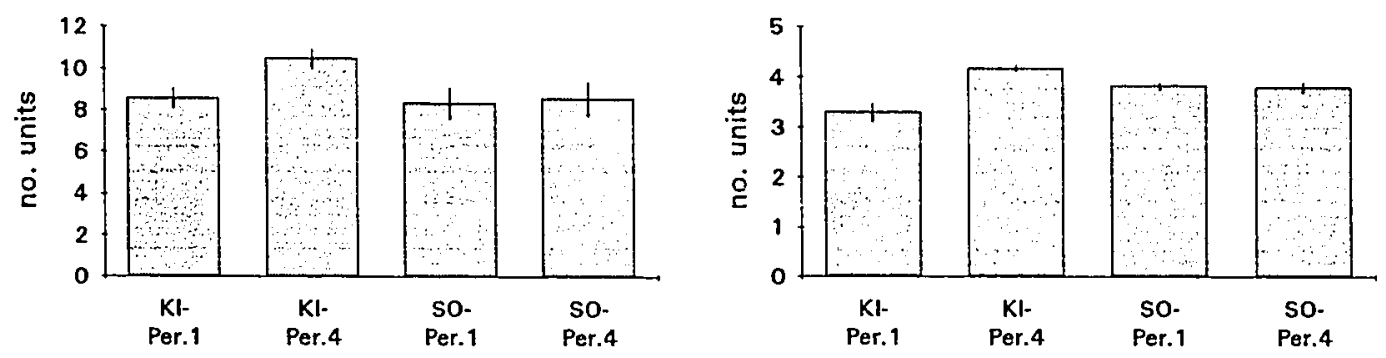

d. Phrase type 2A, subphrase 2.

e. Phrase type 3B, subphrase 1.

Figure 12. Mean number of units per phrase or subphrase for each area and period. Error bars represent one standard error. $\mathrm{KI}=$ Kauai, $\mathrm{SO}=$ Socorro, Per. $1=$ period 1 , Per. 4 = period 4 . 


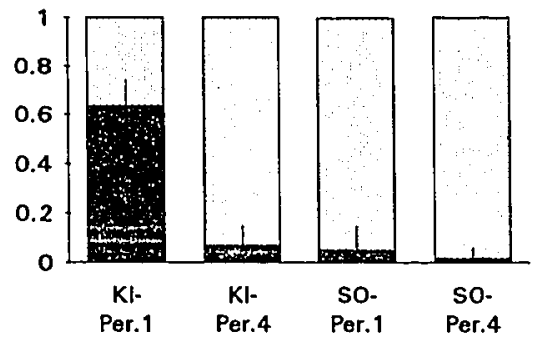

a. 1 b phrases with 2 units.

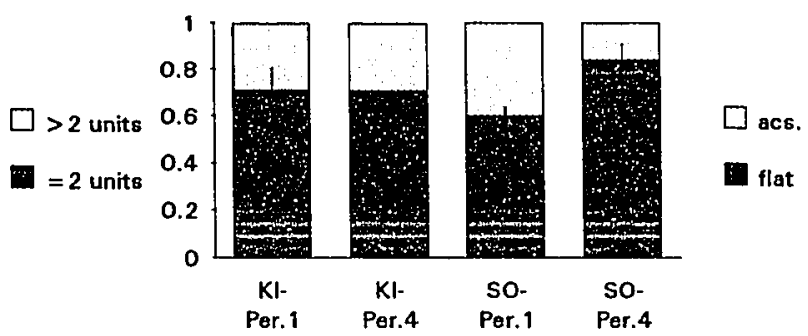

b. Flat and acsending units in $2 A$ subphrase 2.

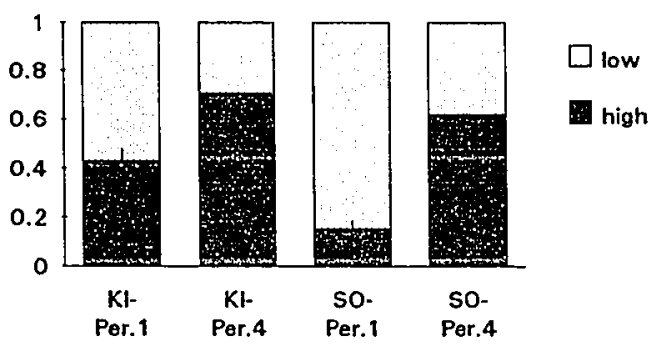

c. High and low frequency units in $3 B$ subphrase1.

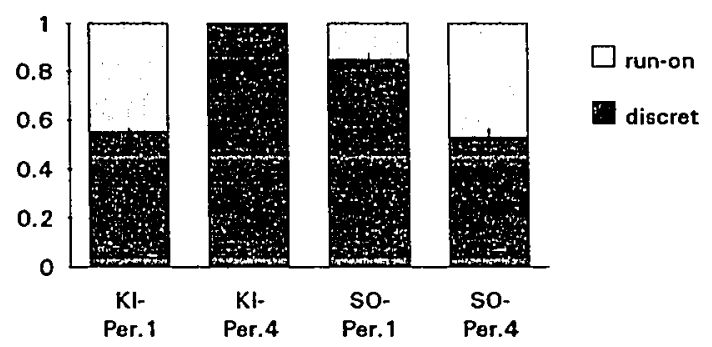

d. Phrases with discrete and run-on units in $3 B$ subphrase 1.

Figure 13. Phrase structure for each area and period. All proportions are arcsine transformed. a. Mean proportion of $1 \mathrm{~b}$ phrases with 2 units. b. Mean proportion of flat and ascending units in $2 A$ subphrase 2. c. Mean proportion of units with all high or low frequency energy in 3B subphrase 1. d. Mean proportion of $3 B$ phrases with all discrete units in subphrase 1 . Error bars represent one standard deviation. $\mathrm{KI}=$ Kauai SO $=$ Socorro, Per. $1=$ period 1 , Per. $4=$ period 4. 


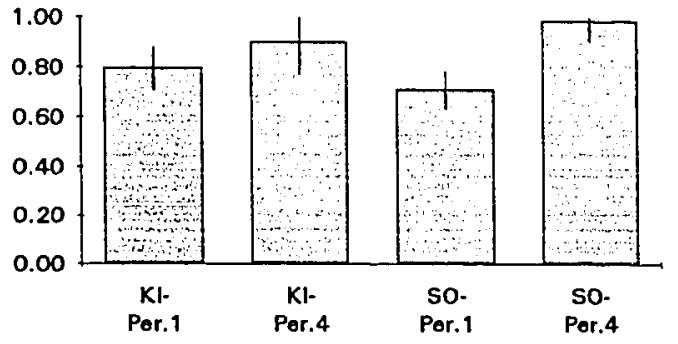

a. Proportion of songs with R.

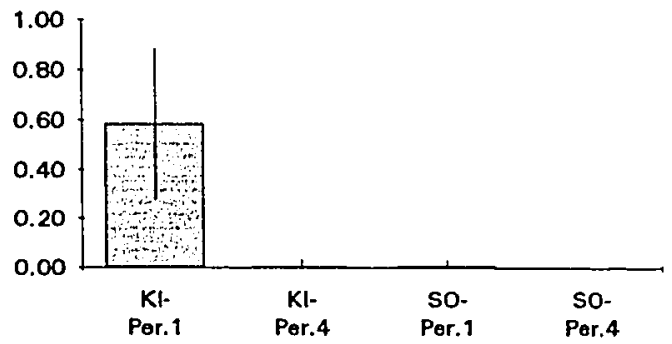

c. Proportion of songs with $3 A$.

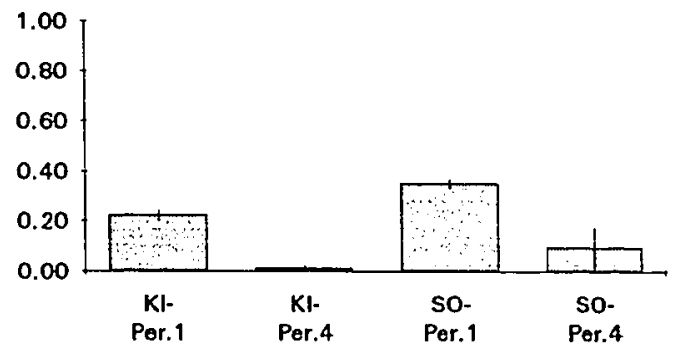

e. Proportion of 2B-1 transitions.

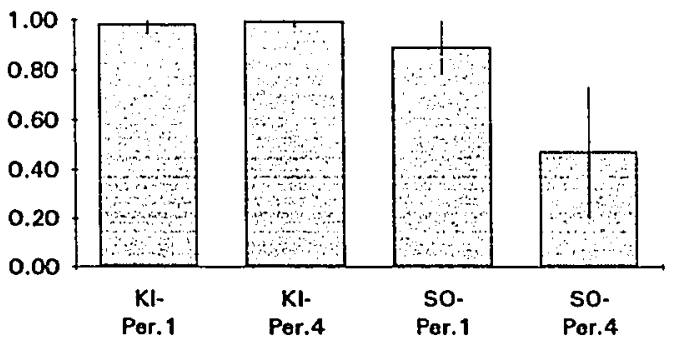

b. Proportion of songs with $2 \mathrm{~B}$.

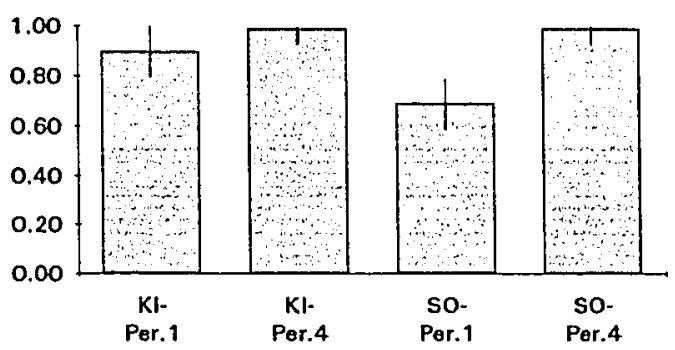

d. Proportion of songs with $3 B$.

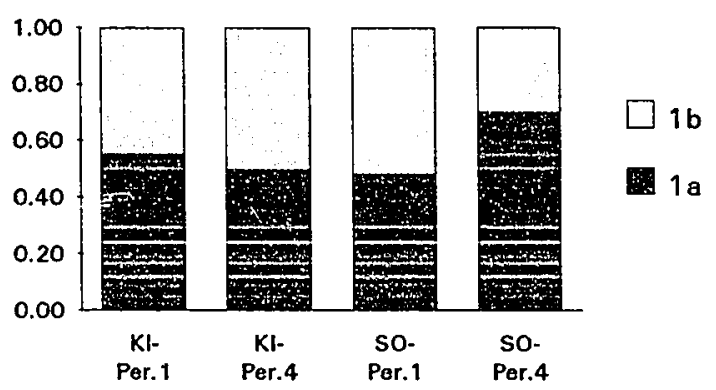

f. Proportion $1 \mathrm{a}$ and $1 \mathrm{~b}$ phrase types.

Figure 14. Inclusion of themes and transitions for each area and period. a. Mean proportion of songs with theme $R$. b. Mean proportion of songs with theme 2B. c. Mean proportion of songs with theme $3 A$. d. Mean proportion of songs with theme 3B. e. Mean proportion of songs with 2B-1 transition. f. Mean proportion of $1 \mathrm{a}$ and $1 \mathrm{~b}$ phrases in theme 1. All proportions transformed by arcsine. Error bars represent one standard deviation. $\mathrm{KI}=$ Kauai, $\mathrm{SO}=$ Socorro, Per. $1=$ period 1, Per. $4=$ period 4. 

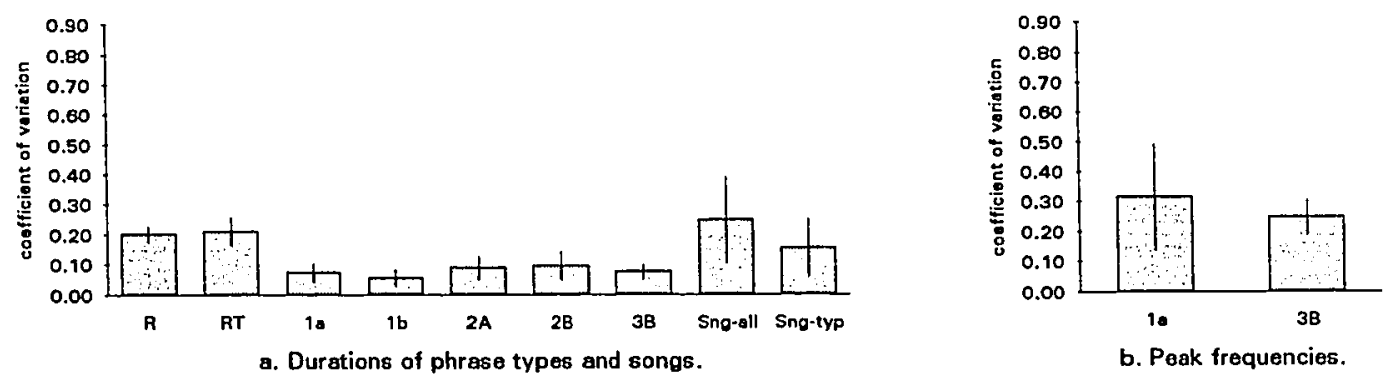

b. Peak frequencies.
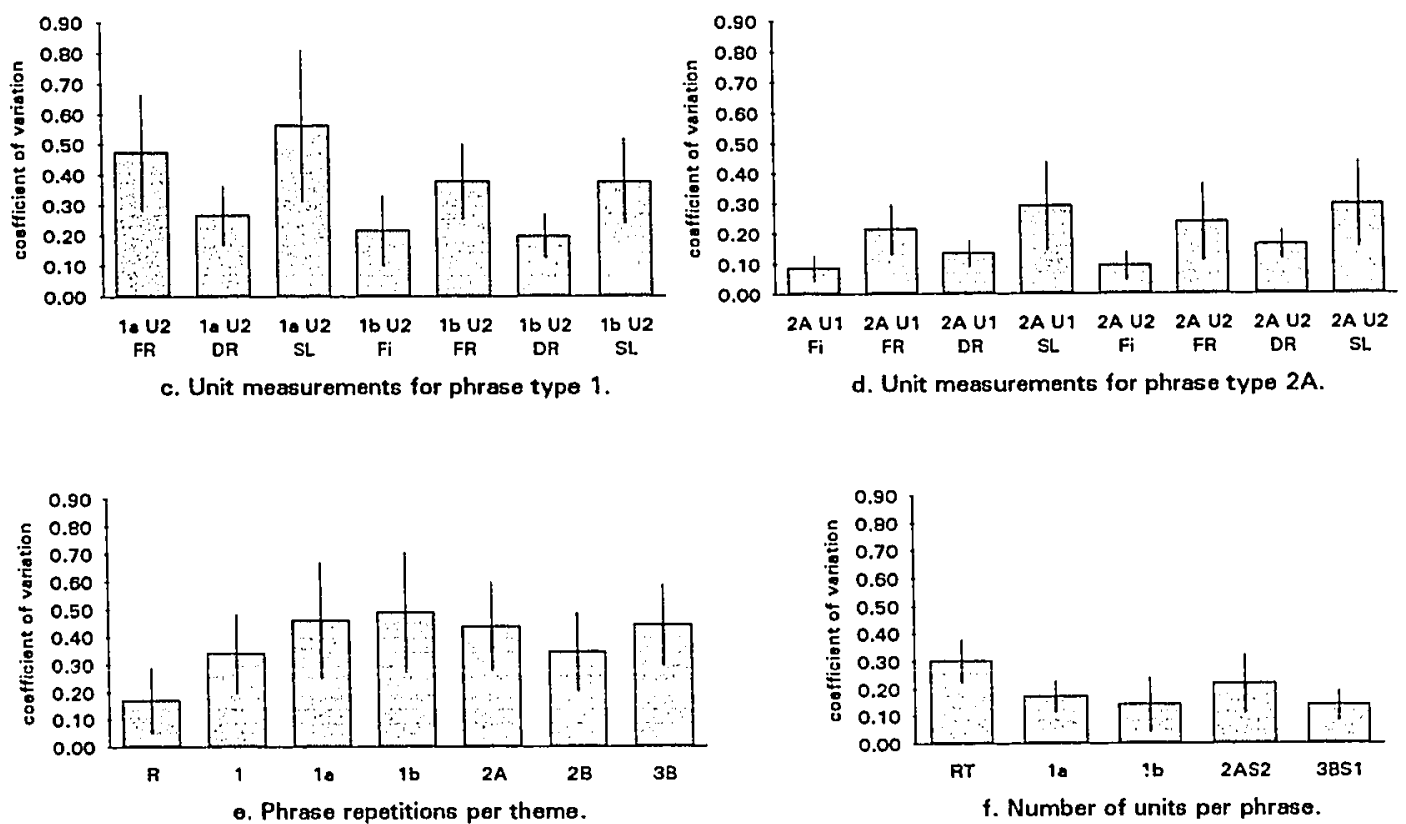

Figure 15. Mean coefficients of variation among all individuals as a measure of within individual variation. A coefficient of variation was calculated for each individual. These values were then averaged for each song variable. Error bars represent one standard deviation. Sng - all $=$ all songs included, Sng - typ $=$ only typical songs, U1 $=$ Unit 1 , $\mathrm{U} 2=\mathrm{Unit} 2, \mathrm{Fi}=$ initial freqency, $\mathrm{FR}=$ freqency range, $\mathrm{DR}=$ duration, $\mathrm{SL}=$ average slope, $2 \mathrm{AS} 2=$ subphrase 2 in phrase type $2 \mathrm{~A}, 3 \mathrm{BSI}=$ subphrase 1 in phrase type $3 \mathrm{~B}$. 

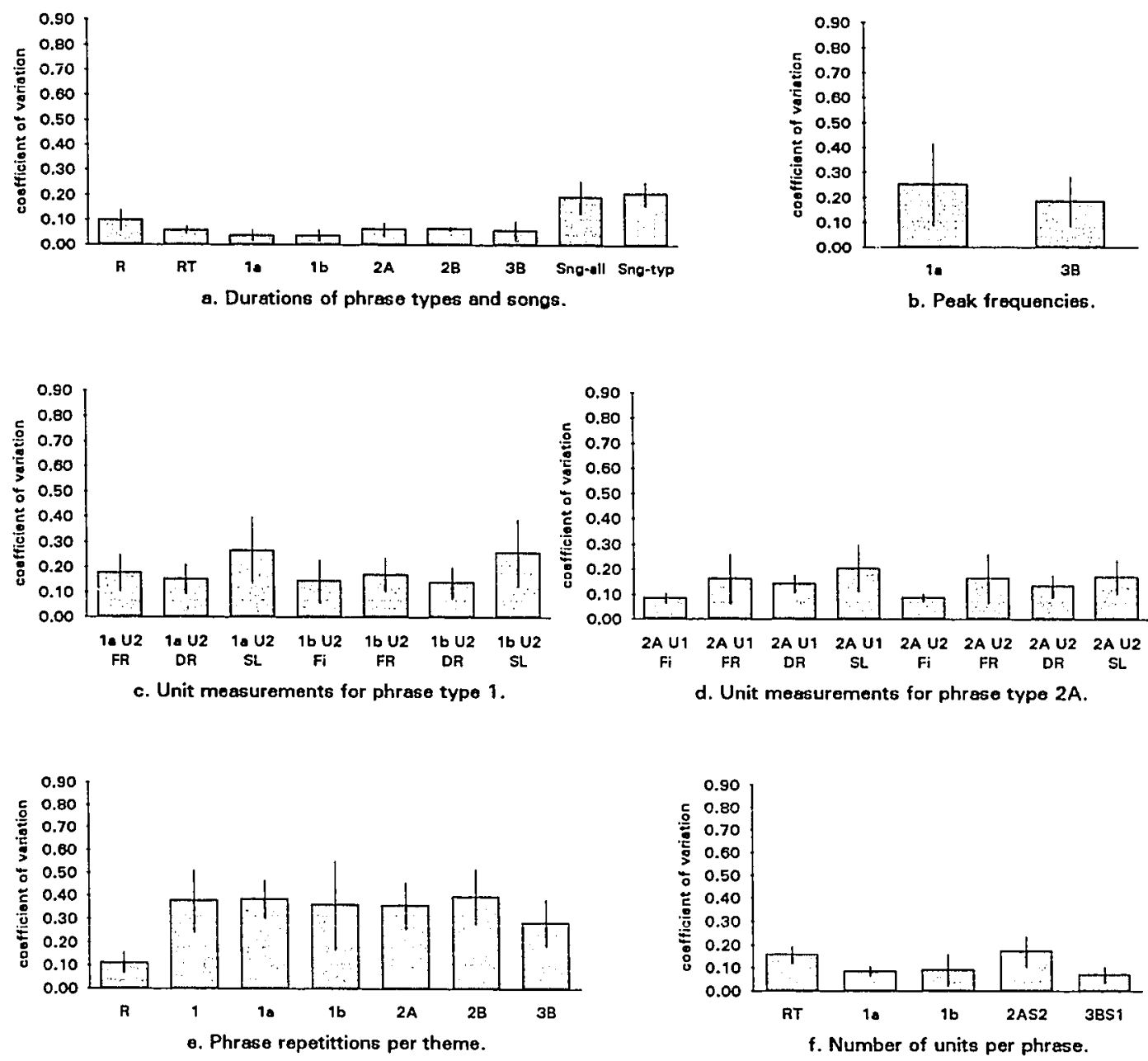

Figure 16. Mean coefficients of variation among all groups as a measure of among individual variation. A coefficient of variation was calculated among individuals in each group (area and time period). These values were then averaged for the following graphs. Error bars represent one standard deviation. Sng - all = all songs included, Sng - typ = only typical songs, $U 1=$ Unit $1, \mathrm{U} 2=$ Unit $2, \mathrm{Fi}=$ initial freqency, $\mathrm{FR}=$ freqency range, $\mathrm{DR}=$ duration, $\mathrm{SL}=$ average slope, $2 \mathrm{AS} 2=$ subphrase 2 in phrase type $2 \mathrm{~A}, 3 \mathrm{BS} 1=$ subphrase 1 in phrase type $3 \mathrm{~B}$. 
Appendix A.1. Coefficients of variation (cv) and sample sizes (n) of phrase and song duration for each singer. Mean coefficient of variation is given for each group and for all singers.

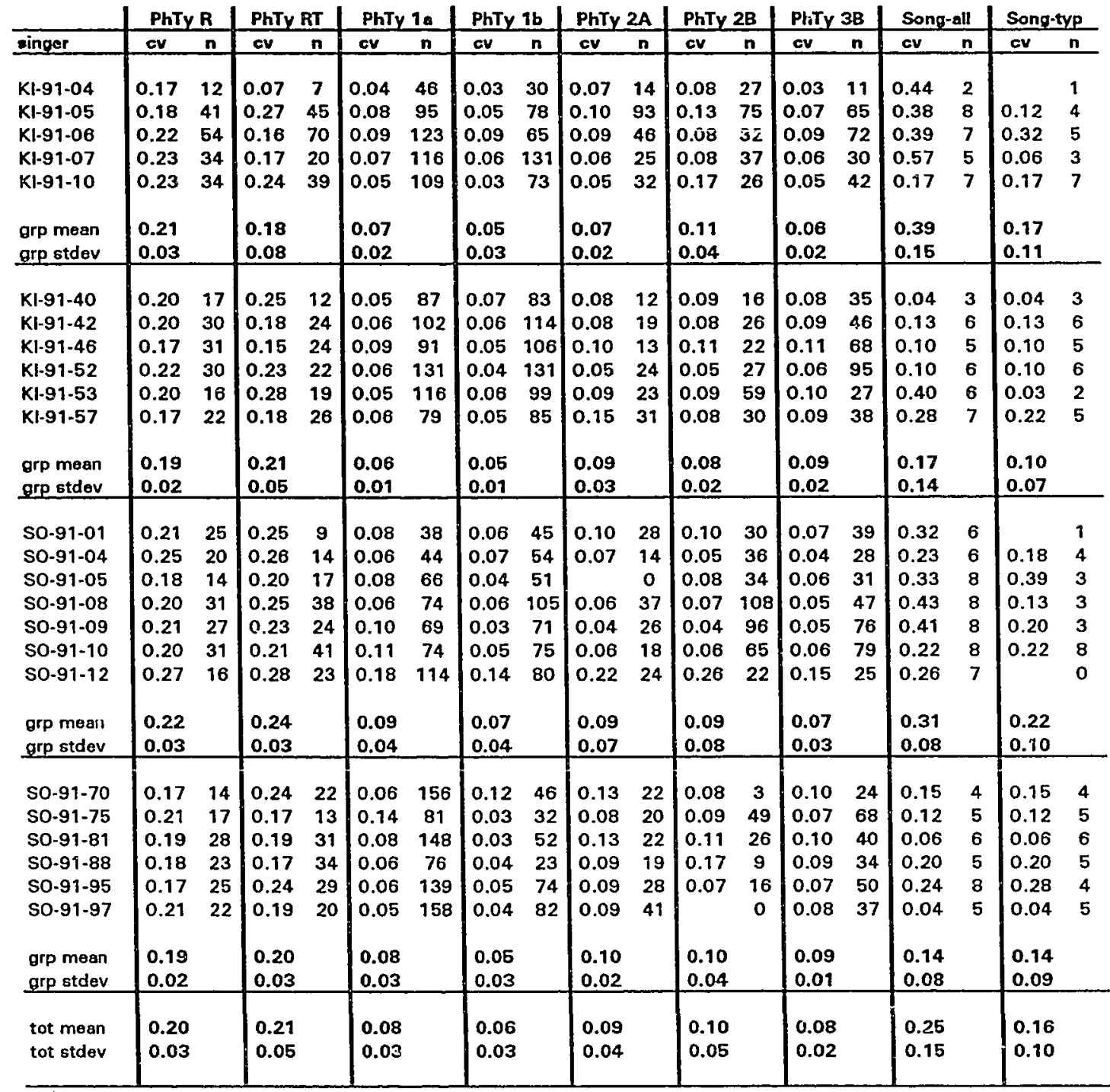

PhTy = Phrese type.

Song-all = All complete songs included.

Song-typ = Only typical songs includod 
Appendix A.2. Coefficients of variation (cv) and sample sizes (n) of peak frequencies per phrase for each singer. Mean coefficient of variation is given for each group and for all singers.

\begin{tabular}{|c|c|c|c|c|}
\hline \multirow{2}{*}{ singer } & \multicolumn{2}{|c|}{ PhTy 1a } & \multicolumn{2}{|c|}{ PhTy 3B } \\
\hline & cv & $\mathbf{n}$ & cv & $n$ \\
\hline$K 1-91-04$ & 0.63 & 4 & 0.28 & 11 \\
\hline KI-91-05 & 0.65 & 13 & 0.21 & 61 \\
\hline $\mathrm{KI}-91-06$ & 0.24 & 10 & 0.21 & 63 \\
\hline KI-91-07 & 0.44 & 7 & 0.34 & 30 \\
\hline KI-91-10 & 0.37 & 8 & 0.26 & 35 \\
\hline grp mean & 0.47 & & 0.26 & \\
\hline grp stdev & 0.17 & & 0.05 & \\
\hline $\mathrm{KI}-91-40$ & 0.09 & 4 & 0.28 & 10 \\
\hline KI-91-42 & 0.10 & 6 & 0.26 & 46 \\
\hline$K 1-91-46$ & 0.18 & 6 & 0.21 & 64 \\
\hline KI-91-52 & 0.11 & 6 & 0.20 & 81 \\
\hline KI-91-53 & 0.39 & 7 & 0.30 & 27 \\
\hline$K 1-91-57$ & 0.39 & 8 & 0.32 & 38 \\
\hline grp mean & 0.21 & & 0.26 & \\
\hline grp stdev & 0.14 & & 0.05 & \\
\hline So-91-01 & 0.56 & 7 & 0.22 & 39 \\
\hline So-91-04 & 0.29 & 6 & 0.23 & 27 \\
\hline So-91-05 & 0.28 & 10 & 0.16 & 29 \\
\hline So-91-08 & 0.63 & 14 & 0.24 & 40 \\
\hline So-91-09 & 0.31 & 10 & 0.30 & 53 \\
\hline so-91-10 & 0.15 & 9 & 0.36 & 68 \\
\hline So-91-12 & 0.29 & 8 & 0.27 & 22 \\
\hline grp mean & 0.36 & & 0.25 & \\
\hline grp stdev & 0.17 & & 0.06 & \\
\hline so-91-70 & 0.33 & 4 & 0.20 & 21 \\
\hline so-91-75 & 0.11 & 5 & 0.14 & 67 \\
\hline SO-91-81 & 0.24 & 7 & 0.25 & 40 \\
\hline SO-91-88 & 0.13 & 7 & 0.22 & 34 \\
\hline so-91-95 & 0.48 & 12 & 0.33 & 50 \\
\hline $50-91-97$ & 0.19 & 6 & 0.17 & 36 \\
\hline grp mean & 0.25 & & 0.22 & \\
\hline grp stdev & 0.14 & & 0.07 & \\
\hline tot mean & 0.32 & & 0.25 & \\
\hline tot stdev & 0.18 & & 0.06 & \\
\hline
\end{tabular}

PhTy 1a = Peak frequency of phrase type 1a / song for all songs.

PhTy $3 B=$ Peak frequency of phrase type $3 B /$ phrase for all phrases of complete themes. 
Appendix A.3. Coefficients of variation (cv) and sample sizes (n) of phrase repetitions per song for each singer. Mean coefficient of variation is given for each group and all singers.

\begin{tabular}{|c|c|c|c|c|c|c|c|c|c|c|c|c|c|c|}
\hline & PhTy & & PhTy & & $\mathrm{PhTy}$ & & PhTy & & PhTy & $2 A$ & PhTy & $2 B$ & PhTy & \\
\hline singer & cv & $n$ & cy & $n$ & cy & $\mathrm{n}$ & cy & $n$ & cv & $n$ & cv & $n$ & cv & $\mathrm{n}$ \\
\hline $\begin{array}{l}\text { KI-91-04 } \\
\text { KI-91-05 } \\
\text { KI-91-06 } \\
\text { KI-91-07 } \\
\text { KI-91-10 } \\
\text { grp mean } \\
\text { grp stdev } \\
\end{array}$ & $\begin{array}{l}0.07 \\
0.09 \\
0.15 \\
0.19 \\
0.15 \\
0.13 \\
0.05 \\
\end{array}$ & $\begin{array}{c}2 \\
9 \\
11 \\
5 \\
8\end{array}$ & $\begin{array}{l}0.47 \\
0.53 \\
0.37 \\
0.62 \\
0.14 \\
\\
0.43 \\
0.18 \\
\end{array}$ & $\begin{array}{c}5 \\
12 \\
10 \\
5 \\
8\end{array}$ & $\begin{array}{l}0.58 \\
0.37 \\
0.37 \\
0.90 \\
0.26 \\
\\
0.50 \\
0.26 \\
\end{array}$ & $\begin{array}{c}4 \\
12 \\
10 \\
5 \\
8\end{array}$ & $\begin{array}{l}0.50 \\
1.06 \\
0.82 \\
0.62 \\
0.25 \\
\\
0.65 \\
0.31 \\
\end{array}$ & $\begin{array}{c}4 \\
11 \\
10 \\
6 \\
9\end{array}$ & $\begin{array}{l}0.38 \\
0.71 \\
0.36 \\
0.27 \\
0.25 \\
\\
0.40 \\
0.18 \\
\end{array}$ & $\begin{array}{c}4 \\
12 \\
10 \\
7 \\
8\end{array}$ & $\begin{array}{l}0.28 \\
0.44 \\
0.29 \\
0.44 \\
0.22 \\
\\
0.33 \\
0.10 \\
\end{array}$ & $\begin{array}{c}4 \\
11 \\
10 \\
6 \\
8\end{array}$ & $\begin{array}{l}0.64 \\
0.67 \\
0.70 \\
0.28 \\
0.32 \\
\\
0.52 \\
0.21 \\
\end{array}$ & $\begin{array}{c}2 \\
8 \\
10 \\
4 \\
8\end{array}$ \\
\hline $\begin{array}{l}\text { KI-91-40 } \\
\mathrm{KI}-91-42 \\
\mathrm{KI}-91-46 \\
\mathrm{KI}-91-52 \\
\mathrm{KI}-91-53 \\
\mathrm{KI}-91-57 \\
\text { grp mean } \\
\text { grp stdev }\end{array}$ & $\begin{array}{l}0.12 \\
0.09 \\
0.05 \\
0.06 \\
0.27 \\
0.11 \\
\\
0.12 \\
0.08 \\
\end{array}$ & $\begin{array}{l}3 \\
6 \\
5 \\
6 \\
4 \\
5\end{array}$ & $\begin{array}{l}0.26 \\
0.36 \\
0.15 \\
0.29 \\
0.40 \\
0.36 \\
\\
0.30 \\
0.09 \\
\end{array}$ & $\begin{array}{l}4 \\
6 \\
6 \\
6 \\
8 \\
8\end{array}$ & $\begin{array}{l}0.24 \\
0.27 \\
0.28 \\
0.58 \\
0.62 \\
0.40 \\
\\
0.40 \\
0.17 \\
\end{array}$ & $\begin{array}{l}3 \\
6 \\
6 \\
6 \\
7 \\
8\end{array}$ & $\begin{array}{l}0.29 \\
0.50 \\
0.29 \\
0.23 \\
0.42 \\
0.50 \\
\\
0.37 \\
0.12 \\
\end{array}$ & $\begin{array}{l}4 \\
6 \\
6 \\
6 \\
8 \\
8\end{array}$ & $\begin{array}{l}0.38 \\
0.37 \\
0.45 \\
0.42 \\
0.22 \\
0.60 \\
\\
0.41 \\
0.12 \\
\end{array}$ & $\begin{array}{l}4 \\
7 \\
6 \\
6 \\
8 \\
9\end{array}$ & $\begin{array}{l}0.20 \\
0.40 \\
0.18 \\
0.37 \\
0.45 \\
0.24 \\
\\
0.31 \\
0.11 \\
\end{array}$ & $\begin{array}{l}4 \\
7 \\
5 \\
6 \\
7 \\
8\end{array}$ & $\begin{array}{l}0.34 \\
0.46 \\
0.23 \\
0.35 \\
0.53 \\
0.52 \\
\\
0.41 \\
0.12 \\
\end{array}$ & $\begin{array}{l}3 \\
7 \\
5 \\
6 \\
4 \\
8\end{array}$ \\
\hline $\begin{array}{l}\text { SO-91-01 } \\
\text { SO-91-04 } \\
\text { SO-91-05 } \\
\text { SO-91-08 } \\
\text { SO-91-09 } \\
\text { SO-91-10 } \\
\text { s0-91-12 } \\
\text { grp mean } \\
\text { grp stdev }\end{array}$ & $\begin{array}{l}0.15 \\
0.48 \\
0.13 \\
0.21 \\
0.13 \\
0.23 \\
0.13 \\
\\
0.21 \\
0.13 \\
\end{array}$ & $\begin{array}{l}4 \\
5 \\
6 \\
7 \\
7 \\
9 \\
4\end{array}$ & $\begin{array}{l}0.58 \\
0.46 \\
0.48 \\
0.28 \\
0.39 \\
0.44 \\
0.41 \\
\\
0.43 \\
0.09 \\
\end{array}$ & $\begin{array}{c}6 \\
6 \\
10 \\
15 \\
8 \\
9 \\
12\end{array}$ & $\begin{array}{l}0.88 \\
0.55 \\
0.59 \\
0.82 \\
0.52 \\
0.39 \\
0.60 \\
\\
0.62 \\
0.17 \\
\end{array}$ & $\begin{array}{c}7 \\
6 \\
9 \\
14 \\
9 \\
9 \\
8\end{array}$ & $\begin{array}{l}0.78 \\
0.68 \\
0.50 \\
0.26 \\
0.40 \\
0.55 \\
0.32 \\
\\
0.50 \\
0.19 \\
\end{array}$ & $\begin{array}{c}6 \\
6 \\
10 \\
15 \\
8 \\
9 \\
8\end{array}$ & $\begin{array}{l}0.52 \\
0.50 \\
\\
0.33 \\
0.40 \\
0.44 \\
0.39 \\
\\
0.43 \\
0.07 \\
\end{array}$ & $\begin{array}{c}6 \\
7 \\
0 \\
15 \\
9 \\
10 \\
8\end{array}$ & $\begin{array}{l}0.40 \\
0.40 \\
0.57 \\
0.30 \\
0.76 \\
0.31 \\
0.24 \\
\\
0.43 \\
0.18 \\
\end{array}$ & $\begin{array}{c}4 \\
7 \\
8 \\
14 \\
6 \\
10 \\
6\end{array}$ & $\begin{array}{l}0.48 \\
0.73 \\
0.63 \\
0.35 \\
0.46 \\
0.44 \\
0.42 \\
\\
0.50 \\
0.13 \\
\end{array}$ & $\begin{array}{l}4 \\
6 \\
6 \\
7 \\
6 \\
9 \\
3\end{array}$ \\
\hline $\begin{array}{l}\text { SO-91-70 } \\
\text { So-91-75 } \\
\text { SO-91-81 } \\
\text { SO-91-88 } \\
\text { SO-91-95 } \\
\text { SO-91-97 }\end{array}$ & $\begin{array}{l}0.52 \\
0.30 \\
0.09 \\
0.11 \\
0.20 \\
0.06\end{array}$ & $\begin{array}{l}5 \\
6 \\
7 \\
7 \\
7 \\
7\end{array}$ & $\begin{array}{l}0.12 \\
0.19 \\
0.23 \\
0.24 \\
0.27 \\
0.13\end{array}$ & $\begin{array}{c}4 \\
5 \\
7 \\
6 \\
12 \\
6\end{array}$ & $\begin{array}{l}0.16 \\
0.21 \\
0.32 \\
0.34 \\
0.52 \\
0.33\end{array}$ & $\begin{array}{c}4 \\
5 \\
7 \\
6 \\
12 \\
6\end{array}$ & $\begin{array}{l}0.42 \\
0.79 \\
0.34 \\
0.25 \\
0.36 \\
0.61\end{array}$ & $\begin{array}{c}4 \\
5 \\
7 \\
5 \\
12 \\
7\end{array}$ & $\begin{array}{l}0.97 \\
0.31 \\
0.31 \\
0.50 \\
0.42 \\
0.55\end{array}$ & $\begin{array}{c}4 \\
7 \\
7 \\
5 \\
12 \\
7\end{array}$ & $\begin{array}{l}0.20 \\
0.33 \\
0.47 \\
0.14\end{array}$ & $\begin{array}{l}1 \\
7 \\
5 \\
2 \\
5 \\
0\end{array}$ & $\begin{array}{l}0.29 \\
0.29 \\
0.28 \\
0.50 \\
0.39 \\
0.36\end{array}$ & $\begin{array}{l}4 \\
7 \\
7 \\
6 \\
8 \\
7\end{array}$ \\
\hline $\begin{array}{r}\text { grp mean } \\
- \text { grp stdev } \\
\end{array}$ & $\begin{array}{l}0.21 \\
0.17 \\
\end{array}$ & & $\begin{array}{l}0.20 \\
0.06 \\
\end{array}$ & & $\begin{array}{l}0.31 \\
0.12 \\
\end{array}$ & & $\begin{array}{l}0.46 \\
0.20 \\
\end{array}$ & & $\begin{array}{l}0.51 \\
0.24 \\
\end{array}$ & & $\begin{array}{l}0.29 \\
0.15 \\
\end{array}$ & & $\begin{array}{l}0.35 \\
0.08 \\
\end{array}$ & \\
\hline $\begin{array}{l}\text { tot mean } \\
\text { tet stdev }\end{array}$ & $\begin{array}{l}0.17 \\
0.12\end{array}$ & & $\begin{array}{l}0.34 \\
0.14\end{array}$ & & $\begin{array}{l}0.46 \\
0.21\end{array}$ & & $\begin{array}{l}0.49 \\
0.22\end{array}$ & & $\begin{array}{l}0.44 \\
0.16\end{array}$ & & $\begin{array}{l}0.35 \\
0.14\end{array}$ & & $\begin{array}{l}0.44 \\
0.15\end{array}$ & \\
\hline
\end{tabular}

PhTy $=$ Phrase type. 
Appendix A.4. Coefficients of variation (cv) and sample sizes (n) of unit measurements in phrase types $1 \mathrm{a}$ and $1 \mathrm{~b}$. Mean coefficients of variation are given for each group and all singers.

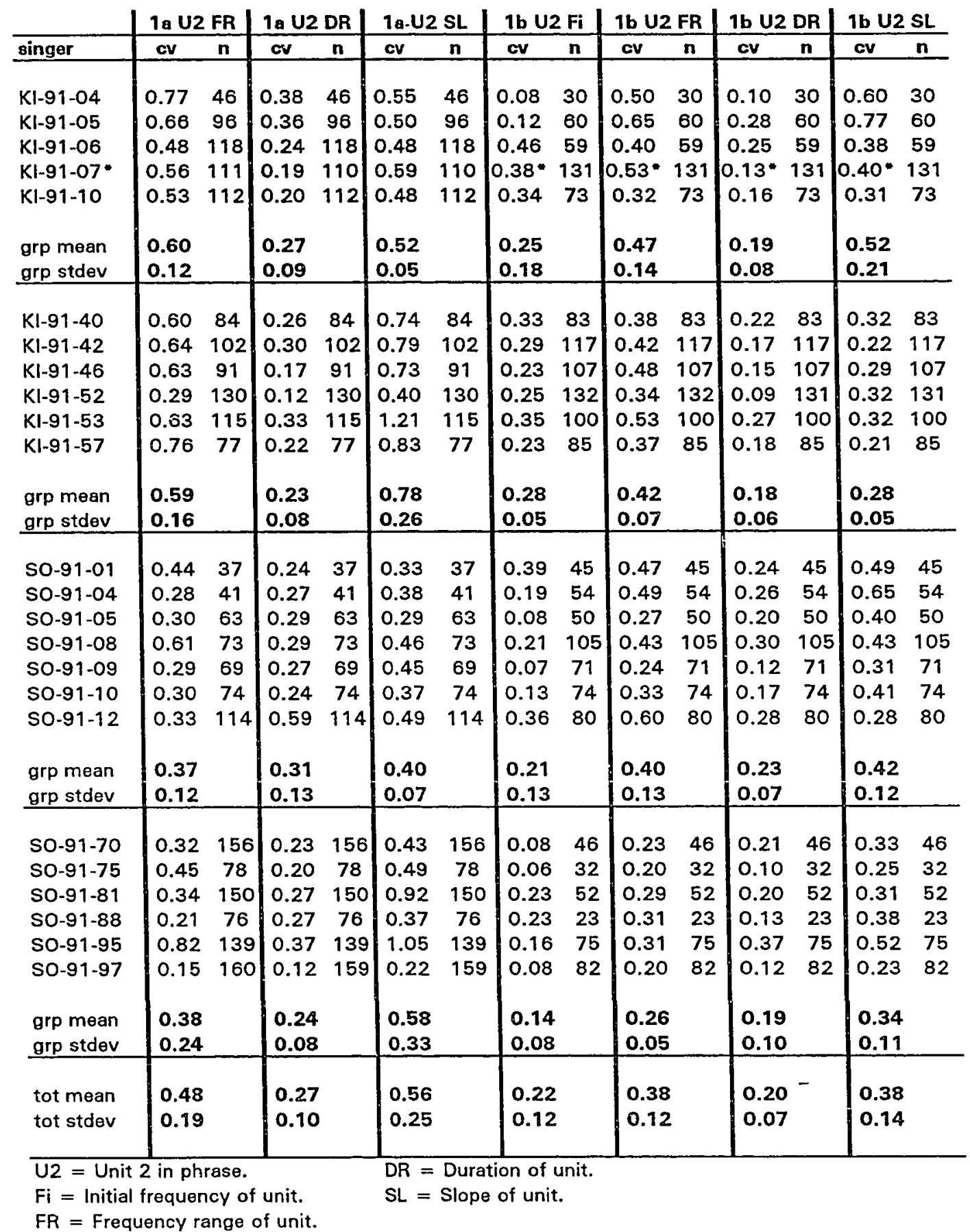


Appendix A.5. Coefficients of variation (cv) and sample sizes (n) of unit measurements in phrase type 2A. Mean coefficients of variation are given for each group and all singers.

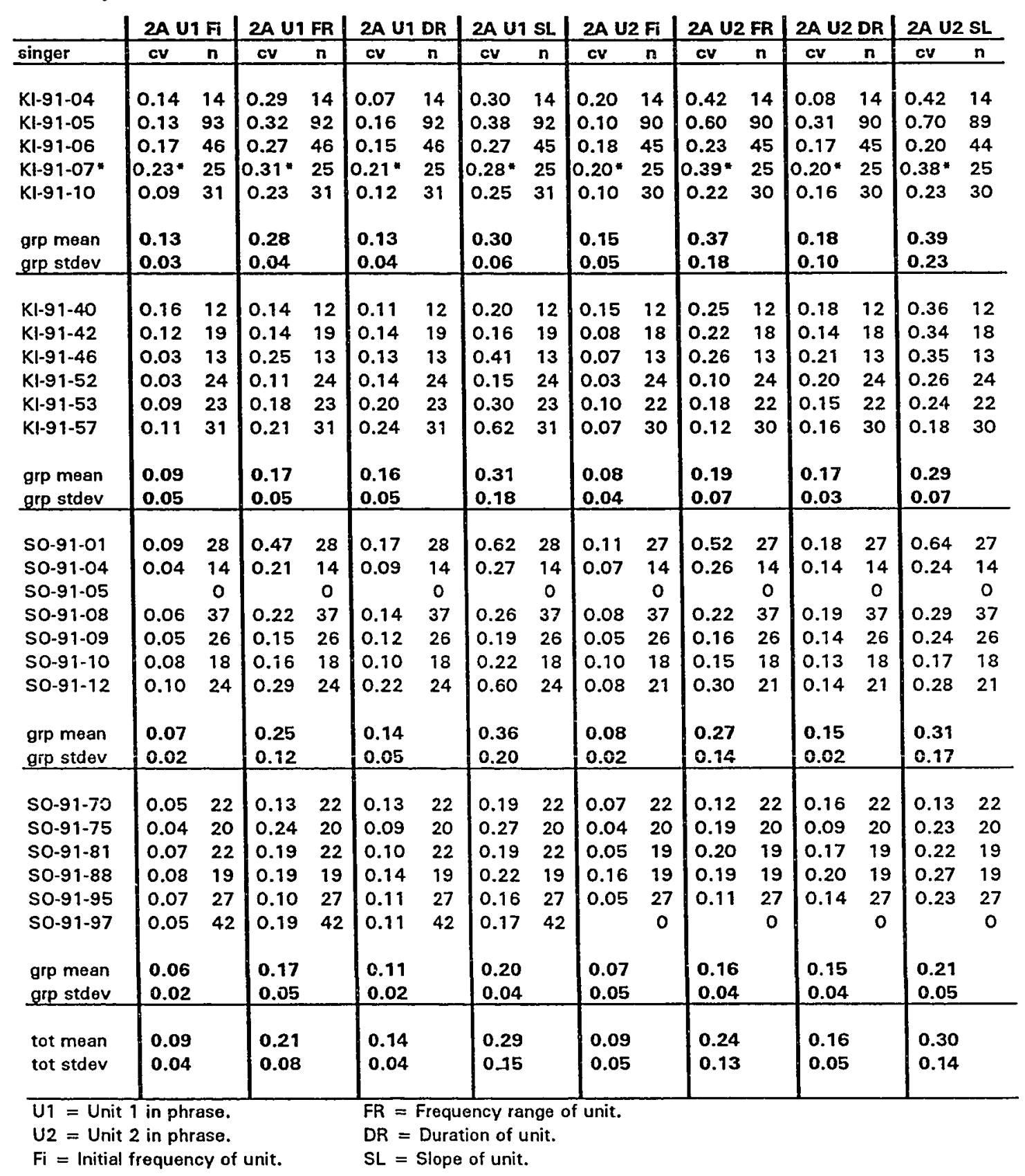


Appendix A.6. Coefficients of variation (cv) and sample sizes ( $n$ ) of number of units per phrase for each singer. Mean coefficient of variation is given for each group and all singers.

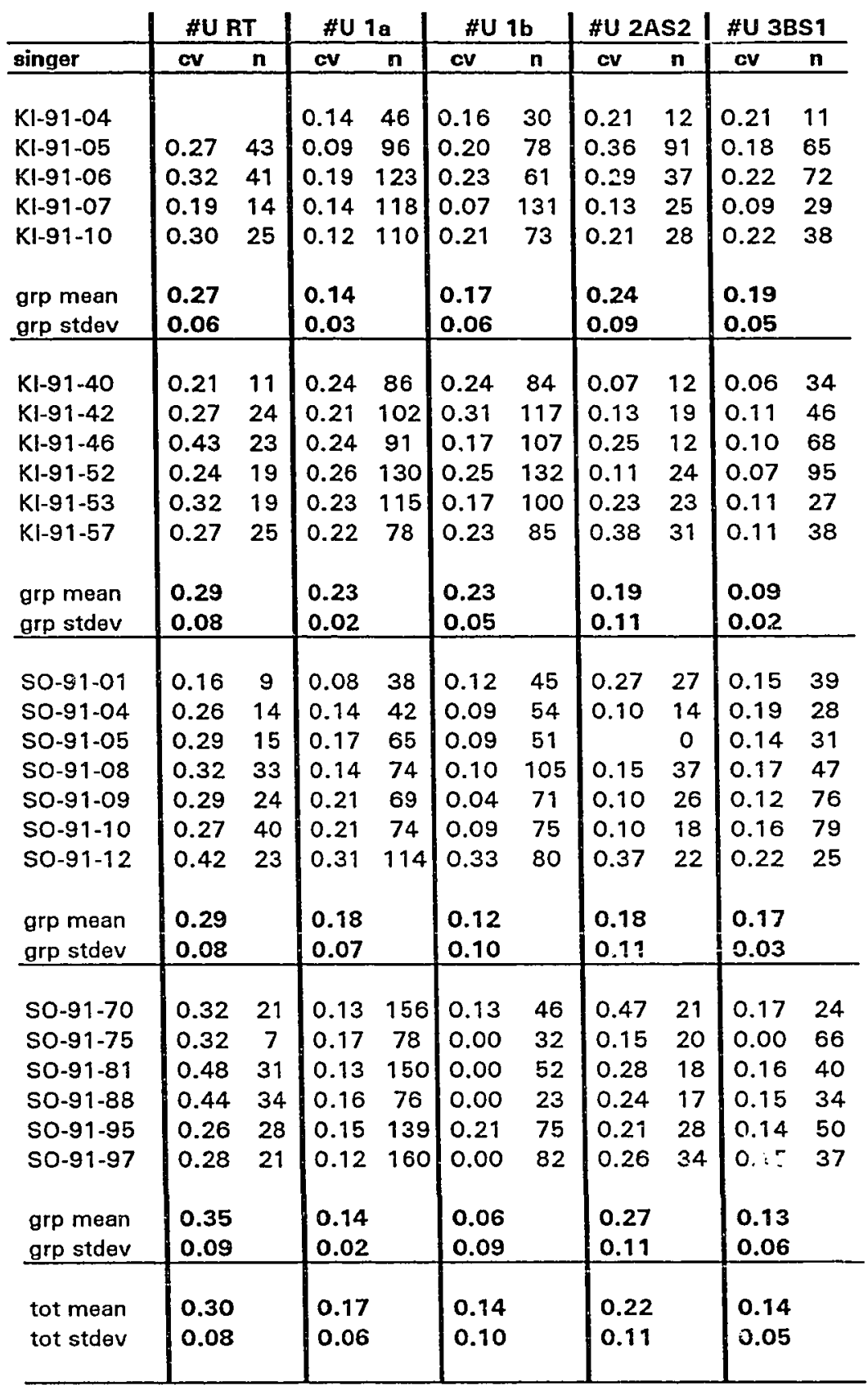

$\# U=$ Number of units in phrase.

$2 A S 2=$ Subphrase 2 in phrase type $2 A$.

3BS1 = Subphrase 1 in phrase type 3B. 